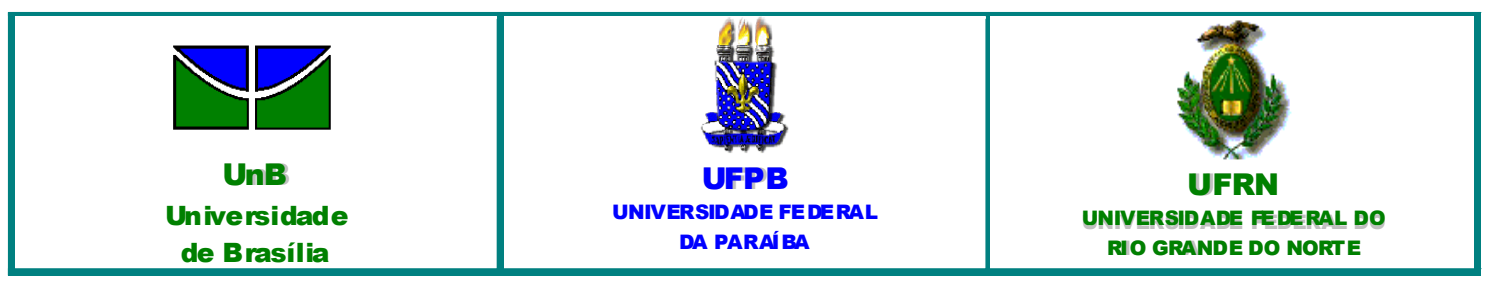

UNIVERSIDADE DE BRASÍLIA - UnB

UNIVERSIDADE FEDERAL DA PARAÍBA - UFPB

UNIVERSIDADE FEDERAL DO RIO GRANDE DO NORTE - UFRN

PROGRAMA MULTI-INSTITUCIONAL E INTER-REGIONAL DE PÓS-

GRADUAÇÃO EM CIÊNCIAS CONTÁBEIS

EDZANA ROBERTA FERREIRA DA CUNHA VIEIRA LUCENA

ANÁLISE DA RELAÇÃO ENTRE A CAPACIDADE COGNITIVA E A OCORRÊNCIA DOS VIESES COGNITIVOS DA REPRESENTATIVIDADE NO JULGAMENTO

NATAL - RN 
UNIVERSIDADE DE BRASÍLIA - UnB

\author{
Reitor: \\ Professor Doutor Ivan Marques de Toledo Camargo \\ Vice-Reitor: \\ Professor Doutora Sônia Nair Báo \\ Decano de Pesquisa e Pós-Graduação: \\ Professor Doutor Jaime Martins de Santana
}

Diretor da Faculdade de Economia, Administração e Contabilidade:

Professor Doutor Roberto de Goes Ellery Júnior

Chefe do Departamento de Ciências Contábeis e Atuariais:

Professor Doutor José Antônio de França

Coordenador-Geral do Programa Multi-institucional e Inter-regional de Pós

Graduação em Ciências Contábeis da UnB, UFPB e UFRN

Professor Doutor Rodrigo de Souza Gonçalves 
Tese apresentada ao Programa Multi-institucional e Inter-Regional de Pós-graduação em Ciências Contábeis UnB/UFPB/UFRN como requisito parcial à obtenção do título de Doutora em Ciências Contábeis

Orientador: Prof. Dr. César Augusto Tibúrcio Silva.

Área de Concentração: Mensuração Contábil

Linha de Pesquisa: Contabilidade para Tomada de Decisão 
Lucena, Edzana Roberta Ferreira da Cunha Vieira.

Análise da relação entre a capacidade cognitiva e a ocorrência dos vieses cognitivos da representatividade no julgamento / Edzana Roberta Ferreira da Cunha Vieira Lucena. - Natal, RN, 2015.

$120 \mathrm{f}$.

Orientador: Profo‥ Dr. César Augusto Tibúrcio Silva.

Tese (Doutorado em Ciências Contábeis) - Universidade Federal do Rio Grande do Norte. Centro de Ciências Sociais Aplicadas. Programa Multi-institucional e inter-regional de Pós-graduação em Ciências Contábeis.

1. Contabilidade comportamental - Tese. 2. Capacidade cognitiva - Tese. 3. Vieses cognitivos Tese. 4. Processos cognitivos - Tese. I. Silva, César Augusto Tibúrcio. II. Universidade Federal do Rio Grande do Norte. III. Título. 


\section{ANÁLISE DA RELAÇÃO ENTRE A CAPACIDADE COGNITIVA E A OCORRÊNCIA DOS VIESES COGNITIVOS DA REPRESENTATIVIDADE NO JULGAMENTO}

Tese apresentada ao Programa Multi-institucional e Inter-regional de Pós-Graduação em Ciências Contábeis UnB/UFPB/UFRN como requisito parcial à obtenção do título de Doutora em Ciências Contábeis.

Aprovada em 23 de fevereiro de 2015.

Prof. Dr. CÉSAR AUGUSTO TIBÚRCIO SILVA

Universidade de Brasília - UnB

Orientador

Prof. Dr. JOSÉ DIONÍSIO GOMES DA SILVA

Universidade Federal do Rio Grande do Norte - UFRN

Membro Examinador Interno

Prof. ㅁ Dr. a ANEIDE OLIVEIRA ARAÚJO

Universidade Federal do Rio Grande do Norte - UFRN

Membro Examinador Interno

Prof. Dr. ADRIANO LEAL BRUNI

Faculdade de Ciências Contábeis da Universidade Federal da Bahia Membro Examinador Externo

Prof. Dr. ANTÔNIO BENEDITO SILVA OLIVEIRA

Pontifícia Universidade Católica de São Paulo

Membro Examinador Externo 
Aos meus pais, Joziana e Edson, ao meu marido André e à minha filha Liz, e aos irmãos Edzângela e Joseeder, os grandes amores de minha vida. 


\section{AGRADECIMENTOS}

Só quem passa por um processo como o de mestrado e o de doutorado sabe o quanto é esperada a hora deste momento de agradecimento. Obrigada, meu Deus, mentor absoluto de minha vida, por não me abandonar em nenhum instante, por sempre me dar forças e sabedoria, para me manter firme e persistente em busca do alcance deste objetivo.

Não poderia deixar de agradecer, também, a minha família, ao meu marido André, parceiro de todas as horas, e à minha filha Liz, que, com apenas um sorriso, me fazia criar forças de onde parecia não poder mais tirar. Aos meus irmãos Edzângela e Joseeder, pessoas sempre presentes em minha vida; minha mãe, exemplo de garra e persistência; vozinha e tia Basília, que me receberam e cuidaram tão bem de mim nas semanas em que as aulas foram em João Pessoa; e Julhinha, pessoa que cuida com tanto zelo e carinho de minha família e de meu lar. A todos vocês, meus amores, obrigada por compreenderem minhas ausências, minha falta de energia, para outras atividades, e meus estresses.

Outra pessoa fundamental para a realização deste trabalho foi meu orientador, professor César Augusto Tibúrcio Silva, a quem muito admiro pela sua simplicidade e por ter sempre a palavra certa no momento preciso, e a quem serei eternamente grata pela compreensão, pela paciência e pelos ensinamentos no decurso desta produção.

Agradeço ao Programa Multiinstitucional e Inter-regional de Pós-Graduação em Ciências Contábeis UnB, UFPB e UFRN, mais especificamente a todos os professores com os quais tive a oportunidade de enriquecimento intelectual: Prof. Dr. César Augusto Tibúrcio Silva, Prof. Dr. Edilson Paulo, Prof. Dr. Jorge Katsumi Niyama, Prof. Dr. José Dionísio Gomes da Silva, Prof. Dr. José Lúcio Capelletto, Prof. Dr. José Matias Pereira, Prof. Otávio Ribeiro de Medeiros, Ph.D. e Prof. Dr. Paulo Roberto Barbosa Lustosa. Além do competente coordenador regional do Rio Grande do Norte, Erivan Ferreira Borges, que sempre esteve pronto para ajudar.

Aos amigos que o doutorado me permitiu conhecer e compartilhar momentos tristes e felizes: Antônio Maria Henri Byle, Antônio Felipe de Paula Júnior, Diana Vaz de Lima, Clayton Levy Lima de Melo, Clésia Camilo Pereira, Lílian Perobon Mazer (amiga de quarto, de confidências e para toda a vida), Orleans Silva Martins e Paulo César de Melo Mendes. Ao amigo-irmão Clayton, meu agradecimento especial, por 
suas brincadeiras contagiantes, que nos traziam a necessária serenidade para seguir o caminho com mais leveza. Que o tempo e a distância não sejam capazes de destruir a nossa amizade.

Agradeço, aos professores, membros da Banca Examinadora, Dr. Adriano Leal Bruni, Dr. ${ }^{a}$ Aneide Oliveira Araújo, Dr. Antônio Benedito Silva Oliveira e Dr. José Dionísio Gomes da Silva, pelo tempo dispensado à leitura e pelas importantes contribuições que engrandeceram este trabalho.

A todos que fazem parte da coordenação e do departamento de Ciências Contábeis da UFRN, professores, funcionários e estagiários, cujos nomes abstenhome de mencionar particurlamente para não incorrer no deslize do esquecimento de merecida citação. Numa menção especial, agradeço aos professores Antônio Sales Mascarenhas e Anailson Márcio Gomes, por me apoiarem e por criarem os melhores meios para eu conciliar docência e discência; à Artemísia Lucena, pela presteza e pela divulgação da pesquisa junto aos alunos; à Giovanna Tonetto Segantini, Maria Aparecida Cavalcanti, Mariana Melo e Rossana Ataide Sampaio, por me ajudarem na aplicação presencial do questionário.

À Universidade Federal do Rio Grande do Norte, com destaque para sua próreitoria de pós-graduação (pelo auxílio financeiro), numa referenciação particular à Professora Edna Maria da Silva e Maria Lassalete da Costa Cruz.

A todas as instituições parceiras na divulgação do questionário, além da já citada UFRN: UNIFACEX, UNI/RN): Universidade Estadual do Rio Grande do Norte, UFERSA, Universidade Potiguar, Universidade Federal da Paraíba, Universidade Estadual da Paraíba, Universidade de Brasília, Universidade Federal do Rio de Janeiro, UNICAP, IPECONT, Programa Multiinstitucional e Inter-regional de Pós Graduação em Ciências Contábeis UnB, UFPB e UFRN, UDESC, USP/RB, USP/SP, Universidade Federal de Viçosa, UFRGS, Universidade Federal de Uberlândia, UNIP, UNIMEP, Universidade de Rio Verde, Centro de Ensino Superior de Conselheiro Lafaiete (CES-CL), Universidade Federal de Alagoas, Fundação Universidade Federal de Rondônia, UNIVATES, ao Conselho Regional de Contabilidade-RN e aos blogs Contabilidade Financeira, Informação Contábil, Contabilidade \& Métodos Quantitativos e Conexão Contábil da UFRN.

Também não poderia deixar de agradecer a todos os participantes, pela colaboração em responder ao questionário; além da amiga Emmanuelle de Oliveira, pela leitura crítica deste estudo, com olhar todo especial da psicologia. 
"Não existe nenhum caminho lógico para a descoberta das leis elementares do Universo - o único caminho é o da intuição".

(Albert Einstein) 


\section{RESUMO}

Esta pesquisa tem como o objetivo investigar a influência da capacidade cognitiva na incidência dos vieses cognitivos gerados pela heurística da representatividade. Em função desse alcance, foi realizado um estudo do tipo levantamento, por meio de um questionário, com um total de 43 questões, o qual contou com uma amostra válida de 1.064 respondentes, entre estudantes de graduação em Ciências Contábeis e contabilistas, dos quais $52,7 \%$ são do sexo do masculino, $48,3 \%$ possuem graduação completa, especialização, mestrado ou doutorado e $70 \%$ residem na região Nordeste do Brasil. Como resultado tem-se que $38,1 \%$ dos respondentes apresentam uma baixa capacidade cognitiva, $42,5 \%$ demonstram média capacidade cognitiva e $19,2 \%$ apresentam alta capacidade cognitiva. Quanto à sensibilidade dos participantes aos vieses cognitivos (quais sejam: insensibilidade à taxa base, insensibilidade ao tamanho da amostra, chance de equívocos, equívocos na regressão, ilusão de validade e insensibilidade à previsibilidade), identificou-se que, para mais de $60 \%$ da amostra, há incidência de todos esses vieses no processo de julgamento e tomada de decisão e que a capacidade cognitiva influencia apenas na incidência dos vieses insensibilidade à taxa base e ilusão de validade. Em se tratando da provável interferência decorrente dos diferentes níveis de instrução em que se situam os sujeitos pesquisados, atestou-se essa implicação pela variação de médias relativas aos vieses insensibilidade à taxa base e insensibilidade ao tamanho da amostra. Registro mais incisivo faz-se em relação à diferença de gênero, que, por si só, não impactou de maneira significativa apenas nas médias do viés insensibilidade à previsibilidade. A região do país influenciou diferentemente os vieses insensibilidade à taxa base e ilusão de validade. Foi encontrada diferença entre as médias do viés insensibilidade à taxa base e ilusão de validade nos grupos com baixa, média e alta capacidade cognitiva, indicando que quanto menor a capacidade cognitiva, maior a sensibilidade do respondente ao viés, corroborando o referencial teórico.

Palavras-chave: Processos cognitivos. Vieses cognitivos. Capacidade cognitiva. Contabilidade Comportamental. 


\begin{abstract}
This research has as objective to investigate the influence of the cognitive ability in the incidence of the cognitive biases generated by the heuristic of representativeness. To achieve it, a study of the survey type was conducted through a questionnaire with a total of 43 questions, which featured a valid sample of 1064 respondents, among undergraduate students in Accounting and accountants, of which $52.7 \%$ male, $48.3 \%$ have an undergraduate degree, specialization, master's or doctoral degree and $70 \%$ live in Northeastern Brazil. As a result it considers that $405(38.1 \%)$ respondents have a low cognitive ability, 452 (42.5\%) have average cognitive ability and $207(19.2 \%)$ have high cognitive ability. As for the sensitivity of the participants to the cognitive biases insensitivity to base rate, insensitivity to sample size, misconceptions of chance, misconceptions of regression, illusion of validity and insensitivity to predictability, it was identified that for more than $60 \%$ of the sample, there is an incidence of all in the judgment and making process. The cognitive ability influence only in the incidence of biases insensitivity to base rate and illusion of validity. In terms of the different levels of education of the respondents, it was verified a difference of averages in biases insensitivity to base rate and insensitivity to sample size in the different levels of education. Gender didn't impact significantly only in biases insensitivity to predictability. The region of the country influenced differently to biases insensitivity to base rate and illusion of validity. It was found a difference between the biases insensitivity to base rate and illusion of validity in the groups with low, average and high cognitive ability, indicating that the lower the cognitive ability, the greater the sensitivity of the bias respondent, confirming the theoretical framework.
\end{abstract}

Keywords: Cognitive processes. Cognitive biases. Cognitive ability. Behavioral Accounting. 


\section{LISTA DE FIGURAS}

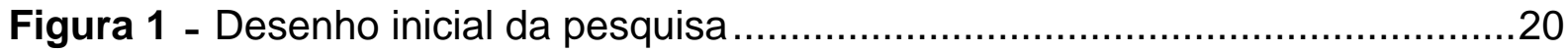

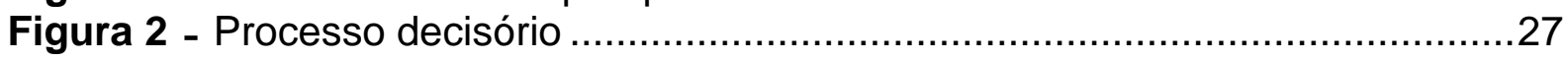

Figura 3 - Processo e Conteúdo nos dois Sistemas Cognitivos .............................31

Figura 4 - Modelo Heurístico/Analítico revisado .............................................. 33

Figura 5 - Síntese do pressuposto principal deste estudo .................................62

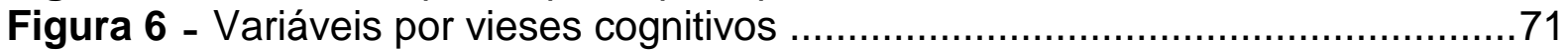

Figura 7 - Desenho final da pesquisa ............................................................. 78

Figura 8 - Mapa perceptual da Análise de Correspondência Múltipla para o CRT e

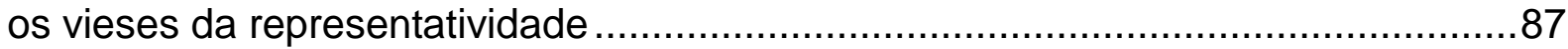




\section{LISTA DE QUADROS}

Quadro 1 - Atributos associados frequentemente com as Teorias de Duplo

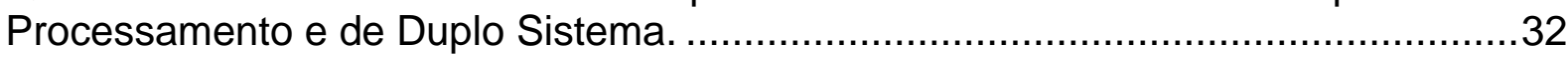

Quadro 2 - Síntese do Instrumento de coleta de dados .......................................65 


\section{LISTA DE TABELAS}

Tabela 1 - Vieses gerados pela heurística da disponibilidade.................................39

Tabela 2 - Vieses gerados pela heurística da ancoragem e ajustamento...............40

Tabela 3 - Vieses gerados pela heurística da representatividade ..........................44

Tabela 4 - Medidas estatísticas para a validação da dimensionalidade e confiabilidade da escala através da análise fatorial dos vieses...............................76

Tabela 5 - Escores fatoriais e Escores somas das variáveis remanescentes ..........78

Tabela 6 - Grau de Instrução da amostra .....................................................79

Tabela 7 - Distribuição dos respondentes por Região ……………....................

Tabela 8 - Região versus Grau de Instrução................................................... 80

Tabela 9 - Distribuição dos respondentes por faixa etária ..................................80

Tabela 10 - Experiência profissional versus Gênero..........................................81

Tabela 11 - Distribuição dos respondentes por tempo de atuação profissional .........81

Tabela 12 - Instituição de ensino .................................................................. 82

Tabela 13 - Formação de nível superior, além de Ciências Contábeis ....................82

Tabela 14 - Distribuição da amostra válida por resposta aos itens do CRT .............83

Tabela 15 - Classificação dos respondentes quanto ao CRT ................................ 84

Tabela 16 - Vieses cognitivos por classificação dos respondentes por grupo de CRT

Tabela 17 - Classificação da sensibilidade dos respondentes aos vieses cognitivos

Tabela 18 - Análise de Correspondência para a influência do CRT sobre os vieses

Tabela 19 - Comparação dos vieses cognitivos estudados, nos grupos alta, média

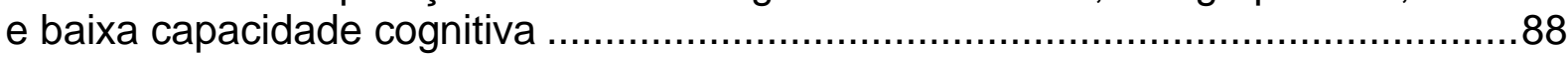

Tabela 20 - Teste de Tukey para os vieses insensibilidade à taxa base e ilusão de validade por CRT

Tabela 21 - Comparação de grau de dificuldade e de como considera seu julgamento e tomada de decisão por classificação do CRT .

Tabela 22 - Teste de Tukey para grau de dificuldade e forma de julgamento e tomada de decisão na opinião dos respondentes por CRT ....................................92

Tabela 23 - Comparação dos vieses cognitivos estudados por grau de instrução...93 Tabela 24 - Teste de Tukey para os vieses insensibilidade à taxa base, insensibilidade ao tamanho da amostra e chance de equívoco por grau de instrução

Tabela 25 - Comparação dos vieses cognitivos estudados por região

Tabel 26 - Teste de Tukey para os vieses insensibilidade à taxa base por regino 96

Tabela 27 - Comparação dos vieses cognitivos estudados por gênero.

Tabela 28 - Resumo dos resultados das hipóteses de pesquisa 


\section{SUMÁRIO}

1 INTRODUÇÃO

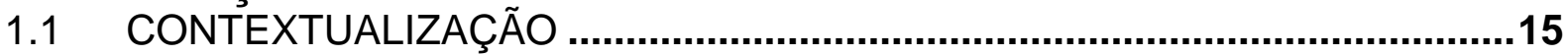

1.2 JUSTIFICATIVA E PROBLEMA DE PESQUISA ...............................................17

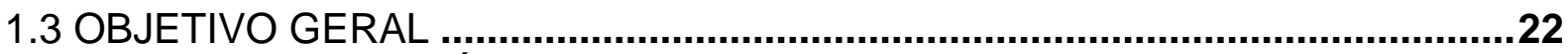

1.4 OBJETIVOS ESPECÍFICOS .....................................................................22

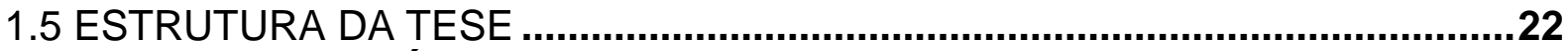

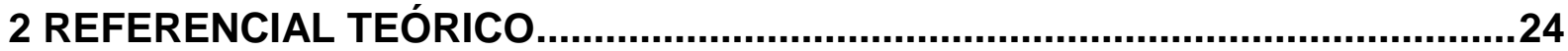

2.1 PSICOLOGIA COGNITIVA E CONTABILIDADE COMPORTAMENTAL .............24

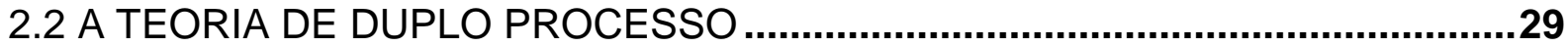

2.3 COGNITIVE REFLECTION TEST (CRT) ….................................................34

2.4 HEURÍSTICAS E VIESES COGNITIVOS........................................................37

2.4.1 Heurísticas da disponibilidade ...................................................................

2.4.2 Heurísticas da ancoragem e ajustamento ...........................................40

2.5 HEURÍSTICA DA REPRESENTATIVIDADE E OS VIESES GERADOS............42

2.6 EVIDÊNCIAS EMPÍRICAS SOBRE OS VIESES COGNITIVOS ORIUNDOS DA HEURÍSTICA DA REPRESENTATIVIDADE E SOBRE COGNITIVE REFLECTION

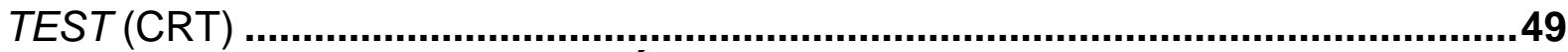

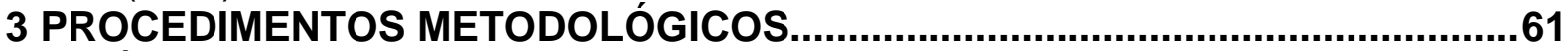

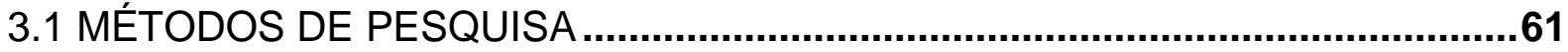

3.2 INSTRUMENTO DE PESQUISA E COLETA DE DADOS..................................62

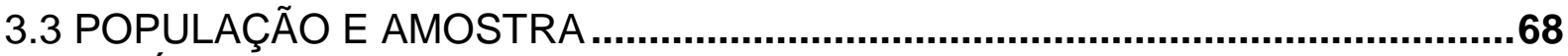

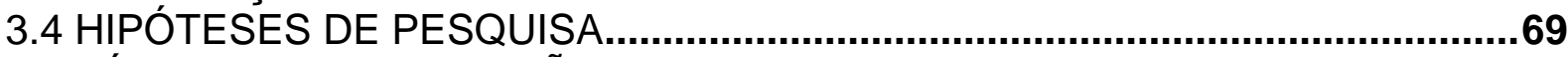

3.5 TÉCNICAS DE VALIDAÇÃO DO CONSTRUCTO DOS VIESES COGNITIVOS E

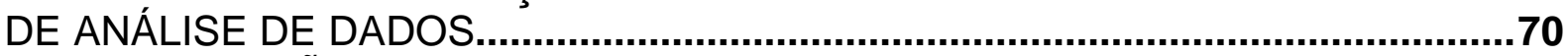

3.6 DELIMITAÇÕES DA PESQUISA …..........................................................74

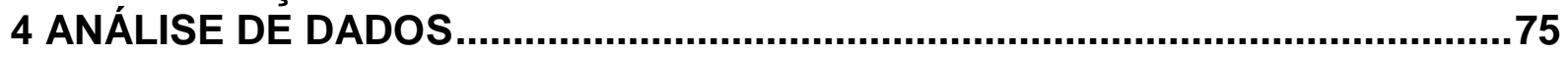

4.1 DIMENSIONALIDADE E CONFIABILIDADE DA ESCALA..................................75

4.2 CARACTERIZAÇÃO DOS PARTICIPANTES ….............................................79

4.3 ANÁLISE DAS HIPÓTESES DE PESQUISA …..............................................86

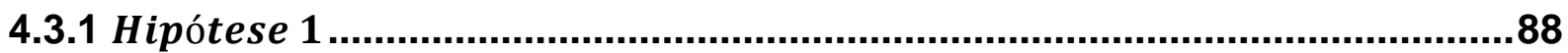

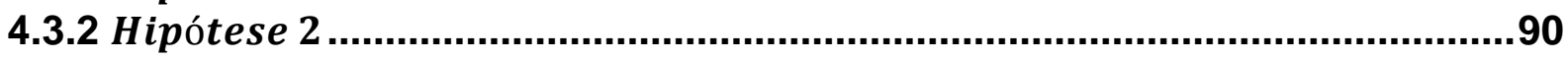

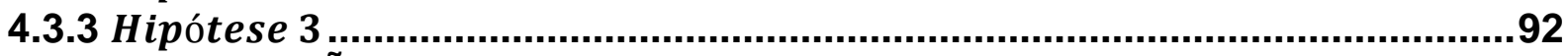

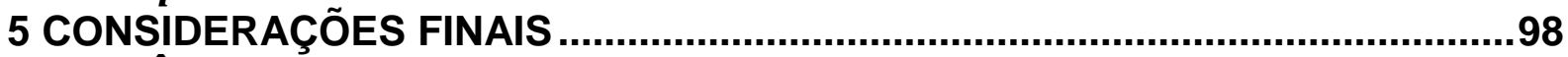

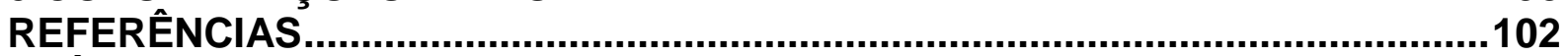

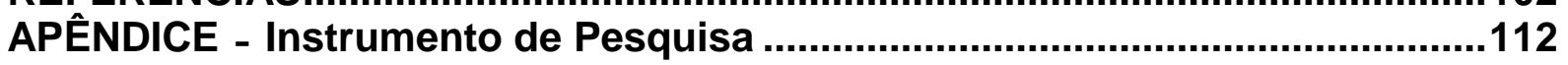




\section{INTRODUÇÃO}

Continuamente os seres humanos julgam e tomam decisões. Nesse processo, é comum o cérebro usar atalhos para reduzir o esforço cognitivo, o que, muitas vezes, se faz em consonância com as urgentes necessidades dos indivíduos. Lilienfeld et al. (2010) consideram a hipótese de que se uma pessoa está caminhando pela rua e vê um homem mascarado sair correndo de um banco, com uma arma, provavelmente tentará sair do caminho o mais rápido possível. Isso porque perceberá, nesse sujeito, características similares (representativas) às de um assaltante de bancos, tal como se costuma ver na televisão e/ou no cinema. Porém, há de considerar que a situação aí imaginada, pode tratar-se apenas de uma representação ficcional, sendo, por isso, uma mera encenação artística.

Nesse caso, conta-se com o atalho mental da representatividade, para se tomar a decisão mais sensata. No entanto, nem sempre essa heurística leva às melhores opções. Tome-se como exemplo um caso muito noticiado pela mídia do Brasil, no ano de 2010, quando um policial militar do Batalhão de Operações Policiais Especiais matou um morador da favela do Andaraí, no Rio de Janeiro, ao confundir uma furadeira, que a vítima estava usando para instalação de um toldo em sua casa, com uma arma (GONDIN, 2010). O referido policial utilizou a heurística da representatividade para julgar que o objeto poderia ser uma arma, devido às suas características serem similares, a certa distância, em se comparando o objeto real e o imaginário.

O cérebro, às vezes, comete lapsos sem que os indivíduos tenham ciência disso. Esses desvios podem ser gerados por falhas no processamento dos dados. Para se julgar acertadamente e, assim, tomar melhores decisões, é necessário reconhecer os "defeitos" da mente para não ser vítima deles. Conhecer as falhas e as dificuldades da mente ajuda os indivíduos a agirem de modo mais consciente, aumentando a probabilidade de alcançar os objetivos pretendidos. Esta pesquisa visa, justamente, investigar a relação existente entre a capacidade cognitiva e a ocorrência dos vieses cognitivos gerados pela heurística da representatividade no julgamento e na tomada de decisão. 


\subsection{CONTEXTUALIZAÇÃO}

Tomar decisão é uma tarefa inerente ao pensamento humano, seja de um único indivíduo ou de um grupo deles, podendo ser realizada com maior ou menor grau de racionalidade. Quando as decisões são tomadas a partir de dados incertos, é comum a existência de erros sistemáticos e recorrentes na avaliação da melhor ação, devido à utilização da heurística de forma equivocada. Esses erros são conhecidos como vieses cognitivos.

O viés cognitivo situa-se em um dos campos de estudo (processo de tomada de decisão) da psicologia cognitiva. Essa abrange, segundo Hogarth (1975), o estudo da percepção, da resolução de problemas, da formação de conceito sobre processos de julgamento, pensamento, e do processamento de informação humana em geral, procurando comparar as habilidades e limitações dos indivíduos com os sistemas de processamento de informação. O referido autor considera que o homem é um sistema de processamento de informações passo a passo, com capacidade limitada.

Para Cagnin (2009), a mente é um processador de informação com capacidade limitada que requer um hardware cerebral, o qual permita a implantação de operações e atividades mentais, cujos processos devem ser detalhados teoricamente.

Alimenta-se, pois, a expectativa de que, ao reagir a um determinado estímulo (como uma informação econômico-financeira), o comportamento do indivíduo seja influenciado pela experiência acerca das necessidades de sua comunidade, pela responsabilidade da qual está investido como representante da sociedade, pela sua visão de mundo e das demais pessoas, pelas suas aspirações em termos de promoção pessoal, dentre outros aspectos (SIMON, 1965; SIEGEL; RAMANAUSKAS-MARCONI, 1989; LIBBY; BLOOMFIELD; NELSON, 2002; MACEDO; FONTES, 2009).

Mas não se visa a esse nível de satisfação, pois o homem possui capacidade limitada no processamento de informação devido à seletividade de sua percepção. Por ser capaz de aprender apenas uma pequena parte de seu meio, suas antecipações determinam, na maioria das vezes, o que irá compreender, os mecanismos de simplificação cognitiva utilizados e a sequência do processamento de informação (HOGARTH, 1975). 
Até os anos 70, segundo Kahneman e Tversky (1979), a Teoria da Utilidade Esperada (TUE) dominou a análise da tomada de decisão em condições de incerteza, sendo aceita como um modelo normativo de tomada de decisão racional e amplamente aplicado para descrever o comportamento econômico.

Para a TUE, os indivíduos são maximizadores de utilidade, por fazerem uso de todas as informações disponíveis para tomarem as melhores decisões, de maneira objetiva, baseadas em um conjunto de preferências definido claramente.

O indivíduo da TUE é um ser racional que, na tomada de decisão, analisa todas as informações disponíveis e considera todas as hipóteses para solução do problema, relacionando os custos com benefícios para, assim, maximizar a sua riqueza. O homem econômico da visão neoclássica não possui defeitos e seu estado físico não é influenciado por sentimentos; ele procura sempre a satisfação dos seus interesses econômicos.

De acordo com Macedo Júnior et al. (2011), psicólogos cognitivos observaram que muitas decisões cotidianas dos indivíduos são tomadas de forma automática, além de ser influenciadas pelas emoções, que frequentemente entram em choque com a maximização da utilidade. Dessa forma, muitas escolhas não respeitam a TUE no momento em que são tomadas.

Gilovich, Griffin e Kahneman (2002) relatam que, no final dos anos 60 e início dos 70, os artigos de Tversky e Kahneman revolucionaram a pesquisa acadêmica sobre o julgamento humano. Eles investigaram o julgamento dos indivíduos sob condições de incerteza. O estudo ficou conhecido como abordagem de heurísticas e vieses (KAHNEMAN, SLOVIC, TVERSKY, 1982; TVERSKY; KAHNEMAN, 1974). Esses autores afirmam que as previsões intuitivas e os julgamentos são, muitas vezes, mediados por um pequeno número de operações mentais distintas, denominada de heurísticas de julgamento, as quais quase sempre são úteis, mas podem levar a vieses (KAHNEMAN, SLOVIC, TVERSKY, 1982; TVERSKY; KAHNEMAN, 1974).

A ideia central de que o julgamento sob incerteza normalmente recai sobre um número limitado de heurísticas simplificadas, ao invés de processamento algorítmico extenso, foi absorvida por outras disciplinas além da psicologia, influenciando suas teorias e pesquisas. Isso devido à tomada de decisão dos indivíduos ser uma questão de interesse de pesquisadores de várias áreas, como 
economia, ciências contábeis, administração, ciência política, sociologia, direito e psicologia.

Em seu trabalho A Behavioral Model of Rational Choice, de 1955, Simon questionava sobre a causa dessa limitação. Em 1974, no artigo intitulado Judgment under uncertainty: heuristics and biases, Tversky e Kahneman indicaram as emoções e a falta de conhecimento adequado como grandes limitações da racionalidade do indivíduo.

Os vieses podem resultar de três grandes heurísticas: a representatividade, a disponibilidade e a ancoragem e ajustamento (BASEL; BRÜHL, 2011; HILBERT, 2012, LAGROUE, 2006; SHANTEAU, 1989; TVERSKY; KAHNEMAN, 1974). Mas vale ressalvar que essas heurísticas não são mutuamente excludentes em um processo de tomada de decisão.

\subsection{JUSTIFICATIVA E PROBLEMA DE PESQUISA}

A Contabilidade tem como objetivo fornecer informações para os diversos usuários, sejam eles internos ou externos. Essas informações podem influenciar a ação ou comportamento desses, quer de forma direta, pelo conteúdo informacional da mensagem transmitida, quer de forma indireta, pelo comportamento do contador, ao gerar e transmitir a informação. Assim, é um desafio conhecer quais vieses cognitivos incidem no processo de julgamento dos contabilistas; estabelecer, de maneira convincente, os efeitos provocados na Contabilidade pelos vieses cognitivos do profissional contábil, os quais podem influenciá-la e, consequentemente, o mercado (nos preços e volume de negócios), bem como saber de que modo as informações de natureza contábil afetam as decisões e o comportamento dos interessados.

Segundo Kimura (2003), o comportamento humano é influenciado por diversos aspectos psicológicos, que podem distorcer o processo racional de tomada de decisão. Complementando, Birnberg, Luft e Shield (2007) afirmam existir uma forte relação entre a Ciência Contábil e o comportamento humano, uma vez que os aspectos psicológicos impactam naquela. Assim, é importante estudar o comportamento do contador e também o de seus usuários. 
O campo de estudos da influência do comportamento humano sobre a tomada de decisão, como já discutido, opõe-se ao pressuposto de racionalidade ilimitada.

Os estudos comportamentais na área das ciências contábeis têm crescido nas últimas décadas. Dyckman (1998) documentou, em seu estudo, o crescimento da pesquisa comportamental na Contabilidade, no período de 1978 a 1998, e verificou que, nos periódicos The Accounting Review e Journal of Accounting Research, houve um aumento na quantidade de publicações sobre esse tema no período analisado; além disso, cresceu o número de professores de Contabilidade que se dedicam às pesquisas comportamentais, bem como o número de instituições que contam, em seu corpo docente, com pelo menos um pesquisador comportamental. No Brasil, é notório o aumento da quantidade de pesquisa em Contabilidade na área Comportamental. É uma área que ganhou espaço em congressos e periódicos, porém, em se comparando com outras áreas, ainda tem muito a conquistar.

Birnberg (2011) assegura que hoje, mais do que nunca, pesquisas sobre contabilidade comportamental (BAR - Behavioral Accounting Research) são mais ricas, devido aos temas abordados, aos métodos utilizados e à gama de subáreas da contabilidade em que são realizadas. O crescimento da BAR foi acompanhado e beneficiado por um aumento semelhante de pesquisas comportamentais em outras disciplinas.

Várias evidências empíricas (BUKSZAR, 2003; HOGARTH, 1975; KAHNEMAN; SLOVIC, TVERSKY, 2001; KIM; BYUN, 2011; MUSSWEILER; ENGLICH, 2005; SAMUELSON; ZECKHAUSER, 1988; TVERSKY; KAHNEMAN, 1974; VEERARAGHAVAN, 2010) contestam a ideia da existência de indivíduo perfeitamente racional e dão impulso a novas pesquisas na área comportamental, comprovando que a heurística, a qual reduz as tarefas complexas de tomada de decisão, pode também levar a graves erros sistemáticos no julgamento.

Em busca de novos saberes, alguns estudos investigam a relação dos vieses com a capacidade cognitiva dos indivíduos (FREDERICK, 2005; HOPPE; KUSTERER, 2011; OECHSSLERA; ROIDERA, SCHMITZ, 2009), que se define como um mecanismo cerebral (a percepção, a aprendizagem, a tomada de decisão) usado para realizar quaisquer atividades, sejam elas simples ou complexas. Pesquisadores (FREDERICK, 2005; KAHNEMAN; FREDERICK, 2002) ressaltam, 
por exemplo, que a teoria da tomada de decisão distingue o processo cognitivo em dois tipos: os executados rapidamente - pouco conscientes (Tipo 1) e os mais reflexivos (Tipo 2).

Nesse sentido, Frederick (2005) adverte que, apesar de o processo de decisão poder ser explicado por dois tipos de processamento: o tácito ou intuitivo e o analítico ou deliberativo, o sistema intuitivo acaba por ter uma ligação maior com as heurísticas ou a estas se sobrepor quando a questão a ser resolvida é vista como fácil demais pelo indivíduo. Isso ocorre quando, em um primeiro momento, sem nenhuma análise mais detalhada, a pessoa já chega a uma alternativa que parece ser boa o suficiente para resolver o problema. Tese essa defendida neste trabalho, cuja inovação é o instrumento de coleta de dados utilizado para mensurar os vieses cognitivos oriundos da heurística da representatividade.

A distração e o estresse dos indivíduos reduzem a eficácia do processo decisório. Isso porque o sistema 2, por ser relativamente lento, pode ter suas operações interrompidas por pressão na variável tempo. Quando dispõem de pouco tempo para a tomada de decisão, as pessoas costumam utilizar heurísticas para avaliar os riscos e benefícios (KAHNEMAN; FREDERICK, 2005).

No entanto, Gladwell (2005) argumenta que as decisões tomadas muito depressa podem alcançar resultados tão positivos quanto aquelas tomadas de maneira cautelosa e deliberada.

Assim, apesar da existência de estudos sobre esse tema, tanto em nível nacional quanto em nível internacional, não foi publicado nenhum registro de resultado na área contábil que desse conta de todos os vieses cognitivos de uma única heurística em um único estudo.

Diante desse contexto, surge o seguinte problema de pesquisa: no julgamento e na tomada de decisões, a capacidade cognitiva influencia na ocorrência dos vieses cognitivos gerados pela heurística da representatividade?

Ao responder essa pergunta, espera-se poder contribuir para uma reflexão sobre a importância de se conhecer os vieses comportamentais oriundos da heurística da representatividade aos quais os profissionais contábeis e os estudantes podem estar sujeitos, assim como outros indivíduos, e como os vieses podem impactar a tomada de decisão em situações de incerteza. Para mensurar a capacidade cognitiva, serão utilizadas três questões do Cognitive Reflection Test (CRT), elaborado por Frederick (2005). 
Figura 1 - Desenho inicial da pesquisa

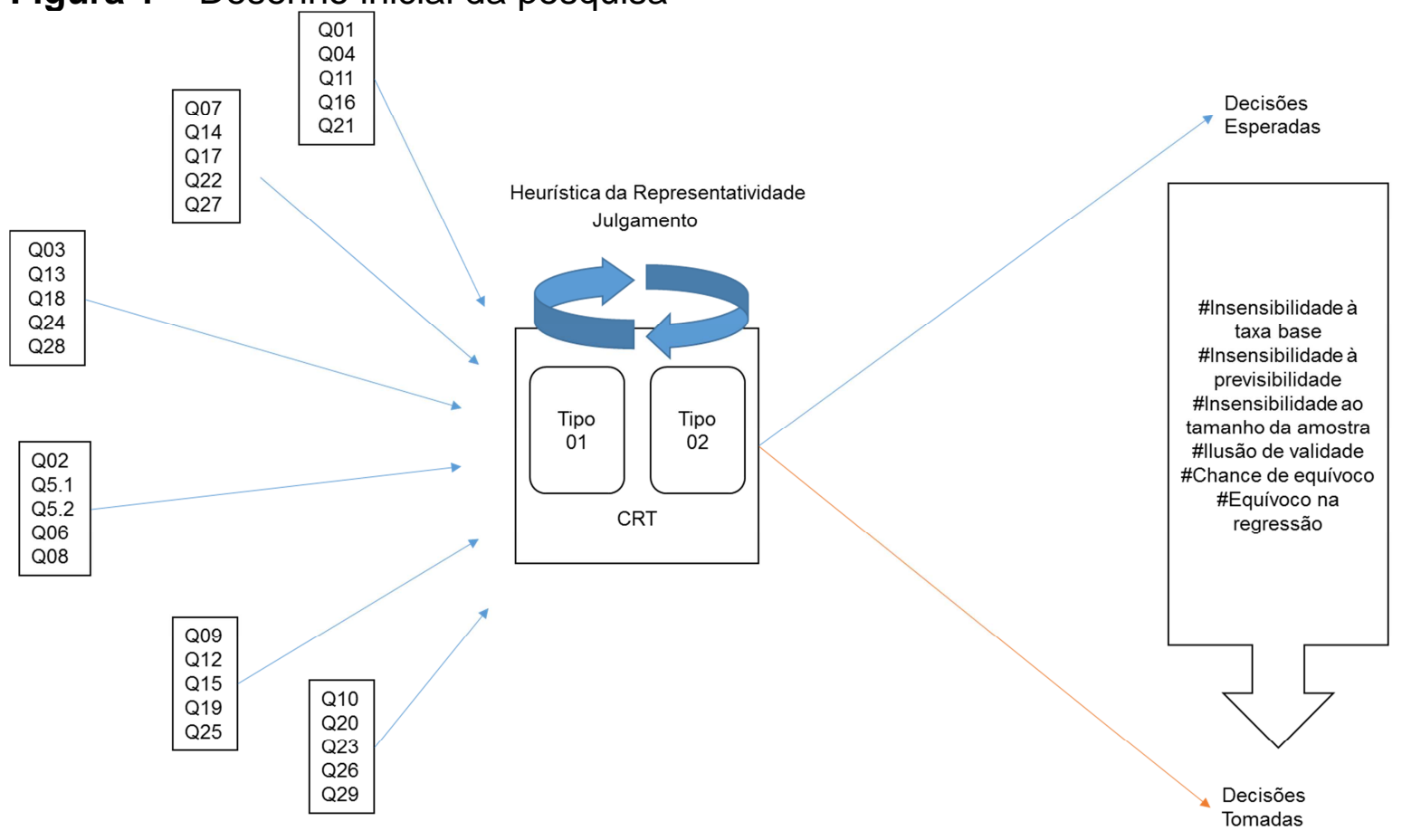

Fonte: Elaboração própria (2015)

A figura 1 representa o desenho inicial desta pesquisa, em que se busca demonstrar que os participantes têm acesso a cinco cenários para cada um dos vieses cognitivos estudados (representados na figura por Q01, Q02, e assim sucessivamente, já organizados por grupos, onde $Q$ corresponde às questões do instrumento de coleta de dados). Ao lê-los, os participantes irão fazer seus julgamentos, utilizando ou não heurísticas da representatividade, e poderão ser afetados pela capacidade cognitiva. Para mensurá-la e para averiguar qual o tipo de processamento utilizado fará uso do Cognitive Reflection Test (CRT). O alcance de uma pontuação igual a zero, no CRT, irá significar a utilização do processamento cognitivo do Tipo 1 (intuitivo); à medida que for aumentando essa pontuação, subentende-se a intervenção do processo do Tipo 2 (reflexivo). Caso façam uso da heurística da representatividade em seus julgamentos, as decisões podem ser afetadas pelos seguintes vieses, de acordo com a ordem dos cenários (de cima para baixo), respectivamente: insensibilidade à taxa base, insensibilidade à previsibilidade, insensibilidade ao tamanho da amostra, ilusão de validade, chance de equívocos, equívoco na regressão.

Os vieses de decisão, de acordo Tversky e Kahneman (1996), devem ser estudados detalhadamente, por várias razões; dentre elas, cabe destacar: o interesse que o tema gera por si próprio; o surgimento de implicações práticas; e a 
possibilidade de esclarecimento dos processos psicológicos que fundamentam a percepção e o julgamento.

Em favor desse conhecimento, existe, na literatura, uma variedade de vieses cognitivos, identificados por estudiosos da cognição, aos quais as pessoas estão sujeitas ao tomarem decisão sob incerteza, quais sejam: insensibilidade à taxa base, insensibilidade ao tamanho da amostra, chance de equívocos, equívoco na regressão, falácia da conjunção, insensibilidade à previsibilidade, ilusão de validade, facilidade de lembrança, recuperabilidade, presença de associação, da efetividade de uma configuração, insuficiente ajustamento da âncora, viés de eventos conjuntivos e disjuntivos, excesso de confiança (BAZERMAN, 1994; DAS; TENG, 1999; EINHORN; HOGARTH, 1981; JOYCE; BIDDLE, 1981; KAHNEMAN; TVERSKY, 1972, 1979; SHANTEAU, 1989; SLOVIC et al., 1977; TAYLOR, 1975; TVERSKY; KAHNEMAN, 1971, 1973, 1974, 1981; WALSH, 1995).

Devido a essa visível diversidade, fica difícil investigá-los em um único estudo; por isso, foram selecionados para ser investigados, na presente pesquisa, os vieses cognitivos gerados por erros na utilização da heurística da representatividade, que possui como atributo a classificação de uma coisa com base na semelhança com um caso típico. Atenta-se, ainda, para o fato de que são muitos os estudos que investigam a incidência desses vieses na tomada de decisões, cabendo registrar, entre outros, Einhorn e Hogarth (1981); Joyce e Biddle (1981); Kahneman e Tversky (1972); Kahneman (2003); Kim e Byun (2011); Tversky e Kahneman (1971, 1974, 1983); Shanteau (1989); e Veeraraghavan (2010).

A fundamental importância do estudo sobre o comportamento e a irracionalidade do homem, mais especificamente sobre vieses cognitivos, na ciência contábil, assim como em outras ciências, centra-se na necessidade de se conhecer os vieses e o modo como esses influenciam o processo de tomada de decisão em situações particulares. E isso, tanto no que concerne ao contabilista, no momento da preparação das informações contábeis para seus diversos usuários, quanto no que diz respeito a estes ao fazerem uso daquelas. Conhecer os vieses pode ajudar na minimização das falhas cognitivas, por ser possível compreender a influência dos fatores cognitivos no processamento das informações pelos seres humanos, e por poder melhorar, dessa forma, a capacidade decisória, pois os erros podem ser corrigidos caso sejam conhecidos. 


\subsection{OBJETIVO GERAL}

O objetivo geral deste estudo é: Investigar se a capacidade cognitiva de estudantes do curso de graduação em Ciências Contábeis, bem como a dos profissionais contábeis, influencia na ocorrência dos vieses cognitivos gerados pela heurística da representatividade.

\subsection{OBJETIVOS ESPECÍFICOS}

Para alcançar o objetivo geral, serão definidos os seguintes objetivos específicos:

a) Mensurar a capacidade cognitiva através dos três itens do Cognitive Reflection Test (CRT), elaborado por Frederick (2005) e, consequentemente, o tipo de processo cognitivo utilizado.

b) Verificar a incidência dos vieses cognitivos insensibilidade à taxa base, insensibilidade ao tamanho da amostra, chance de equívocos, equívocos na regressão, ilusão de validade e insensibilidade à previsibilidade no processo de julgamento e de tomada de decisão dos indivíduos.

c) Investigar se o nível de escolaridade, o gênero e a região influenciam diferentemente na incidência dos vieses cognitivos estudados.

d) Verificar a existência (ou não) de diferença estatística da variável grau de dificuldade dos respondentes nos três itens do CRT e a capacidade cognitiva, além da relação dessa última variável com a opinião dos indivíduos sobre seu julgamento e tomada de decisão.

e) Determinar a existência (ou não) de diferença entre o nível de capacidade cognitiva e os seis vieses cognitivos estudados.

\subsection{ESTRUTURA DA TESE}

Esta pesquisa é constituída por cinco capítulos. Neste primeiro, a Introdução, fornece-se uma visão geral da tese, situando o leitor no contexto do estudo, contemplando-se a contextualização; a justificativa e o problema de pesquisa; o objetivo geral e os específicos; e a estrutura composicional do texto. 
No segundo capítulo, Referencial teórico, desenvolve-se o embasamento do tema investigado, a partir da revisão da literatura existente, abordando-o sob o enfoque da Psicologia Cognitiva e da Contabilidade Comportamental; da Teoria de Duplo Processo e Cognitive Reflection Test (CRT); das Heurísticas e Vieses Cognitivos; e das Evidências empíricas sobre os vieses cognitivos oriundos da heurística da representatividade e sobre CRT.

No terceiro capítulo, discorre-se sobre os Procedimentos Metodológicos, explicitando, de forma detalhada e rigorosa, todas as ações desenvolvidas na pesquisa. No quarto capítulo, apresentam-se os resultados da pesquisa, reservandose ao quinto o registro das Considerações finais. As referências e apêndice também fazem parte da estrutura composicional, na medida em que, por esses recursos, se relacionam todas as obras que contribuíram para a realização deste trabalho, e o instrumento de coleta de dados, respectivamente. 


\section{REFERENCIAL TEÓRICO}

Este capítulo conterá uma exposição sistemática de abordagens conceituais necessárias à compreensão do tema estudado.

\subsection{PSICOLOGIA COGNITIVA E CONTABILIDADE COMPORTAMENTAL}

A Psicologia Cognitiva é definida como aquela área da pesquisa em que métodos e teorias da psicologia experimental são usados na tentativa de se obter uma compreensão científica de fenômenos cognitivos que ocorrem no mundo real da atividade e experiência humana e de resolver problemas práticos que surgem na educação, nos negócios, no governo e nas empresas (HOFFMAN; DEFFENBACHER, 1992). Essa ciência visa ao estudo do pensamento humano e dos processos mentais subjacentes ao comportamento, incluindo memória, resolução de problemas, percepção, linguagem, processamento da informação, com o objetivo de identificar como a tomada de decisão é influenciada por esses fatores.

$\mathrm{Na}$ área de pesquisa sobre psicologia cognitiva, há uma vasta literatura documentando os erros sistemáticos que as pessoas cometem na maneira como pensam, alegando-se como causa o excesso de confiança, o alto peso atribuído à experiência recente, às preferências individuais, entre outras (RITTER, 2003).

De acordo com Cowan (2000), uma das contribuições principais da psicologia cognitiva é a investigação das limitações existentes na capacidade humana de processar e armazenar informações. No processamento da informação, etapa anterior à tomada de decisão, a mente humana é considerada um processador com capacidade limitada, que, para armazenar a informação, deve permitir a implantação de operações e atividades mentais, as quais sofrem detalhamento teórico de seus processos.

Essa capacidade limitada de processamento de informação dos indivíduos proporciona uma percepção seletiva da informação, pelo fato de eles não serem capazes de captar todos os dados do ambiente em que estão inseridos e ainda porque suas antecipações determinam, na maioria das vezes, o que eles percebem. Adicionalmente, isso gera o uso de heurísticas e mecanismos de simplificação cognitiva, além do processamento de informações de maneira sequencial, devido à impossibilidade da integração simultânea de uma grande quantidade de informação. 
Segundo Birnberg e Ganguly (2012), o estudo sobre processos cognitivos dos indivíduos envolve duas atividades: (a) observar as escolhas humanas, a partir de dados de campo ou de experimentos controlados em laboratório, juntamente com as entradas principais para essas escolhas e (b) desenvolver e testar teorias que mapeiam essas escolhas, baseadas na ligação entre as entradas e saídas de tomada de decisão humana, através de simples correlações observadas ou de inferências sobre o funcionamento da "caixa preta" (denominação dada ao cérebro pelos autores). Uma solução a que recorrem, historicamente, os pesquisadores, para aprender sobre o funcionamento da caixa preta, é estudar os vieses sistemáticos na tomada de decisão humana.

Com o objetivo de entender a mente humana, estudos vêm sendo realizados, desde Platão e Aristóteles, buscando explicar a natureza do conhecimento do indivíduo. Esse assunto permaneceu sendo centro de interesse da filosofia até o século XIX, período em que surgiu a psicologia experimental dedicada a investigar, de forma sistemática, as operações mentais (COSTA, 2005).

Alguns anos depois, em 1919, foi publicado por Watson, o livro Psychology from the Standpoint of a Behaviorist, que deu início à era do behaviorismo, o qual dominou a psicologia por aproximadamente 50 anos (SCHOEKE et al., 2004). Esse movimento dá ênfase aos aspectos comportamentais externos, examinando como o comportamento observável do ser humano responde aos estímulos passíveis de observação no ambiente em que vive, e afirma ser impossível o estudo científico da consciência e das representações mentais.

As proposições do behaviorismo foram rompidas no fim dos anos de 1950, mais precisamente em setembro de 1956, no simpósio sobre teoria da informação, que ocorreu no Instituto Massachusetts de Tecnologia, com a participação dos pesquisadores Noam Chomsky, George Miller, Allen Newell e Herbert Simon, cujos trabalhos versavam sobre processos mentais. Nesse cenário, surge a ciência cognitiva, com ênfase no caráter representacional da cognição, a qual gera um grande número de pesquisas experimentais sobre os fenômenos mentais (VASCONCELLOS; VASCONCELLOS, 2007).

Cowan (2000) considera a revisão teórica de Miller, Magical number seven, plus or minus two, no ano de 1956, como o trabalho mais seminal na literatura sobre investigações dos limites na capacidade de armazenamento da memória no curto 
prazo. Para Psychological Review, em edição de 1994, o referido artigo foi qualificado como o mais influente de todos os tempos.

O desenvolvimento da psicologia cognitiva é justificado pelo fracasso do behaviorismo como proposta à cognição humana (COSTA, 2005). Outras áreas, como ciências contábeis, economia, administração, fazem uso de suas teorias para analisar a mente humana como um processador de informações.

A Contabilidade, ao lidar com os processos de tomada de decisões, utiliza-se de princípios comportamentais, oriundos da psicologia. Essa área estabelecida no pensamento contábil é denominada Contabilidade Comportamental e integra a dimensão do comportamento humano aplicado à Contabilidade, assim como Finanças Comportamentais, Economia Comportamental, Neuroeconomia, Psicologia Econômica, entre outras (LUCENA; FERNANDES; SILVA, 2011).

A Contabilidade comportamental é uma interface da ciência contábil e social, que está preocupada, dentre outras, com as influências do comportamento humano na mensuração dos dados contábeis e nas decisões dos negócios e com o estudo da reação humana ao formato e conteúdo dos relatórios contábeis (SIEGEL; RAMANAUSKAS-MARCONI, 1989). Esses mesmos autores afirmam ser esse o terceiro maior ramo da ciência contábil, cujo interesse é o relacionamento entre o comportamento humano e o sistema da Contabilidade.

Os dados contábeis são coletados, processados e as informações geradas em um ambiente onde opera o comportamento organizacional e há intercessão do comportamento humano em cada uma dessas fases. Da mesma forma, percebe-se que o comportamento também influencia a forma como as pessoas reagem às informações contábeis e tomam decisões.

Conforme Williams et al. (2006), pesquisar sobre contabilidade comportamental é uma preocupação para os estudiosos, por ser essa uma atividade construída a partir de valores humanos e seus resultados serem importantes para compreender e moldar sua prática.

A Contabilidade necessita da inserção de medidas subjetivas na preparação da informação, exigindo de seu profissional um julgamento que represente fielmente a realidade, de modo a fazer-se relevante e poder ajudar, da melhor maneira, no processo decisório dos seus usuários. No momento do julgamento, tentando fornecer a melhor decisão, o contador pode ser influenciado por vieses cognitivos, os quais podem prejudicar a qualidade das demonstrações contábeis. Assim, é 
importante estudar os vieses cognitivos, para conhecê-los, entender suas causas e, dessa forma, poder minimizar a sua ocorrência.

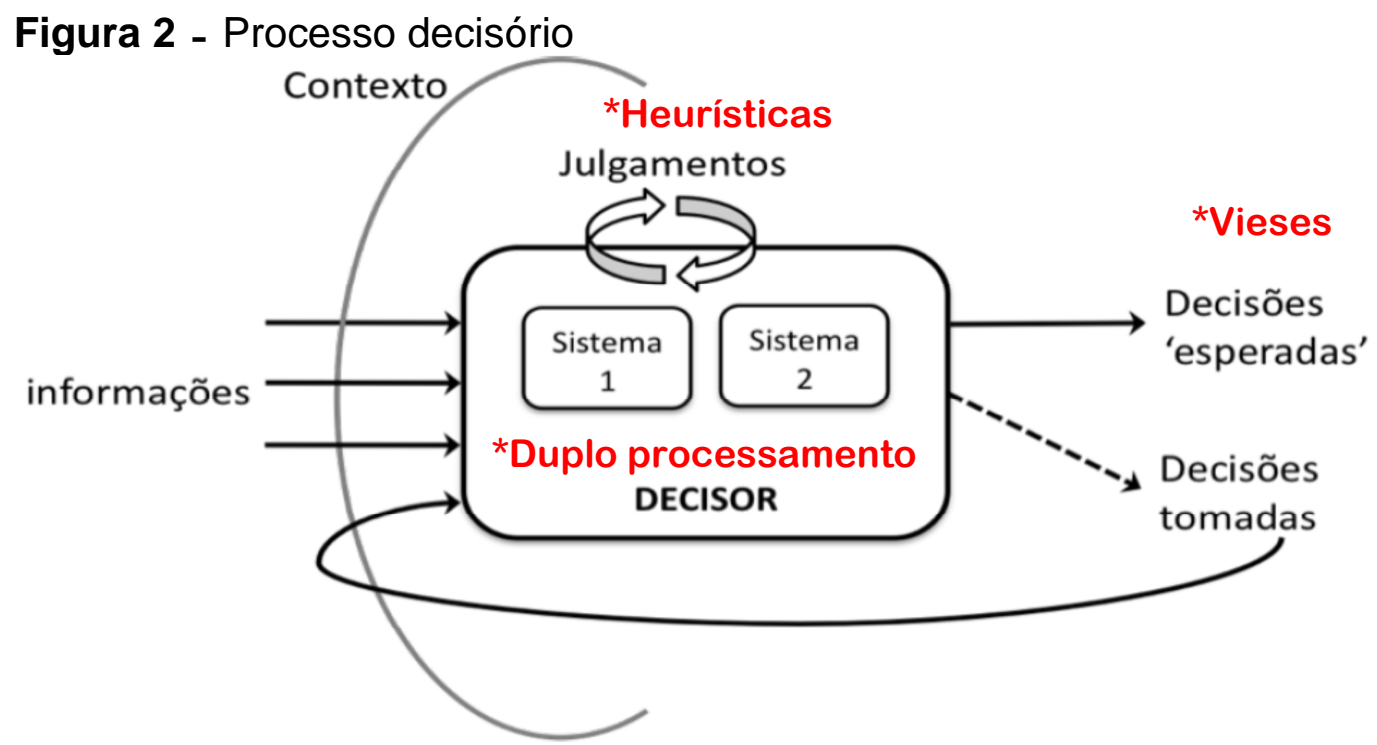

Fonte: Adaptada Spiegel; Caulliraux (2013)

A figura 2 apresenta uma síntese do processo de tomada de decisão, tendose como entrada as informações, as quais serão utilizadas dentro de determinado contexto para se efetuar os julgamentos, podendo-se fazer uso de heurísticas. No julgamento, o decisor utiliza-se de seu duplo processamento (Sistema 1 e 2) para tomar decisões que podem ser influenciadas pelos vieses cognitivos.

Pesquisadores de julgamento e tomada de decisão dos indivíduos, em áreas como contabilidade comportamental, economia, finanças e marketing, ao longo das últimas quatro décadas, catalogaram uma variedade de regras simples (heurísticas), as quais a mente humana utiliza para lidar com decisões complexas e escolhas, especialmente em situações de incerteza e ambiguidade (BIRNBERG; GANGULY, 2012).

No que se refere ao julgamento, de acordo com Belkaoui (2002), a entrada principal para esse processo é um problema ou um fenômeno contábil que, para ser resolvido, exige um pré-julgamento ou uma decisão. $O$ modelo do processo de tomada de decisão pode ser representado pelos seguintes passos (BELKAOUI, 2002):

a) Observação do fenômeno contábil por quem vai tomar a decisão: o tomador de decisão tem a oportunidade de observar o fenômeno contábil, para cuja compreensão pode solicitar alguma informação. As suas 
expectativas sobre o fenômeno contábil podem determinar o tipo de informação procurada e podem influenciá-lo na seleção de algumas informações ao invés de outras.

b) Formação de esquema ou construção do fenômeno contábil: nessa fase, a informação relevante é codificada, ou seja, categorizada com base na experiência e organizada em esquemas ao longo da memória ou estrutura de conhecimento. O esquema pode ser uma atualização de modelos existentes ou um novo modelo gerado pela ocorrência de um novo fenômeno contábil.

c) Organização ou armazenamento de esquema: as informações sobre o fenômeno contábil movem-se através de sistemas de memória diferentes e separados, terminando com um armazenamento de longo prazo.

d) Processamento de estímulos, atenção e reconhecimento: esse passo depende da acessibilidade na memória, na probabilidade de que eles podem ser ativados, seja usando a entrada de uma nova informação ou a recuperação de uma previamente armazenada.

e) Recuperação das informações armazenadas necessárias ao julgamento da decisão: há possibilidade da existência de diferentes tipos de vieses nessa fase, devido à utilização da heurística da disponibilidade.

f) Reconsideração e integração de informações recuperadas com novas informações: nessa fase, o processo envolve a integração da informação recuperada a partir da memória e de outras informações disponíveis. É nesse passo que a familiaridade com o fenômeno está presente e as rotinas previamente aprendidas são recuperadas. Esse processo também é sujeito a vários vieses; uma das razões para que isso ocorra é o fato de as pessoas vincularem e darem grande peso para algum tipo de informação; subutilizarem ou desconsiderarem taxa base; entre muitas outras causas, pelas heurísticas envolvidas nas decisões sobre os fenômenos contábeis.

g) Processo de julgamento: julgamento requer um acesso consciente de todos os processos mentais implicados no modelo. No entanto, se os processos de atenção, reconhecimento, recuperação e integração forem resultado de processos automáticos, a sentença não será consciente. 
h) Tomada de decisão: é o último passo do modelo; é a seleção de uma resposta para fenômeno contábil, ou seja, a saída do processo de julgamento, sendo influenciado por todos os processos mentais e vieses.

Através do processo de julgamento anterior, pode-se observar que os vieses cognitivos são considerados uma das limitações dos indivíduos no momento da tomada de decisão, a qual pode gerar a seleção equivocada de uma das alternativas envolvidas, como pode ser visto na figura 2. Segundo Sequeira et al. (2013), o julgamento e a tomada de decisão em condições de incerteza é um domínio de investigação em constante evolução.

Assim, essa dimensão do comportamento humano é estudada pela psicologia cognitiva, que investiga a percepção, a resolução de problemas, os processos de julgamento, o pensamento, a formação de conceito e o processamento de informação humana em geral, visando especificar as habilidades e limitações dos indivíduos com o sistema de processamento de informação (HOGARTH, 1975). Esse estudo faz uso das teorias sobre psicologia cognitiva para alcançar seu objetivo.

\subsection{A TEORIA DE DUPLO PROCESSO}

Em 1950, James defendia a Teoria de Duplo Processo de Raciocínio na tomada de decisão, em seu livro The principles of psychology. Segundo a Teoria, o raciocínio humano compreende dois tipos de sistema de processamento: um é fácil, impulsivo, associativo e executado rapidamente, com pouca deliberação; já o outro é lento, analítico, reflexivo e com maior necessidade de esforço (BASILE, 2012; SOUZA, 2010).

As Teorias de Duplo Processo de pensamento e raciocínio, nas últimas décadas, tornaram-se cada vez mais influentes, talvez pela necessidade de explicar a descoberta de uma série de vieses cognitivos que violem regras de lógica, em tarefas de raciocínio e tomada de decisão (BARROUILLET, 2011). Essas teorias, inicialmente, tentaram explicar as aparentes dissociações que foram observadas entre os raciocínios intuitivo e reflexivo (WASON; EVANS, 1975). No entanto, as formas mais fortes de evidências que emergiram nos últimos anos vão muito além. Manipulações experimentais tentam mudar o equilíbrio entre o Tipo 1 e 2 (ou Sistemas 1 e 2) de processamento através da utilização de instruções, prazos e 
cargas de memória de trabalho; e métodos de neurociência demonstram que diferentes regiões do cérebro são ativadas de acordo com o tipo de processamento (BARROUILLET, 2011).

De acordo com a Teoria de Duplo Processo, também denominada de Teoria de Duplos Sistemas de Cognição, o pensamento humano é composto por dois sistemas distintos, embora interajam entre si. Esses sistemas envolvem diferentes arquiteturas cognitivas e, na maioria dos modelos atuais, funções distintas (OAKSFORD; CHATER, 2010 apud RICCO; OVERTON, 2011).

Pesquisadores, como Frederick (2005) e Kahneman e Frederick (2002), classificam o processo cognitivo em processos executados rapidamente e processos mais reflexivos e regidos por regras, denominados, por Stanovich e West (2000), de sistema 1 e 2 . Segundo esses autores, o sistema 1 é caracterizado como automático, em grande parte, inconsciente, pouco exigindo, por isso, da capacidade mental, enquanto o sistema 2 envolve operações que requerem esforço, motivação, concentração e execução de regras aprendidas.

Segundo Barrouillet (2011), o sistema 2 depende fortemente do controle cognitivo e da capacidade de memória de trabalho, os quais evoluem fortemente com a idade, enquanto o sistema 1, por ser independente da inteligência e da memória de trabalho, é relativamente independente da idade.

Existe um consenso considerável sobre as características que distinguem os dois tipos de processos cognitivos, as quais podem ser resumidas na Figura 3 (KAHNEMAN, 2003). 
Figura 3 - Processo e Conteúdo nos dois Sistemas Cognitivos

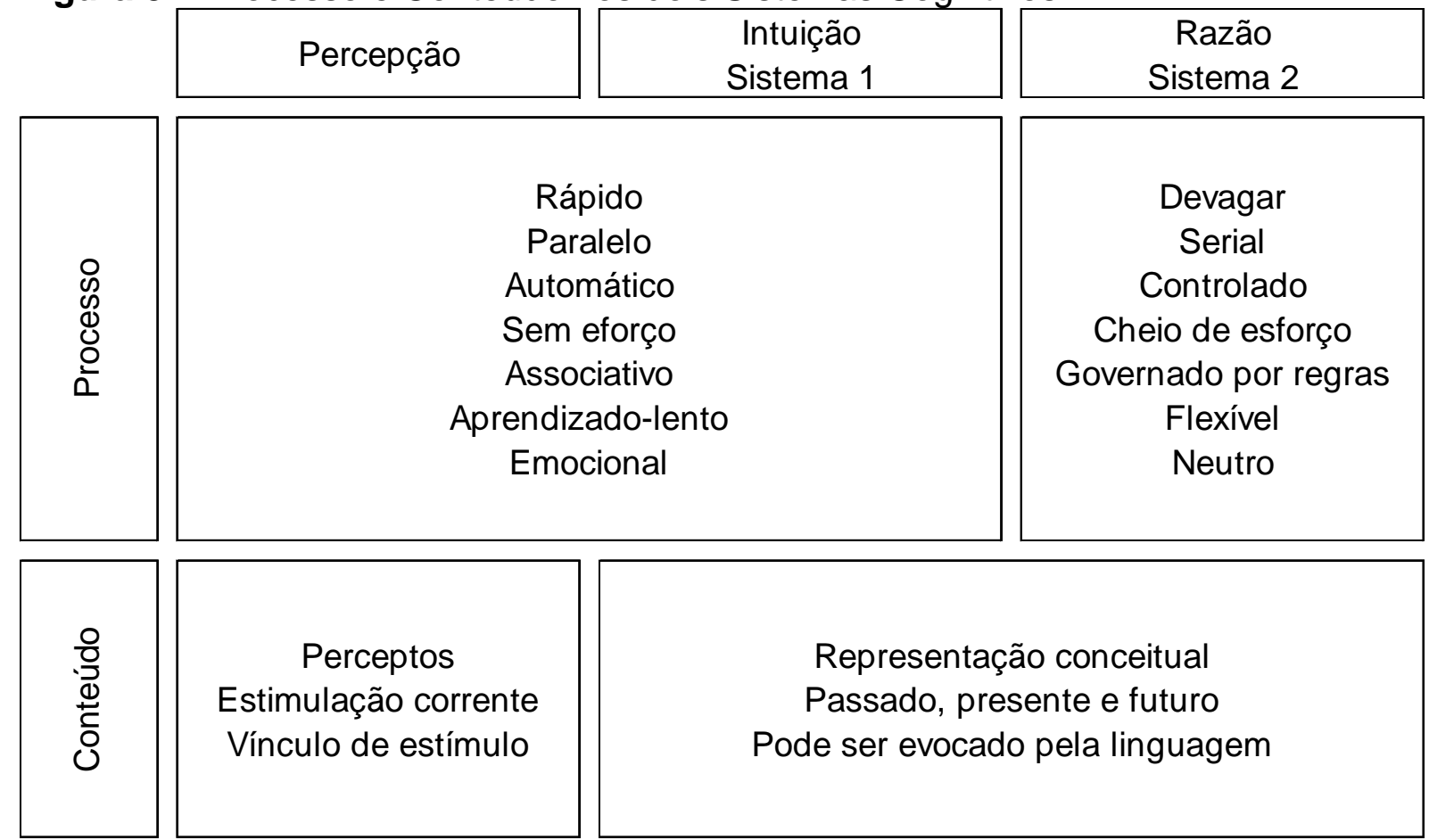

Fonte: Kahneman (2003)

Na Figura 3, é possível observar que o Sistema 1 é, normalmente, rápido, paralelo, automático, sem esforço, associativo, de aprendizagem lenta e, muitas vezes, carregado emocionalmente. E como é guiado por costumes, suas operações são difíceis de controlar ou modificar. As características de funcionamento desse sistema são semelhantes às características de processos perceptuais.

O Sistema 2, por sua vez, é mais lento, serial, relativamente flexível, regido por regras; também exige maior esforço cognitivo, pois há uma maior probabilidade de as operações mentais e de comportamento serem monitoradas conscientemente e deliberadamente controladas.

Assim, os processos de julgamento espontâneos são baseados na intuição, ocorrem mais rápido e com mais vieses na tomada de decisão, enquanto a decisão racional tende a ser fruto de um julgamento mais reflexivo, organizado e flexível. O Sistema 2 está envolvido em todos os processos em que há momentos de julgamento da informação, ao passo que o Sistema 1 geralmente se baseia em impressões preestabelecidas. As pessoas que já estão acostumadas a tomar um determinado tipo de decisão tendem a usar o Sistema 1 sempre que situações semelhantes aconteçam. No entanto, muitas vezes elas deixam de perceber a 
totalidade da situação e são mais passíveis de cometer erros em função de seguirem padrões de respostas aprendidos (TONETTO; RENCK; STEIN, 2012).

Alguns estudos (STANOVICH; WEST; TOPLAK, 2011; EVANS, 2011; EVANS; STANOVICH, 2013) utilizam a terminologia Tipo 1 e Tipo 2, no lugar de Sistema 1 e Sistema 2, devido a esses últimos termos, segundo eles, serem ambíguos, pois, às vezes, funcionam como sinônimos de duas mentes, além de distinguir os dois tipos de processamento; e sugerem falsamente que os dois tipos de processos estão localizados em apenas dois sistemas cognitivos ou neurológicos específicos.

O termo Sistema 1 e 2 deveria estar no plural, pois cada um se refere a um conjunto de sistemas no cérebro. Os termos Tipo 1 e 2 de processamento indicam formas distintas de processamento e ainda deixam subentendido que vários sistemas cognitivos e neurais podem estar subjacentes a eles.

Quadro 1 - Atributos associados frequentemente com as Teorias de Duplo Processamento e de Duplo Sistema.

\begin{tabular}{|l|l|}
\hline Tipo 1 (intuitivo) & Tipo 2 (reflexivo) \\
\hline Não requer memória de trabalho & Requer memória de trabalho \\
Autônomo & Dissociação cognitiva; simulação mental \\
Rápido & Lento \\
Paralelo & Serial \\
Inconsciente & Consciente \\
Respostas enviesadas & Respostas normativas \\
Contextualizado & Resumido \\
Automático & Controlado \\
Associativo & Baseado em regras \\
Tomada de decisão baseada em experiência & Tomada de decisões consequentes \\
Independente da capacidade cognitiva & Correlacionada com a capacidade cognitiva \\
\hline Sistema 1 (mente velha) & Sistema 2 (mente nova) \\
\hline Evolui cedo & Evolui tarde \\
Semelhante à cognição animal & Distintamente humano \\
Conhecimento implícito & Conhecimento explícito \\
Emoções básicas & Emoções complexas \\
\hline
\end{tabular}

Fonte: Evans e Stanovich (2013)

Ao comparar a Figura 3 e o Quadro 1, é possível observar que Kahneman (2003) utiliza a nomenclatura Sistema 1 e 2, sem qualquer pressuposto subjacente da singularidade nos níveis cognitivos ou neurais, apenas para distinguir os dois tipos de processamento. A terminologia Tipo 1 e 2 de processamento começou a ser usada apenas mais recentemente (STANOVICH; WEST; TOPLAK, 2011; EVANS, 2011; EVANS; STANOVICH, 2013). O Quadro 1, além de contemplar as características evidenciadas da Figura 3, adiciona outras como: a utilização da 
memória de trabalho, também conhecida como atenção controlada, pelo Tipo 2, dentre outras como pode ser observado no próprio quadro.

Figura 4 - Modelo Heurístico/Analítico revisado

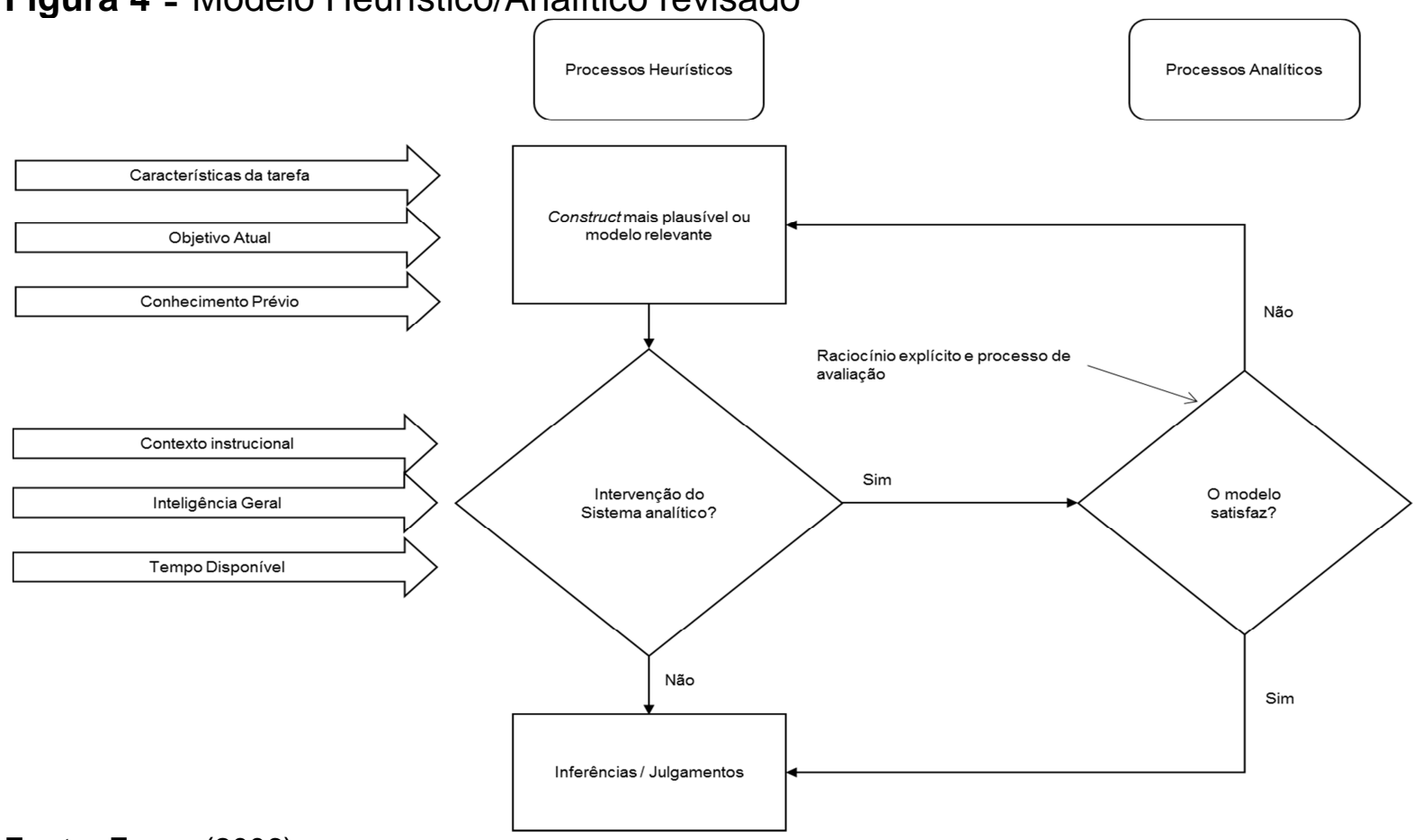

Fonte: Evans (2006)

De acordo com o Modelo Heurístico/Analítico de Evans (2006), conforme Figura 4, os processos heurísticos são os sistemas padrão, enquanto que os processos analíticos são opcionais, podendo ou não intervir para rejeitar, modificar as representações e respostas fornecidas pelo processo heurístico ou substituir a representação padrão.

O sistema heurístico tem como função entregar conteúdo relevante para a consciência por meio da construção de modelo mais plausível, considerando o conhecimento prévio, as crenças, as características das tarefas e os objetivos perseguidos pelo indivíduo. A intervenção do sistema analítico pode ser estimulada pelas fortes instruções de raciocínio dedutivo e pode ser mais provável de ocorrer em indivíduos com maior capacidade cognitiva ou uma disposição para pensar de forma reflexiva ou crítica (STANOVICH, 1999 apud EVANS, 2008; EVANS, STANOVICH, 2013).

Cabe frisar, em se tratando de Tipo 1 e 2 de processamento, que o QI não é suficiente para determinar a racionalidade do pensamento, pois pessoas inteligentes podem comportar-se de forma ignorante, devido a crenças falsas, falta ou 
contaminação de aparato mental (STANAVICH, 2009; BARROUILLET, 2011). A intervenção do processamento do Tipo 2, no processo de tomada de decisão, geralmente ocorre quando se possui mais tempo disponível (suficiente para avaliar com cuidado a resposta padrão. É motivada pelo contexto instrucional, que explicita a necessidade de raciocinar logicamente) ou capacidade intelectual (suficiente para suplantar a atratividade do processamento do Tipo 1).

\subsection{COGNITIVE REFLECTION TEST (CRT)}

Frederick (2005) definiu reflexão cognitiva como a capacidade ou disposição para resistir a fornecer a resposta que primeiro vem à mente. Seu Cognitive Reflection Test (CRT) cumpre justamente a finalidade de medir essa disposição de pensar.

Relativamente à diferenciação dos tipos de processamento da informação já contemplada no tópico 2.2 deste trabalho, cabe frisar que os três itens do Cognitive Reflection Test (CRT), introduzidos por Frederick (2005), e usados na presente pesquisa, induzem as pessoas a usarem o processamento de Tipo 1, por achar ser de fácil compreensão e solução.

Segundo Browne et al. (2014), a ativação de processos deliberativos do Tipo 2 é presumivelmente necessária para dissociar a resposta intuitiva e calcular a resposta correta. Corroborando Baron (2014), o processamento das respostas corretas exige a superação de uma resposta intuitiva inicial.

Porém, no CRT, os indivíduos podem responder equivocadamente aos itens por processarem a informação de maneira impulsiva. Segundo Frederick (2005), a proposição de que os três problemas do CRT geram respostas intuitivas incorretas é baseada nos seguintes fatos:

a) Todas as possíveis respostas erradas fornecidas pelas pessoas são intuitivas.

b) Mesmo respondendo corretamente, a resposta errada foi inicialmente considerada pelos indivíduos, por resultar da introspecção, de relatos verbais e rabiscos.

c) Os indivíduos que responderam corretamente ao teste consideram-no mais difícil do que os que forneceram respostas erradas, devido ao fato de 
esses últimos não terem observado a complexidade existente, já que responderam intuitivamente.

d) As pessoas respondem melhor a problemas análogos ao teste utilizado, os quais levam a uma maior reflexão ou maior processamento.

No CRT, os indivíduos que acertaram os três itens do teste serão considerados integrantes do grupo de alta capacidade cognitiva; aqueles que obtiverem 1 ou 2 acertos são do grupo de média capacidade cognitiva; e os que errarem todos os problemas constituem o grupo de baixa capacidade cognitiva. Essa informação será necessária na análise dos dados deste estudo, na medida em que, por esse recurso, será possível relacionar o CRT à incidência de vieses cognitivos.

Alguns estudos relacionam a inteligência aos vieses no processamento de informações, mas nem sempre essa correlação existe, como é o caso da ancoragem, cuja incidência independe do nível de inteligência (WEST; MESERVE; STANOVICH, 2012). Complementando, como já citado anteriormente, pessoas inteligentes podem agir ignorantemente, por possuírem falsas crenças, por ausência ou contaminação de aparato mental (STANAVICH, 2009; BARROUILLET, 2011).

Em contrapartida, outras pesquisas constatam a relação dos vieses com a capacidade cognitiva dos indivíduos (FREDERICK, 2005; HOPPE; KUSTERER, 2011; OECHSSLERA; ROIDERA, SCHMITZ, 2009; STANOVICH; WEST; TOPLAK, 2011).

Nas referidas pesquisas, o CRT é um bom mensurador da relação entre a capacidade cognitiva e os vieses. Nesse teste, aparentemente simples, como já foi evidenciado, os respondentes que tomam decisões impulsivas fornecem a primeira resposta que vem à mente; no entanto, para fornecer a resposta correta basta superar o impulso inicial, assim como acontece com os vieses cognitivos oriundos das heurísticas.

O CRT é um teste rápido e simples, que pode ser comparado, em termos da relação entre seus resultados e o comportamento observado, a testes mais complexos de inteligência. Esse teste diferencia os tomadores de decisão mais impulsivos dos mais reflexivos. Para isso, cada uma das três questões do CRT tem uma resposta intuitiva, mas incorreta, que vem logo à mente (OECHSSLERA; ROIDERA; SCHMITZ, 2009). 
Baron (2014) argumenta que o Cognitive Reflection Test é, comprovadamente, uma medida útil no estudo das diferenças individuais de pensamento, julgamentos e decisões, pois mede uma propriedade fundamental dos dois tipos de raciocínio ou até mesmo da inteligência: a disposição de verificar ou questionar uma resposta inicial e alterá-la. Seus três itens são altamente confiáveis; de acordo com o a de Cronbach (BARON, 2014).

Frederick (2005) mostra que as pontuações do CRT são preditivas dos tipos de opções característicos de testes das teorias de tomada de decisão (TUE e a Prospect Theory), sendo a relação tão forte que as preferências funcionam como expressões da capacidade cognitiva. Em seu estudo, o autor analisa as relações do CRT com duas importantes características na tomada de decisão: tempo de recebimento e preferência de risco. Como resultado, descobriu que a capacidade cognitiva influencia no tempo de recebimento e na preferência de risco. Também comparou esse teste com outras medidas de capacidade cognitiva (Wonderlic Personnel Test - WPT, Need for Cognition scale - NFC e scores de auto relato do SAT e ACT), entre as quais verificou a existência de correlações moderadas, um forte indício de que todos os cinco testes provavelmente refletem fatores comuns.

Nesta pesquisa, opta-se pelo uso do CRT por ser, dentre os testes de mensuração da capacidade cognitiva, o mais curto e, segundo Royzman et al. (2014), uma das medidas mais úteis de desempenho cognitivo disponíveis. Dentre os testes de capacidade cognitiva, cujas mensurações captam características distintas, é o que mensura a capacidade ou disposição para resistir ao impulso de responder o que primeiro vem à mente, assim como funcionam as heurísticas.

Oechsslera, Roidera e Schmitz (2009) identificaram, em sua pesquisa, que indivíduos com alta pontuação no CRT cometem menos falácias lógicas e são menos altoconfiantes do que aquele com baixa pontuação.

Segundo Moritz, Siemsen e Kremer (2013), a reflexão cognitiva tem sido utilizada para investigar erros na tomada de decisões. Se heurísticas de decisão são baseadas na intuição equivocada, os tomadores de decisão com maior reflexão cognitiva devem ser mais capazes de substituir essa resposta e aplicar o processamento do Tipo 2 para melhorar a decisão.

A distinção entre as respostas imediatas e naturais, de um lado, e as respostas reflexivas, de outro, parece clara e relevante para muitas perguntas sobre o raciocínio e julgamento (EVANS; STANOVICH, 2013). 
O desafio da presente pesquisa, além da verificação dos resultados do CRT, é a descoberta de quais vieses oriundos da heurística da representatividade incidem no momento da tomada de decisão sob incerteza em diferentes situações. Essa é uma das inovações: a reunião de todos os vieses de uma heurística em um único trabalho. Não obstante, vale ressalvar o fato de que não é objetivo deste trabalho tratar o CRT; visa-se usá-lo somente como instrumento de análise.

\subsection{HEURÍSTICAS E VIESES COGNITIVOS}

Para minimizar as exigências no processamento das informações na tomada de decisão, sob condição de incerteza, as pessoas desenvolvem heurísticas ou regras simplificadas. As heurísticas possuem como base as representações dos indivíduos sobre situações específicas, a disponibilidade e a capacidade de adaptação da memória para as informações e experiências adquiridas, dependendo da maneira como um problema foi armazenado.

Quando essas são usadas de maneira equivocada geram erros sistemáticos e recorrentes, denominados de vieses cognitivos. Segundo Das e Teng (1999), elas estão sempre presentes na tomada de decisões estratégicas.

A tomada de decisão, que envolve avaliação subjetiva da probabilidade, é semelhante à de quantidades físicas incertas, como distância ou tamanho. Esses julgamentos são baseados em dados de validade limitada, os quais são processados de acordo com heurísticas que, em geral, são bastante úteis, mas podem levar a graves erros sistemáticos. Os vieses podem resultar de três grandes heurísticas: a representatividade, a disponibilidade e a ancoragem e ajustamento (BASEL; BRÜHL, 2011; HILBERT, 2012, HSIAO et al. (2013); LAGROUE, 2006; SHANTEAU, 1989; TVERSKY; KAHNEMAN, 1974). Mas vale esclarecer que essas heurísticas não são mutuamente excludentes em um processo de tomada de decisão.

Além das heurísticas, conforme Hilbert (2012), os vieses cognitivos também podem ser gerados por mecanismos emocionais, motivações morais, bem como as influências sociais. Todavia, só serão objetos deste estudo os vieses cognitivos gerados pelas heurísticas da representatividade.

Como dito anteriormente, os vieses são gerados por três grandes heurísticas. Neste tópico, será realizada uma breve discussão sobre disponibilidade e ajuste e 
ancoragem. A representatividade, por ser objeto deste estudo, será discutida em tópico específico (2.5).

\subsubsection{Heurísticas de disponibilidade}

As Heurísticas de disponibilidade são regras criadas para mensurar a frequência de chances de um evento acontecer, utilizando lembranças facilmente disponíveis na memória. Bazerman (1994) argumenta que, nessa heurística, o julgamento é feito por estereótipo, cujas bases são modelos mentais de referência disponíveis.

Tversky e Kahneman $(1973,1974)$ asseguram que existem situações nas quais as pessoas avaliam a frequência de uma classe ou a probabilidade de um evento pela facilidade com que instâncias ou ocorrências são trazidas à mente. Essa heurística é chamada de disponibilidade, pois a disponibilidade mental fornece pista útil para avaliar a frequência ou a probabilidade. Para melhor esclarecimento, os referidos autores citam, como exemplos, que a avaliação do risco de ataque cardíaco em pessoas de meia idade pode ser realizada recordando tais ocorrências entre os próprios conhecidos; de modo semelhante, a mensuração da probabilidade de um empreendimento comercial falir pode ser calculada imaginando as várias dificuldades possíveis de ser encontradas por ele.

Segundo Bazerman e Moore (2010), a heurística da disponibilidade descreve as inferências que se constroem às semelhança de um evento, com base na facilidade com que se pode lembrar de casos recorrentes.

Outros fatores não detectados na frequência e probabilidade podem também afetar a disponibilidade, levando a erros no processo de cognição (TVERSKY; KAHNEMAN, 1973, 1974; BAZERMAN, 1994). Quando, por exemplo, um evento é muito vivenciado por uma pessoa, ele se torna facilmente lembrado, por estar mais disponível. Já situações desconfortáveis, que podem gerar sentimentos negativos no indivíduo, são tornadas lembranças menos disponíveis ou até indisponíveis. Assim, na heurística da disponibilidade, um tomador de decisão deixa de examinar todas as alternativas ou procedimentos, por basear-se em conhecimentos prontamente disponíveis, e isso pode gerar vieses cognitivos.

Em relação a essa afirmação, Tversky e Kahneman (1973) argumentam que a disponibilidade é uma regra válida para decisões sobre eventos frequentes por 
serem esses mais facilmente recordados ou imaginados do que os raros. Entretanto, ela pode ser afetada também por vários fatores os quais não estão relacionados com a frequência real. Assim, se a heurística da disponibilidade for aplicada, esses fatores afetarão a frequência das classes e a probabilidade subjetiva dos acontecimentos, levando a erros sistemáticos.

Tabela 1 - Vieses gerados pela heurística da disponibilidade

\begin{tabular}{|c|c|c|}
\hline $\begin{array}{l}\text { Tversky e } \\
\text { Kahneman }\end{array}$ & Bazerman & Forma de ocorrência \\
\hline \multicolumn{2}{|c|}{ Nomenclatura } & \\
\hline Recordação & $\begin{array}{l}\text { Facilidade de } \\
\text { lembrança }\end{array}$ & $\begin{array}{l}\text { Eventos mais recordados facilmente na memória são } \\
\text { considerados mais numerosos do que outros com mesma } \\
\text { frequência, porém menos facilmente lembrados }\end{array}$ \\
\hline $\begin{array}{l}\text { Recuperabili- } \\
\text { dade }\end{array}$ & $\begin{array}{l}\text { Recuperabili- } \\
\text { dade }\end{array}$ & $\begin{array}{l}\text { A estrutura da memória individual, dependendo de como ela afeta } \\
\text { o processo de busca, pode distorcer a frequência percebida de } \\
\text { eventos }\end{array}$ \\
\hline $\begin{array}{l}\text { Correlação } \\
\text { ilusória }\end{array}$ & $\begin{array}{l}\text { Presunção de } \\
\text { associações }\end{array}$ & $\begin{array}{l}\text { A probabilidade de dois eventos concomitantes é frequentemente } \\
\text { superestimada }\end{array}$ \\
\hline $\begin{array}{l}\text { Vieses da } \\
\text { efetividade de } \\
\text { uma } \\
\text { configuração de } \\
\text { busca }\end{array}$ & - & $\begin{array}{l}\text { Diferentes tarefas provocam no indivíduo recordações que } \\
\text { direcionarão as respostas para o que for mais facilmente } \\
\text { pesquisado na mente. }\end{array}$ \\
\hline
\end{tabular}

Fonte: Adaptado de Bazerman (2002 apud Lagroue, 2006) e Tversky e Kahneman (1974)

Como exemplo do viés da recordação, pode ser citado o risco envolvido em uma expedição de aventura, avaliado ao se imaginar os imprevistos para os quais a expedição não está preparada. Se muitas dessas dificuldades são lembradas, a expedição pode parecer excessivamente perigosa. Mas, apesar da facilidade com que desastres são imaginados, não necessariamente refletem a probabilidade efetiva de sua ocorrência. Por outro lado, o risco envolvido em uma empresa pode ser subestimado se alguns dos possíveis perigos são difíceis de acontecer ou simplesmente não vêm à mente.

Quanto ao viés da recuperabilidade, Tversky e Kahneman (1974) afirmam que o impacto de ver uma casa queimar sobe a probabilidade subjetiva de tais acidentes mais que a leitura sobre um incêndio em jornal local. Bazerman e Moore (2010) defendem a ideia de que o mundo se estrutura de acordo com nossas estratégias de busca.

Em se tratando da correlação ilusória, Tversky e Kahneman (1974) esclarecem que esta pode ser gerada no julgamento de frequência de dois eventos 
ocorrerem concomitantemente, sendo ela baseada na intensidade do vínculo associativo entre tais eventos. Se a associação é forte, gera a conclusão de que os acontecimentos são frequentemente associados. Em relação ao viés da efetividade de uma configuração de busca, os referidos autores argumentam que diferentes tarefas provocam vários conjuntos de busca. Imagina-se, por exemplo, um questionamento feito a um indivíduo sobre qual a probabilidade de selecionar uma palavra (com três letras ou mais), de forma aleatória, em um texto em inglês, que começa com a letra $R$ ou tem a terceira letra sendo $R$. Para responder ao questionamento, ele recordará de palavras com essas especificações, sendo que é muito mais fácil pesquisar mentalmente palavras por sua primeira letra do que pela terceira. Assim, em sua resposta, haverá uma maior possibilidade de palavras que se iniciam com $\mathrm{R}$ serem selecionadas. Porém, em inglês, a letra $\mathrm{R}$ é mais frequente na terceira posição do que na primeira.

\subsubsection{Heurísticas da ancoragem e ajustamento}

Nas Heurísticas da Ancoragem e Ajustamentos, segundo Bazerman (1994), Slovic et al. (1977), Tversky e Kahneman (1974), há uma avaliação da estimativa do acontecimento de um evento com base em um valor inicial (uma âncora) e, em seguida, se faz o ajuste para produzir a resposta final.

Diferentes âncoras geram diferentes estimativas de resultados, que são inclinadas para os valores iniciais, devido ao fato de esses servirem de ponto de referência ou de partida para o julgamento.

A Tabela 2 contém os vieses cognitivos causados pela heurística da ancoragem e ajustamento, de acordo com Bazerman (2002 apud LAGROUE, 2006).

Tabela 2 - Vieses gerados pela heurística da ancoragem e ajustamento

\begin{tabular}{l|l}
\hline $\begin{array}{l}\text { Insuficiente ajustamento da } \\
\text { âncora }\end{array}$ & $\begin{array}{l}\text { ajustamentos insuficientes são feitos a partir do valor de uma âncora } \\
\text { inicial }\end{array}$ \\
\hline $\begin{array}{l}\text { Viés de eventos } \\
\text { conjuntivos e disjuntivos }\end{array}$ & $\begin{array}{l}\text { eventos conjuntivos são muitas vezes superestimados e os } \\
\text { disjuntivos são subestimados }\end{array}$ \\
\hline Excesso de confiança & $\begin{array}{l}\text { indivíduos tendem a ser confiantes da infalibilidade de seu } \\
\text { julgamento ao responderem perguntas de nível de dificuldade } \\
\text { moderado a extremamente difícil }\end{array}$ \\
\hline
\end{tabular}

Fonte: Bazerman (2002 apud Lagroue, 2006)

Para Tversky e Kahneman (1974), os erros podem ser classificados tal como segue: 
a) Ajustamento insuficiente: a âncora ocorre não só quando o ponto de partida é dado para o sujeito mas também quando o assunto baseia sua estimativa no resultado de alguma computação incompleta.

b) Viés na avaliação de eventos conjuntivos e disjuntivos: a probabilidade total de um evento conjuntivo é inferior à probabilidade de cada evento elementar, enquanto que a probabilidade total de um evento disjuntivo é maior. Assim, devido à ancoragem, a probabilidade total vai ser superestimada em problemas de eventos conjuntivos e subestimada nos disjuntivos. Como exemplo, pode ser citado o desenvolvimento de um novo produto, que apresenta um caráter conjuntivo: para a empresa ter sucesso, uma série de eventos deve ocorrer. Mesmo quando os eventos são muito prováveis, a probabilidade de sucesso pode ser bastante baixa, se o número de eventos for grande. A tendência geral de superestimar a probabilidade de eventos conjuntivos leva ao otimismo injustificado na avaliação da probabilidade de que um plano será bem sucedido ou um projeto concluído a tempo.

c) Ancoragem na avaliação de probabilidades subjetivas de distribuições. $\mathrm{Na}$ análise de decisão, os especialistas demonstram a necessidade de expressar suas crenças sobre uma quantidade, tais como o valor da média Dow-Jones em um determinado dia, sob a forma de uma distribuição de probabilidade. Tal distribuição é geralmente construída, selecionando valores da quantidade que corresponde a percentis especificados da sua distribuição de probabilidade subjectiva. Na maioria dos estudos, os valores reais das quantidades avaliadas são menores do que $X_{01}$ ou maior do que $X_{99}$, em aproximadamente $30 \%$ dos problemas. Esse resultado sugere que os sujeitos indicam intervalos de confiança excessivamente estreitos, refletindo mais certeza do que se justifica por seu conhecimento sobre as quantidades avaliadas.

Assim como Bazerman (2002, apud LAGROUE, 2006), Tversky e Kahneman (1974) consideraram o insuficiente ajustamento da âncora, viés de eventos conjuntivos e disjuntivos e o viés do excesso de confiança, como sendo erros provenientes da heurística ancoragem e ajustamento, apesar da outra denominação que dão a este último viés. 


\subsection{HEURÍSTICA DA REPRESENTATIVIDADE E OS VIESES GERADOS}

Na heurística da representatividade, um evento ou amostra é julgado provável na medida em que representa as características essenciais de sua população e reflete o processo pelo qual foi gerado (HOGARTH, 1975; KAHNEMAN; FREDERICK, 2002; KAHNEMAN; TVERSKY, 1972; KAHNEMAN; SLOVIC; TVERSKY, 1982; TVERSKY; KAHNEMAN, 1973).

McDowell et al. (2013) afirmam que, ao fazer uso da heurística da representatividade, as pessoas realizam seus julgamentos baseados na similaridade de um evento ou objeto com uma classe conhecida. Corroborando essa menção, Uribe et al. (2013) revelam que, na heurística da representatividade, os julgamentos sobre eventos ou pessoas são, frequentemente, extrapolações baseadas na análise de alguns exemplos individuais, permitindo às pessoas fazerem inferências, que criam ou modificam suas atitudes, independentemente do tamanho da amostra.

"A heurística da representatividade resulta de uma suposição de homogeneidade sobre as categorias que as pessoas estão raciocinando e uma disposição para concluir de acordo com a similaridade" (REISBERG, 2001 apud LIMA FILHO et al., 2010, p. 46).

Os indivíduos, ao fazerem uso da heurística da representatividade, desconsideram as regras estatísticas e levam em consideração a similaridade de evento, objeto ou amostra com uma categoria conhecida. Além da crença de existência de aleatoriedade.

Muitas das questões que envolvem a mensuração de probabilidade pelos indivíduos pertencem a um dos seguintes tipos: qual a probabilidade de que um objeto $A$ pertença à classe $B$ ? Qual é a probabilidade de um evento ser originado de um processo B? Qual a probabilidade do processo $R$ gerar um evento A? Para responder a tais questões, as pessoas geralmente dependem da heurística da representatividade, em que as probabilidades são avaliadas pelo grau em que $A$ é representativo de $B$, ou seja, grau em que $A$ assemelha-se a $B$ (TVERSKY; KAHNEMAN, 1973).

A similaridade da amostra em relação à população e a ponderação sobre aleatoriedade são os elementos que determinam a representatividade (KAHNEMAN; 
TVERSKY, 1972; VERIM, 2014). As pessoas, normalmente, julgam por semelhança e porque acreditam na existência de aleatoriedade dos dados, não considerando as regras de probabilidade.

Os vieses da representatividade não estão limitados a sujeitos ingênuos; foram também encontrados no julgamento intuitivo de psicólogos, ao superestimarem a probabilidade de ocorrência de um resultado significativo na população, acreditando que a hipótese nula foi rejeitada, mesmo possuindo uma amostra de tamanho insuficiente (KAHNEMAN; TVERSKY, 1972).

Os indivíduos veem uma amostra aleatória ou probabilidade de um evento como altamente representante de uma população, sendo todas as características essenciais daquela, semelhantes a essa, mais do que a teoria sobre amostragem prediz, ou seja, superestimam a representatividade de uma amostra.

Em outras situações, as pessoas parecem seguir a regra de que um detalhe adicional pode tornar um evento mais provável de ocorrer. Porém, de acordo com a teoria da probabilidade, o acréscimo de mais detalhes sobre o evento deve torná-lo menos provável. Essa heurística é explicada por uma série de exemplos empíricos com erros previsíveis e sistemáticos na avaliação de eventos sob incerteza. Um deles é o seguinte: todas as famílias com seis crianças (de uma cidade) foram pesquisadas. Em 72 famílias, a ordem exata de nascimentos de meninos (B) e meninas $(G)$ foi $G B G B B G$. Qual é a estimativa do número de famílias pesquisadas em que a ordem exata dos nascimentos seja de GBBBBB? As duas sequências de natalidade são igualmente prováveis, mas a maioria das pessoas (75 em um total de 92) concordam que eles não são igualmente representativos e a segunda sequência não reflete a proporção de meninos e meninas na população (KAHNEMAN; TVERSKY, 1972).

Os indivíduos, ao fazerem uso da heurística da representatividade, podem incorrer em vieses cognitivos avaliando, para mais ou para menos, a probabilidade ou a quantidade física de determinado evento acontecer. Isso ocorre devido ao estereótipo, criado mentalmente, da população, o qual deve ser refletido na amostra, deixando de fora da análise outros fatores importantes para o julgamento em questão. 
Tabela 3 - Vieses gerados pela heurística da representatividade

\begin{tabular}{|c|c|c|}
\hline $\begin{array}{l}\begin{array}{c}\text { Tversky e } \\
\text { Kahneman }\end{array} \\
\text { Nomen }\end{array}$ & Bazerman & Forma de ocorrência \\
\hline $\begin{array}{l}\text { Insensibilidade } \\
\text { à probabilidade } \\
\text { prévia ou } \\
\text { frequência à } \\
\text { taxa base }\end{array}$ & $\begin{array}{l}\text { Insensibilidade } \\
\text { à taxa base }\end{array}$ & $\begin{array}{l}\text { As taxas básicas tendem a ser ignoradas se a informação } \\
\text { descritiva for fornecida, mesmo que irrelevante }\end{array}$ \\
\hline $\begin{array}{l}\text { Insensibilidade } \\
\text { ao tamanho da } \\
\text { amostra }\end{array}$ & $\begin{array}{l}\text { Insensibilidade } \\
\text { ao tamanho da } \\
\text { amostra }\end{array}$ & $\begin{array}{l}\text { O tamanho da amostra é, frequentemente, ignorado na avaliação } \\
\text { da confiabilidade de suas informações }\end{array}$ \\
\hline $\begin{array}{l}\text { Chance de } \\
\text { equívocos }\end{array}$ & $\begin{array}{l}\text { Chance de } \\
\text { equívocos }\end{array}$ & $\begin{array}{l}\text { Espera-se que uma sequência de eventos gerados por um } \\
\text { processo aleatório represente as suas características essenciais, } \\
\text { mesmo em sequência curta }\end{array}$ \\
\hline $\begin{array}{l}\text { Equívocos na } \\
\text { regressão }\end{array}$ & $\begin{array}{l}\text { Regressão à } \\
\text { média }\end{array}$ & $\begin{array}{l}\text { Eventos extremos tendem a regredir à média em testes } \\
\text { subsequentes }\end{array}$ \\
\hline- & $\begin{array}{l}\text { Falácia da } \\
\text { conjunção }\end{array}$ & $\begin{array}{l}\text { Conjunções (dois eventos concomitantes) são considerados mais } \\
\text { prováveis do que outras ocorrências cuja conjunção é um } \\
\text { subconjunto }\end{array}$ \\
\hline $\begin{array}{l}\text { llusão de } \\
\text { validade }\end{array}$ & - & $\begin{array}{l}\text { Gerada quando a confiança indevida é produzida por um bom } \\
\text { ajuste entre o resultado previsto e as informações de entrada }\end{array}$ \\
\hline $\begin{array}{l}\text { Insensibilidade } \\
\text { à previsibilidade }\end{array}$ & - & $\begin{array}{l}\text { Ocorre quando os indivíduos fazem previsões numéricas, como o } \\
\text { valor futuro de uma ação ou a demanda por uma mercadoria, com } \\
\text { base na representatividade das informações }\end{array}$ \\
\hline
\end{tabular}

Fonte: Adaptado de Bazerman (2002 apud Lagroue, 2006) e Tversky e Kahneman (1974)

$\mathrm{Na}$ tabela 3, é possível identificar os vieses cognitivos causados pela heurística da representatividade na tomada de decisão em condições de incerteza, segundo os autores Bazerman (2002, apud LAGROUE, 2006) e Tversky e Kahneman (1974). Apesar de o estudo de 1974, desses últimos autores, não considerar falácia da conjunção entre os vieses, em pesquisas posteriores, esse registro é feito (1983; 1996).

Em se tratando do viés insensibilidade à taxa base, Riahi-Belkaoui (2002) afirma que não é só difícil a sua determinação; a evidência também mostra que as pessoas tendem a ignorá-la em julgamentos intuitivos.

Embora, a taxa base e as informações específicas sejam relevantes para o julgamento, os indivíduos negligenciam-na e direcionam sua atenção para outras informações (KAHNEMAN; TVERSKY, 1973; HINSZ et al., 2008).

Segundo Verim (2014), a falácia de taxa básica é um tipo de erro de raciocínio que está enraizado em julgamentos sobre a probabilidade de algum estado ou evento, ocorrer com base em crenças e intuições anteriores, representativas do problema, negligenciando a probabilidades de taxa básica. 
Os indivíduos, ao usarem a heurística da representatividade para efetuar julgamentos, negligenciam a taxa base quando se deparam com informações descritivas. Porém, quando nenhuma descrição é fornecida, a taxa base é usada corretamente.

Tversky e Kahneman (1974) exemplificam a insensibilidade à taxa base com o seguinte experimento:

a) A um grupo foram fornecidas breves descrições de personalidade de várias pessoas, com a informação de que foram selecionadas aleatoriamente de um grupo de 100 profissionais engenheiros e advogados;

b) outro grupo recebeu a informação de que as descrições de personalidade foram extraídas de um grupo de 70 engenheiros e 30 advogados;

c) no terceiro grupo, os indivíduos foram informados de que os dados seriam de um grupo composto por 30 engenheiros e 70 advogados.

A todos os grupos foi solicitado avaliar a probabilidade de cada descrição ser de um engenheiro. Dessa forma, esperava-se que a probabilidade de qualquer descrição pertencer a um engenheiro seria maior no segundo grupo do que no terceiro, em que se registrava uma maior quantidade de advogados. Os resultados evidenciaram que os participantes do experimento avaliaram a probabilidade de a descrição pertencer a um engenheiro baseados nos estereótipos. Outras pesquisas, como Kahneman (2003); Kahneman e Frederick (2001); Kahneman e Frederick (2005); Joyce e Biddle (1981); Stanovich e West (2000), chegaram a esses mesmos resultados.

Os indivíduos também aplicam a heurística da representatividade para avaliar a probabilidade de se obter determinado resultado de uma amostra extraída de uma população qualquer. Sabe-se que, em uma pequena amostra, existe uma maior probabilidade de captar os desvios extremos da população do que em grandes amostras, devido ao fato de aquela (a pequena amostra) ser mais suscetível de refletir as características da população.

A crença dos indivíduos na lei dos pequenos números é suficiente para explicar por que pessoas, incluindo cientistas, são, muitas vezes, excessivamente confiantes em testes estatísticos baseados em pequenas amostras e até revela tendência para apoiar conclusões baseadas nelas (TVERSKY; KAHNEMAN, 1971). 
$\mathrm{Na}$ tomada de decisão ante qual experimento prosseguir ou abandonar, os pesquisadores são excessivamente sensíveis aos resultados de análises preliminares baseadas em pequenas amostras, podendo, por outro lado abandonar experimentos cujos resultados preliminares pareçam apresentar falhas na base de dados, e prosseguir com aqueles que, aparentemente, terão sucesso, vez que os $\rho$ values são significativos ou marginalmente significativos (YU et al., 2014).

Tversky e Kahneman (1972) utilizam o experimento a seguir, para mostrar a existência do viés insensibilidade ao tamanho da amostra:

Uma cidade possui dois hospitais. No hospital maior, cerca de 45 bebês nascem diariamente e no hospital menor, aproximadamente 15 bebês por dia. Como você sabe, cerca de $50 \%$ de todos os bebês são meninos. No entanto, o exato percentual varia diariamente, sendo, às vezes, maior do que $50 \%$ e em outras vezes menor. Durante o período de 1 ano, esses dois hospitais registraram os dias em que mais de $60 \%$ do número de bebês eram do sexo masculino. Em sua opinião, em qual (is) hospital (ais) foram mais registrados esses dias? (KAHNEMAN; TVERSKY, 1972)

( ) O hospital maior

( ) O hospital menor

( ) A quantidade foi a mesma, no hospital maior e menor

Nesse experimento, foi possível observar que a maioria dos entrevistados julgou ser a mesma a probabilidade de obtenção de mais de $60 \%$ de meninos, tanto no hospital maior quanto no menor, considerando-os igualmente representativos da população. Mas, pela teoria da amostragem, essa ocorrência seria mais esperada no hospital menor, pois, em uma grande amostra, é mais provável não se afastar dos $50 \%$.

Para exemplificar o viés chance de equívocos, Tversky e Kahneman (1974) explicam que, ao considerar, no lançamento de uma moeda, a probabilidade de dar cara $(\mathrm{K})$ ou coroa $(\mathrm{C})$, as pessoas levam em conta a sequência KCKCKC, mais provável que KKKCCC, por essa não parecer aleatória, e ser mais provável do que KKKKCK, por não aparentar uma moeda justa.

Quanto ao viés equívoco na regressão, as pessoas assumem que os resultados futuros serão diretamente previsíveis a partir de resultados passados, com a suposição de uma correlação perfeita entre os dados futuros e passados.

Segundo Tversky e Kahneman (1974), esse viés pode ter consequências perigosas, como pode ser visto no seguinte exemplo: em uma discussão sobre um treinamento de voo, instrutores experientes observaram que o elogio de uma aterrissagem suave é seguido por um pior pouso na tentativa seguinte. Enquanto 
duras críticas depois de um pouso ruim, são geralmente seguidas de melhora na próxima tentativa. Dessa forma, os instrutores concluíram que as recompensas verbais são prejudiciais à aprendizagem, já as penalidades são benéficas, ao contrário do que é realmente aceito.

Regressão à média significa que se uma pessoa possui escores mais altos do que a média em um teste, em um próximo teste equivalente, ela tenderá a obter uma pontuação mais perto da média. A falta de atenção dos seres humanos para esse fenômeno pode resultar em erros de interpretação nocivos, como no exemplo citado anteriormente (VERIMM, 2014).

Em relação à falácia da conjunção, as interpretações recentes postulam que as pessoas avaliam a probabilidade de uma conjunção de acordo com regras não normativas (TENTORI et al., 2013). Os indivíduos incorrem nesse viés ao julgarem a conjunção de dois eventos mais provável de ocorrer do que um desses eventos sozinho. Para exemplificar esse viés, foram apresentados os seguintes dados por Tversky e Kahneman (1982, p. 92 apud KAHNEMAN; FREDERICK, 2005): "Linda tem 31 anos, é solteira, extrovertida e muito inteligente. Ela é formada em filosofia. Como estudante, ela era bastante preocupada com questões de discriminação e justiça social e também participou de demonstrações antinucleares". De posse desses dados, os participantes deveriam julgar a probabilidade de ocorrência das seguintes alternativas: (A) Linda é caixa de banco; e (B) Linda é caixa de banco e ativista do movimento feminista.

Os resultados mostram um erro de julgamento por violar a regra da inclusão, princípio fundamental da probabilidade. Por essa regra, a probabilidade da alternativa $B$ deve ser menor ou igual à alternativa $A$. Porém, de acordo com os resultados do estudo, a alternativa $B$ foi considerada mais provável que a $A$.

Para Rodrigues e Abreu-Rodrigues (2007), é relevante discutir a falácia da conjunção por três motivos: esse fenômeno indica que, quando se confrontam com eventos conflitantes, os indivíduos julgam erroneamente as informações disponíveis; julgamentos de probabilidade dos eventos são frequentemente solicitados em contextos educacionais e profissionais; e tais erros de julgamento são comumente cometidos até mesmo por indivíduos com treino formal em lógica e teorias de tomada de decisão. Os julgamentos intuitivos da probabilidade de um evento composto negligenciam considerações outras que não aquelas relacionadas com a similaridade entre um exemplo e um modelo. 
As pessoas costumam fazer previsões confiáveis sobre um indivíduo, com base em dados falíveis, mesmo quando sabem da baixa validade desses dados, devido ao viés ilusão de validade, também conhecido por excesso de confiança. Tversky e Kahneman (1973) afirmam que o grau de confiança que se tem em uma previsão reflete o grau no qual o resultado selecionado é mais representativo de um input do que os outros o são.

Como é o caso, por exemplo, das muitas informações que são colocadas na internet e, muitas vezes, disseminadas sem a verificação de sua validade. Assim, ao utilizar informações para fazer julgamento e tomar decisões, é necessário verificar o rigor de seu conteúdo, mesmo que esse nos pareça verídico.

Erceg e Galic (2014) asseguram que o fenômeno do excesso de confiança é comum e frequente em julgamento e tomada de decisão. Esse viés reflete a alta confiança que as pessoas demonstram em seus julgamentos, não coincidindo com precisão real.

As pessoas insistem em crenças inválidas, por serem sensíveis à ilusão de validade. Einhorn e Hogarth (1978) analisaram a discrepância substancial entre os resultados de pesquisas sobre a falibilidade e confiança no julgamento das pessoas e seu próprio julgamento. Concluíram que as pessoas são propensas a realizar pesquisas para confirmar evidências, e não desconfirmar as provas.

Esse viés ocorre devido ao fato de os indivíduos terem suas preferências suportadas por suas crenças ou as informações disponíveis serem consistentes com as crenças mais acessíveis. Se, por exemplo, se tem como entrada a descrição de uma pessoa que combina com um estereótipo formado da figura do contador, com base nisso, mesmo dispondo de uma descrição limitada, não confiável ou desatualizada, conclui-se, com excesso de confiança, que essa pessoa é realmente um contador.

A insensibilidade à previsibilidade ocorre quando, por exemplo, é dada a um indivíduo uma descrição de uma empresa para que ele possa prever o lucro futuro. Se a descrição é muito favorável, um lucro muito alto aparecerá como sendo mais representativo da empresa do que a descrição; o contrário também é verdade. Porém, se as pessoas preveem apenas em termos do favorecimento da descrição, as previsões serão insensíveis à confiabilidade das evidências e à precisão esperada da previsão (TVERSKY; KAHNEMAN, 1974). 
Pesquisas que investigam a insensibilidade à taxa base, insensibilidade ao tamanho da amostra, chance de equívocos, equívocos na regressão, falácia da conjunção, insensibilidade à previsibilidade e ilusão de validade, assim como o CRT, serão evidenciadas no tópico 2.6.

\subsection{EVIDÊNCIAS EMPÍRICAS SOBRE OS VIESES COGNITIVOS ORIUNDOS DA HEURÍSTICA DA REPRESENTATIVIDADE E SOBRE COGNITIVE REFLECTION TEST (CRT)}

Neste tópico, realiza-se uma breve revisão de pesquisas que tratam sobre a existência de vieses cognitivos oriundos da heurística da representatividade no processo de tomada de decisão sob incerteza, além de estudos que fazem uso do CRT.

No Brasil, nos últimos anos, houve um aumento significativo no número de pesquisas na área de Finanças e Contabilidade Comportamental (LIMA, 2007; LIMA et al., 2012; LUCENA, FERNANDES, SILVA, 2011; MELO; SILVA, 2010; SILVA; GONÇALVES, 2011, por exemplo). Atualmente, é considerável a quantidade de estudos publicados em eventos ou periódicos que tratam sobre os vieses cognitivos da representatividade que afetam a tomada de decisão em condições de incerteza e utilizam o CRT para mensurar a capacidade cognitiva. Dentre outras, cabe destacar as pesquisas a seguir.

Barros (2005) investigou, empiricamente, a possibilidade da influência do otimismo e do excesso de confiança nas decisões de investimentos e de financiamento dos gestores das empresas. Para isso, utilizou uma amostra de 153 empresas brasileira observadas no período de 1998 a 2003. O estudo apresenta como predição o fato de que as empresas gerenciadas por indivíduos otimistas e/ou excessivamente confiantes são mais alavancadas financeiramente.

O viés ilusão de validade ocorre devido ao excesso de confiança dos indivíduos em suas próprias previsões, sem averiguar a validade das informações; isso porque a confiança depositada em suas opiniões é coerente com suas crenças. Esse viés também é denominado de excesso de confiança.

Macedo et al. (2012) analisaram o comportamento decisório de profissionais de contabilidade, por meio do estudo dos vieses de decisão, oriundos do uso da Teoria dos Prospectos e das Heurísticas da Representatividade e Disponibilidade. 
$\mathrm{Na}$ pesquisa de campo, foi aplicado um questionário, com 4 questões fechadas, a um grupo de 73 alunos de pós-graduação em Ciências Contábeis, no Rio de Janeiro. Os resultados, quanto às heurísticas de julgamento, evidenciaram a presença dos vieses relativos ao uso da falácia da conjunção, da concepção errônea do acaso (chance de equívoco) e da tendência a ignorar informações.

Lima Filho et al. (2012) mediram as possíveis correlações entre as variáveis idade, gênero e formação e a existência de vieses cognitivos em decisões relacionadas ao orçamento. Os sujeitos submetidos a essa investigação são representados por 128 estudantes de pós-graduação de Salvador, escolhidos entre diferentes cursos de doutorado, mestrado ou especialização, de cursos relacionados à Administração e Contabilidade. Para testar as hipóteses, utilizou-se o desenho da pesquisa quase-experimental, com a aplicação de um questionário dividido em dois blocos. No primeiro bloco, apresentaram-se 3 cenários para cada uma das possíveis heurísticas inseridas (ancoragem, disponibilidade e representatividade), solicitando ao respondente a tomada de decisão; no segundo bloco, levantaram-se alguns dados pessoais, tais como idade, formação e gênero. Os resultados encontrados confirmaram a ocorrência de heurísticas em todas as perspectivas; mas somente na variável gênero esta relação demonstrou-se significativa.

Em sua tese, Liberali (2012) investigou o papel da memória no julgamento e tomada de decisão, por meio de três artigos. Em um deles fez uma revisão sistemática de 273 artigos sobre o comportamento do consumidor, com o foco na influência de memória no julgamento e tomada de decisão de compra. Outro artigo apresentou versões em português, adaptadas ao Brasil, de medidas de avaliação psicométricas, através de instrumentos capazes de avaliar diferenças individuais que podem afetar o julgamento e a tomada de decisão: a Numeracy Scale, a Subjective Numeracy Scale e o Cognitive Reflection Test. Essas medidas mostraram ser instrumentos de fácil e rápida aplicação e bem aceitos pelos sujeitos pesquisados, 259 estudantes universitários de três diferentes instituições de ensino superior e de três diferentes cursos universitários (Administração, $n=210$; Engenharia, $n=32$; e Contabilidade, $n=17$ ), que apresentaram bons desempenhos psicométricos, com medidas de fidedignidade adequadas (consistência interna) e validade de construtos, o que sugere a adequação desses instrumentos para avaliação de numerácia e reflexão cognitiva em participantes brasileiros. $O$ terceiro artigo da tese investigou a relação entre as falácias da conjunção e da disjunção em julgamentos 
de probabilidade e julgamentos de memória. Os resultados indicaram que julgamentos sobre o passado e sobre o futuro estão relacionados, como o estão na memória.

O artigo de Lima Filho e Bruni (2013) teve como objetivos detectar a presença de erros em julgamentos envolvendo situações relativas ao orçamento e investigar se esses erros estariam associados ao envolvimento com práticas orçamentárias. Para isso, os autores utilizaram uma amostra de 128 estudantes de pós-graduação de Salvador-BA. As decisões a serem tomadas pelos participantes envolviam cenários com informações contábeis e financeiras. Os resultados evidenciaram que existem diferenças significativas presentes nas situações envolvendo ancoragem e representatividade e que, quanto mais envolvidos com práticas orçamentárias, mais os indivíduos podem cometer erros em seus julgamentos.

O nível de habilidade cognitiva dos gestores e o nível de comprometimento com a profissão e com a carreira influenciam as decisões de alocação de recursos organizacionais, considerando-se suas preferências intertemporais? Essa foi a questão de pesquisa de Pereira e Bruni (2013), com uma amostra formada por 125 estudantes de pós-graduação de diferentes cursos. Para mensurar a capacidade cognitiva dos respondentes, foi utilizado o CRT. Os dados foram analisados por meio de regressão logística múltipla, para a amostra pesquisada, obtendo-se, como resultado, que o comprometimento com a profissão e com a carreira não influenciou as decisões de alocação de recursos a projetos organizacionais, considerando-se as preferências intertemporais dos respondentes. No entanto, foi possível verificar a presença de relação negativa significante entre o nível de habilidade cognitiva dos respondentes e o comprometimento afiliativo com a profissão e com a carreira. Parece esse um indício de que indivíduos com alto nível de habilidade cognitiva não são voláteis aos mecanismos institucionais que orientam a profissão e a carreira a que se filiam, mantendo-se psicologicamente independentes da profissão que exercem.

Quintanilha e Macedo (2013) analisaram o comportamento decisório de futuros contadores diante de situações de julgamento, para verificar a presença de vieses de decisão (concepção errônea do acaso e da falácia da conjunção), provenientes das heurísticas de julgamento e da Teoria dos Prospectos. $O$ estudo usa o Cognitive Reflection Test para estabelecer uma conexão entre a habilidade cognitiva dos indivíduos e a presença desses vieses de decisão. Para isso, foi 
aplicado, a um grupo de 155 estudantes de graduação em Ciências Contábeis de uma Universidade Pública do Rio de Janeiro, um questionário com duas versões, dividido em duas partes (CRT e seis questões fechadas, sendo 4 relacionadas à Teoria dos Prospectos e 2 às Heurísticas de Julgamento). Como resultado, 22,58\% dos indivíduos foram classificados como de baixa habilidade cognitiva e 31,62\% de alta, por somarem três pontos no CRT. Em relação ao viés concepção errônea do acaso, $75,5 \%$ dos respondentes foram sensíveis a ele e $40 \%$ sofreram impacto da falácia da conjunção. Apenas esse último viés apresentou relação positiva com as respostas do CRT, indicando que um alto nível de habilidade cognitiva pode reduzir a probabilidade de ocorrência do viés cognitivo falácia da conjunção.

$\mathrm{O}$ artigo de Feitosa et al. (2014) teve como objetivo diagnosticar possíveis vieses cognitivos e motivacionais, como o excesso de confiança, o otimismo e a ancoragem, em gestores de uma grande empresa do setor de construção civil do Brasil. Para isso, aplicaram um questionário estruturado com instrumentos selecionados na literatura sobre processo decisório junto a 120 gestores de uma grande empresa brasileira de construção civil, sendo 84 questionários respondidos. A sistemática relacionada à avaliação do viés de excesso de confiança envolveu a análise do número de acertos dos indivíduos em relação ao número de acertos esperados, dado o nível de confiança relatado pelos participantes. A diferença entre o que o gestor esperava obter e o total de acertos indicou o seu excesso de confiança. Os autores concluíram, portanto, que os gestores da empresa analisada são excessivamente confiantes em suas estimativas.

Pereira e Bruni (2014) verificaram se os aspectos intuitivos dos seres humanos impactam nas escolhas intertemporais na elaboração do orçamento, por meio de pesquisa de campo realizada por questionário dividido em dois blocos de perguntas (um para mensurar o nível de habilidade cognitiva dos respondentes e outro para testar as decisões intertemporais na elaboração do orçamento). Esse instrumento foi aplicado a 125 estudantes de pós-graduação inscritos em diferentes cursos. Os achados sugerem que a classificação dos indivíduos como intuitivos ou não intuitivos não contribui para a explicação das escolhas intertemporais. Para ser possível essa análise, devido à pequena representatividade de sujeitos, os indivíduos com pontuação 1 e 2 no CRT foram adicionados ao grupo de alta capacidade cognitiva. Porém, a aplicação do teste não paramétrico de MannWhitney, considerando apenas os grupos com pontuação 0 e 3 no CRT, sugeriu a 
existência de uma associação entre a classificação cognitiva dos indivíduos e as escolhas intertemporais. Também revelou que a participação no processo orçamentário não influencia significativamente na relação entre a intuição e as escolhas intertemporais dos indivíduos.

Nardy e Famá (2013) investigaram a produção adadêmica brasileira sobre as finanças comportamentais, de 2001 a 2012, em periódicos e encontros, listados por Qualis CAPES, na área de Administração, e classificadas como A1, A2, B1 e B2, além de Associação Nacional de Pós-Graduação e Pesquisa em Administração (Anpad) e Sociedade Brasileira de Finanças (SBFIN). Os conteúdos dos artigos foram analisados em relação à contribuição que estes aportam (descobertas) e em que aspecto os trabalhos se enquadram na comportamentalização das finanças. 24 publicações foram encontradas em eventos e 23 em periódicos, no período analisado. Outra evidência é que $64 \%$ do total dos trabalhos correspondem a artigos sobre vieses cognitivos e emocionais.

Como pode ser visto, no Brasil, há alguns estudos publicados sobre os vieses cognitivos, oriundos da representatividade, que afetam a tomada de decisão em condições de incerteza, assim como, pesquisas que fazeram uso do CRT para mensurar a capacidade cognitiva. Porém, não foi encontrada nenhuma pesquisa que investiga todos os vieses da representatividade. E ainda cabe observar que esses estudos são de anos recentes.

Em 1972, o periódico Cognitive Psychology publicou o artigo intitulado Subjective Probability: A Judgment of Representativeness dos autores Kahneman e Tversky, que investiga a heurística da representatividade, através de exemplos empíricos de erros previsíveis e sistemáticos na avaliação de eventos incertos, nos quais os sujeitos investigados julgaram a probabilidade de o evento ser mais representativo das características principais do processo ou da população a partir do que foi originado. Os dados foram coletados junto a 1500 estudantes do ensino médio em Israel, através de um questionário de 24 questões. Para não existir problemas em relação à idade dos respondentes e com a escolaridade, foram realizados pré-testes com os alunos de graduações da Universidade que apresentou resultados indiferentes.

Como achado, Kahneman e Tversky (1972) revelam que as pessoas estão muitas vezes dispostas a crer em um resultado em termos percentuais, sem se preocuparem com o número de observações; é muito provável que a heurística da 
representatividade seja aplicada quando os eventos são caracterizados em termos de suas propriedades gerais. Os autores ainda salientam que os resultados e especulações apresentadas no trabalho fornecem apenas um outline da introdução da heurística como tema para o estudo da competência e realização de julgamentos sob incerteza.

Tversky e Kahneman (1974) descreveram exemplos das três heurísticas empregadas na tomada de decisões sob incerteza: a representatividade, a disponibilidade de instâncias ou cenários e ajustamento por uma âncora. Deixam claro que elas são altamente econômicas e geralmente eficazes; no entanto, levam a erros sistemáticos e previsíveis. Além disso, afirmam que a melhor compreensão dessas heurísticas (e dos desvios a que levam) poderia melhorar julgamentos e decisões em situações de incerteza.

Das e Teng (1999) sugerem existir associação entre os vieses cognitivos e o processo de decisão estratégica. Para testar tal possibilidade, exploram a presença de quatro tipos básicos de viés cognitivo em cinco diferentes modelos de tomada de decisão, em uma série de proposições-chave a fim de facilitar os testes empíricos. Os resultados mostram que os quatro tipos de viés cognitivo (hipóteses preestabelecidas e foco em objetivos limitados; exposição a alternativas limitadas; insensibilidade às probabilidades de resultado; e ilusão de gerenciamento), em conjunto, tem um importante papel em todos os cinco modelos de decisão estratégica. Os autores tiveram uma preocupação em mostrar como cada tipo de viés pode ocorrer em situações práticas de tomada de decisão estratégica; no entanto, observaram que nem todos os quatro tipos básicos de viés cognitivo estão presentes nos processos de decisão.

Korte (2003) apresenta um breve levantamento da literatura sobre tomada de decisão e sobre as formas para reduzir a influência dos vieses nesse processo, além de descrever as implicações dos vieses para os profissionais de recursos humanos. Os vieses analisados foram os mesmo de Das e Teng (1999). Korte afirma que há uma grande diferença entre teoria e prática sobre a eficácia da tomada de decisão, haja vista, na prática, o processo decisório sofrer variações em sua complexidade e ser fortemente influenciado por pressupostos e vieses dos tomadores de decisão. $O$ conhecimento e compreensão dos tipos de vieses, juntamente com medidas para reduzir seus efeitos, conduzirão a melhores decisões. Para minimizar os efeitos da 
subjetividade e dos vieses, os tomadores de decisão devem solicitar e analisar diversos pontos de vista e considerar uma ampla gama de soluções alternativas.

Para Frederick (2005), as habilidades cognitivas são importantes determinantes causais da tomada de decisão. $O$ autor apresentou, em sua pesquisa, o teste de reflexão cognitiva (CRT) como uma medida simples de um tipo de capacidade cognitiva; em seguida, examinou suas relações com duas características de tomadas de decisões: preferência de tempo e de risco. Foram aplicados 3.428 questionários, durante 26 meses, sendo a maioria dos respondentes alunos de graduação, os quais receberam US \$ 8 para preencher o questionário de 45 minutos. Os resultados mostraram que existe uma diferença considerável entre o CRT de homens e mulheres. As três questões corretas do teste tenderam a se correlacionar positivamente com a opção de se esperar mais tempo para se ter maiores recompensas posteriores, sendo essa tendência mais acentuada nas mulheres do que nos homens. Em relação à tolerância risco, essa correlação foi mais forte para as pessoas do sexo masculino. Observou-se ainda que os entrevistados que pontuam de forma diferente no CRT fazem escolhas diferentes.

Chen et al. (2007) estudaram decisões de investimento no mercado emergente e verificaram se os investidores chineses tomam más decisões na negociação de suas ações, incorrendo nos vieses efeito da disposição, excesso de confiança e representatividade. Consideraram, para tal, que o grau de desempenho e os vieses comportamentais estão relacionados com a experiência em investir, com a idade, a frequência de negociação, a riqueza pessoal e o local de residência dos investidores. Para realizar as análises, verificaram 46.969 contas individuais de uma corretora na China, nos períodos de maio/1998 a setembro/2002. Os resultados evidenciam que os investidores cometem erros de negociação e estão propensos aos vieses comportamentais estudados, sendo que os investidores individuais tendem mais aos vieses comportamentais que os institucionais. Quase $43 \%$ dos investidores da amostra apresentaram mais de um viés.

Oechssler, Roidera e Schmitz (2009) usaram os três itens do CRT para investigar se os vieses comportamentais, que desempenham um papel proeminente na economia e finanças comportamentais, estão relacionados às habilidades cognitivas. Participaram do estudo 1.814 sujeitos, sendo $90 \%$ universitários. Foi constatado que escores mais altos no teste de reflexão cognitiva estão correlacionados com menores incidências do conservadorismo na atualização de 
probabilidades, falácia da conjunção, excesso de confiança, preferência ao risco e tempo. Não foi encontrada nenhuma influência sobre a ancoragem. No entanto, mesmo os vieses sendo menores para as pessoas com altas habilidades cognitivas, estes continuaram sendo substanciais.

Dohmen et al. (2010) investigaram se existe uma relação entre a capacidade cognitiva, a aversão ao risco, e a impaciência. Para isso, selecionaram uma amostra aleatória constituída por 1.012 sujeitos adultos. Como resultado, descobriram que a baixa capacidade cognitiva está associada a uma maior aversão ao risco e impaciência mais acentuada.

Bergman et al. (2010) verificaram que pagamentos por bens de consumo diversos podem ser manipulados por uma âncora informativa e que o efeito ancoragem diminui, mas não desaparece, com uma maior capacidade cognitiva, mensurada através do CRT. Para chegarem a esse resultado, fizeram uso de um experimento parecido com o de Ariely et al. (2003), com quatro sessões realizadas de maio a agosto de 2008, com um total de 116 indivíduos, que dispunham de 20 minutos para responder 44 questões.

Hoppe e Kusterer (2011) investigaram se os resultados do teste de reflexão cognitiva (CRT) de 414 estudantes da Universidade de Cologne estão relacionados com a ocorrência dos vieses falácia à taxa base, conservadorismo, excesso de confiança e efeito dotação. Observaram que os sujeitos do grupo de CRT baixo são mais suscetíveis aos vieses analisados, com exceção do efeito dotação, que não é reduzido, mesmo quando os sujeitos apresentam uma maior capacidade cognitiva.

O estudo de Libby e Rennekamp (2012) forneceu evidências de que o viés excesso de confiança está presente quando os gestores realizam as previsões de lucros. A amostra do estudo para o experimento abstrato totalizou 47 participantes de um curso de MBA na Universidade de Cornell, com média de idade de 27 anos e 4,71 anos de experiência profissional. O experimento abstrato permitiu isolar as variáveis de interesse enquanto controlou as características de empresa e ambientais não relacionadas com a pesquisa. Para averiguar se os resultados do experimento são generalizáveis às decisões de previsão de lucro real, também foi realizada uma pesquisa com 109 gestores financeiros e contábeis matriculados em um curso de formação profissional. O tempo médio de experiência profissional foi de 14,71. Os resultados sugeriram que os gestores podem fornecer previsões com maior grau de velocidade quando uma empresa está se saindo bem, 
independentemente do desempenho ser impulsionado por fatores internos ou externos.

Liberali et al. (2012) realizaram dois estudos, um no Brasil, com uma amostra de 259 estudantes universitários, e outro nos EUA, com 190 estudantes universitários. A razão de se usar dois grupos de sujeitos foi dar maior confiabilidade aos resultados, por ser possível avaliar a habilidade para a aritmética e reflexão cognitiva em diferentes contextos. Para medi-las, foram utilizados a Numeracy Scale (NS), Subjective Numeracy Scale (SNS) e o CRT, no intuito de avaliar se elas mensuram constructos similares. Em seguida, testou-se o poder preditivo desses fatores para explicar os vieses e falácias em julgamentos de probabilidade. As duas amostras, apesar de obtidas em países diferentes, apresentaram resultados muito semelhantes na Numeracy Scale (NS), Subjective Numeracy Scale (SNS) e no CRT, podendo ser agrupados em dimensões interpretáveis dos fatores de análises e permitindo prever, com sucesso, desempenho de memória, falácias de conjunção e disjunção, além do viés de proporção em julgamento de probabilidade.

Sequeira et al. (2013) procuraram construir uma bateria de problemas de julgamento para a língua portuguesa (Portugal), no intuito de assegurar que 0 material disponível para a investigação feita em português é metodologicamente rigoroso e acompanha os desenvolvimentos teóricos e conceituais deste domínio de investigação. Para isso, adaptaram para a língua e a realidade portuguesa alguns dos problemas utilizados em pesquisa em outras línguas, além de elaborarem um conjunto de novos itens para procurar manter a natureza e a estrutura dos problemas originais. O experimento foi composto por itens do CRT, problemas de raciocínio disjuntivo, silogismos, problemas de viés com base no resultado (outcome bias) e de viés retrospetivo (hidsight bias), problemas de probabilidades de partida (insebilidade à taxa base), problemas de conjunção de probabilidades (falácia da conjunção) e, também, problemas de falácia do jogador (chance de equívocos). Participaram, voluntariamente, da pesquisa 117 estudantes, do Mestrado Integrado em Psicologia na Faculdade de Psicologia, da Universidade de Lisboa. No que diz respeito ao desempenho no CRT, foi possível observar que, para os itens originais, o padrão de desempenho é semelhante ao reportado por Frederick (2005): mais de $65 \%$ dos participantes forneceram respostas impulsivas. Como contribuição, as questões desse estudo podem ser usadas em outras pesquisas de língua portuguesa, podendo ser adaptado de forma mais conveniente à investigação. 
O estudo de Morsanyi et al. (2013) teve como objetivo principal explorar as consequências cognitivas de experimentos com geradores aleatórios (como, por exemplo, jogo de dados e de moedas) e o aprendizado da lei dos grandes números. Participaram do estudo 108 estudantes de psicologia. Por meio de sessões de treinamento, com 4 atividades, conseguiu-se reduzir o viés equiprobabilidade (ou chance de equívocos), pois reforçou a compreensão de aleatoriedade e probabilidade, sendo a redução maior em participantes com altas habilidades. Esse tipo de experiência com geradores aleatórios teve um efeito positivo sobre a compreensão geral de probabilidade dos alunos; no entanto, pode aumentar a suscetibilidade para a heurística representatividade.

A motivação para o estudo de Yu et al. (2014) decorreu da "lei dos pequenos números" de Tversky e Kahneman (1971), também conhecida como viés da insensibilidade ao tamanho da amostra; isso porque há uma discussão em curso entre os cientistas sobre o teste de significância da hipótese nula dos dados e análise Bayesiana, a qual especula sobre as práticas e as consequências de "graus de liberdade do pesquisador". O artigo tomou por base as seguintes questões: como os cientistas tomam decisões no curso de sua pesquisa? Qual o impacto dessas decisões nas conclusões científicas? Para respondê-las, solicitaram a 314 pesquisadores que coletassem dados em um ambiente de pesquisa simulado, onde se tomavam inúmeras decisões, na implantação e curso do experimento, e se analisavam os dados. Através de simulações Monte Carlo, os resultados mostraram que alguns pesquisadores usaram a heurística na coleta de dados, desviando-se da metodologia prescrita. $O$ estudo destacou que o maior problema não se encontra em pequenos números de fraude, mas na falta de entendimento da relação entre o comportamento do pesquisador, os processos de amostragem tendenciosa e a análise estatística.

Browne et al. (2014) utilizaram, em sua pesquisa, o CRT para mensurar o estilo cognitivo analítico, em um grupo de 1.093 pessoas. Apenas 10,6\% alcançaram um score "altamente analítica" (pontuação do CRT igual a 2 ou 3 acertos). Como resultado, descobriram que o estilo cognitivo analítico possui relação positiva com nível de escolaridade, e negativa com o aumento da idade e o fato de ser do sexo feminino, além da evidência de relação do estilo cognitivo analítico com uma menor probabilidade de filiar-se a uma denominação religiosa e uma maior probabilidade de possuir forte fé religiosa. 
Em sua pesquisa, Baron et al. (2014), também fizeram uso do Teste de Reflexão Cognitiva (CRT) por se correlacionar com as medidas de julgamento moral utilitarista. Os autores afirmam que o CRT é comprovadamente uma das medidas mais úteis no estudo das diferenças individuais, quer do pensamento, dos julgamentos e das decisões, sendo um teste altamente confiável. Com base nos seus resultados, concluíram que o CRT pode ser considerado um teste de reflexão e impulsividade.

Moritz et al. (2014) analisaram como as diferenças individuais afetam o desempenho de julgamento de previsão de séries temporais. Um total de 61 participantes foram recrutados em uma grande universidade pública para o estudo, obtendo-se 2.990 observações válidas. Por meio de três estudos, as hipóteses foram confirmadas para previsão de série temporal: 1 - o desempenho é melhor para os indivíduos com alta reflexão cognitiva (mensurada pelo CRT); 2- o desempenho piora se as previsões são feitas muito rapidamente; assim fornecem evidências de que o desempenho em previsão pode ser melhorado através da manipulação de velocidade de decisão, limitando a quantidade de tempo disponível.

O objetivo do estudo de Erceg e Galic (2014) foi explorar a ocorrência do viés de excesso de confiança e a falácia da conjunção entre apostadores frequentes e esporádicos, ao realizarem suas apostas, e testar se são influenciados pelo formato (probabilidade versus frequências). Fizeram parte da amostra 67 apostadores frequentes e 63 esporádicos, os quais fizeram suas apostas em jogos de futebol disponíveis em um questionário on-line, para, em seguida, estimar se foram bem sucedidas. Ambos os apostadores (frequentes e esporádicos) mostraram semelhantes níveis do viés excesso de confiança. Porém, os apostadores frequentes são mais persistentemente sensíveis à falácia da conjunção. A apresentação da tarefa em termos de frequência reduziu significativamente o viés excesso de confiança em comparação com as avaliações em termos de probabilidade, mas a falácia da conjunção não foi afetada.

Como se pode ver neste tópico, existem atualmente inúmeras pesquisas, tanto em nível nacional quanto internacional, que estudam vieses específicos da representatividade e também fazem uso do CRT para mensurar a capacidade cognitiva e, por meio desta, o tipo de processamento cognitivo. Porém não foi encontrado nenhum estudo que tenha como objetivo investigar, conjuntamente, a insensibilidade à taxa base, insensibilidade ao tamanho da amostra, chance de 
equívocos, equívocos na regressão e insensibilidade à previsibilidade, como é o caso desta tese. 


\section{PROCEDIMENTOS METODOLÓGICOS}

Neste capítulo, serão descritas todas as etapas da pesquisa: métodos de pesquisa, população e amostra, descrição do instrumento e procedimento de coleta de dados, hipóteses, análise de dados e delimitação da pesquisa.

\subsection{MÉTODOS DE PESQUISA}

O método científico é o conjunto de procedimentos para se atingir um objetivo material ou conceitual e entender o processo de investigação (MATIAS-PEREIRA, 2010).

Raupp e Beuren (2004) consideram as particularidades da Contabilidade e, dessa forma, agrupam as tipologias de delineamentos de pesquisas em três categorias: pesquisa quanto aos objetivos, quanto aos procedimentos e quanto à abordagem do problema. Esta pesquisa faz uso dessa tipologia.

Para alcançar os objetivos propostos, toma-se por guia a pesquisa exploratória e descritiva. Essa opção justifica-se pelo propósito de investigar sobre a capacidade cognitiva e a incidência dos vieses cognitivos oriundos da heurística da representatividade (insensibilidade à taxa base, insensibilidade ao tamanho da amostra, chance de equívocos, equívocos na regressão, ilusão de validade e insensibilidade à previsibilidade) no momento do julgamento e tomada de decisão sob incerteza dos indivíduos, visando proporcionar maior familiaridade e conhecimento a respeito do tema. Segundo Gil (1999), esse tipo de pesquisa é desenvolvido com o objetivo de proporcionar visão geral, de tipo aproximativo, sobre determinado fato, constituindo, muitas vezes, a primeira etapa de uma investigação mais ampla.

Ainda, de acordo com Gil (1999), a pesquisa descritiva tem como objetivo a descrição das características de determinada população ou fenômeno ou ainda o estabelecimento de relações entre variáveis. Assim esta pesquisa adquire um caráter descritivo por estudar as características dos estudantes de graduação em Ciências Contábeis e contabilistas através da observação, dos registros, das análises, da classificação e interpretação da capacidade cognitiva e da incidência 
dos vieses da representatividade, sem a interferência da pesquisadora, além de analisar a relação dessas duas variáveis.

Quanto aos procedimentos, é do tipo levantamento ou survey, uma vez que a população é numerosa, existindo a impossibilidade de estudar detalhadamente cada objeto. Gil (1999) esclarece que esse tipo de pesquisa caracteriza-se pela interrogação das pessoas cujo comportamento se deseja conhecer. Para isso, solicitam-se informações a um grupo significativo de pessoas sobre o problema estudado; em seguida, mediante análise quantitativa, obtém-se as conclusões correspondentes dos dados coletados. Complementando, Raupp e Beuren (2004) explicam que os dados podem ser coletados com base em uma amostra retirada de determinada população que se deseja conhecer.

Em relação à abordagem do problema, é de natureza quantitativa, pois são empregados instrumentos estatísticos no tratamento dos dados. Raupp e Beuren (2004) informam que, nesse tipo de abordagem, os instrumentos estatísticos são usados, tanto na coleta como no tratamento dos dados, sendo bastante comum seu uso em estudos do tipo levantamento para entender, por meio de uma amostra, o comportamento de uma população.

Figura 5 - Síntese do pressuposto principal deste estudo

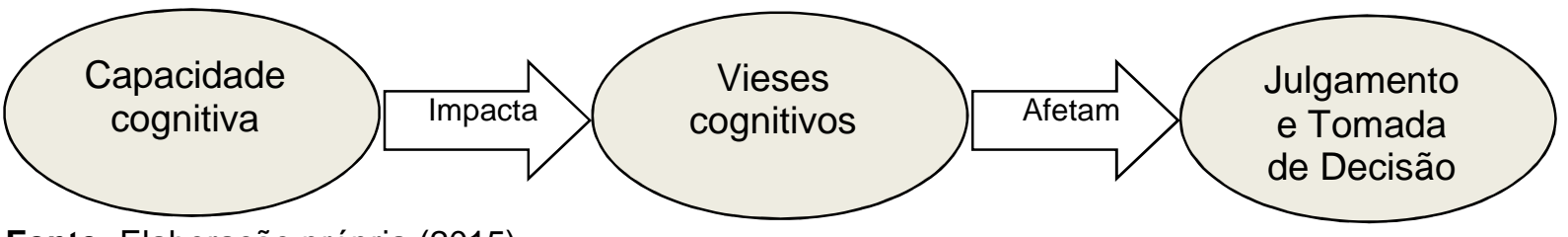

Fonte: Elaboração própria (2015)

Assim, será realizada uma pesquisa survey, para observar a capacidade cognitiva dos contabilistas e estudantes de graduação em Ciências Contábeis, mensurada pelo Cognitive Reflection Test (CRT). Em seguida, será verificada a influência da capacidade cognitiva nos vieses cognitivos oriundos da heurística da representatividade $\mathrm{e}$, consequentemente, se esses vieses afetam o julgamento e a tomada de decisão, desviando a decisão esperada da decisão tomada.

\subsection{INSTRUMENTO DE PESQUISA E COLETA DE DADOS}

A primeira versão do questionário ficou dividida em três partes. A primeira se referia a questões sociodemográficas, como o gênero, a idade, o grau de instrução, 
se possui outra graduação além de Ciências Contábeis, se possui experiência profissional e tempo de atuação; em caso de ser estudante, a instituição de ensino em que está matriculado e a região onde reside.

$\mathrm{Na}$ segunda parte, foram coletados os dados necessários à mensuração da capacidade cognitiva das pessoas pesquisadas, por meio do CRT adaptado de Frederick (2005), realizado através de três questões. Nesse teste, as questões são projetadas de forma a levar os indivíduos pesquisados a responder, equivocadamente, situações simples de forma intuitiva. Além dessas, há uma questão para avaliar a opinião dos indivíduos investigados sobre o grau de dificuldade e outra para estimar a probabilidade de acertos (viés da ilusão de validade) no teste.

Já a terceira parte foi composta de 30 questões, sendo 4 para mensurar viés da ilusão de validade, 5 questões para cada um dos outros vieses analisados, em que a propabilidade de determinado evento deve ser julgada, haja vista esse julgamento impactar a tomadas de decisão, podendo ou não o respondente ser influenciado pelos vieses cognitivos objetos deste estudo. Soma-se ainda uma questão para identificar a opinião de como o respondente considera seu julgamento e tomada de decisão, em uma escala de 0 a 10, sendo 0 para a resposta "baseado na razão" e 10 para a resposta "baseado na intuição". Na construção dos cenários para mensuração dos vieses estudados, houve a preocupação de não se avaliar o conhecimento contábil dos respondentes; assim, eles forneciam dados de situações corriqueiras.

Cada viés cognitivo, estimado por 5 variáveis observáveis, foi mensurado pela escala Likert, com 11 pontos, variando de 0 a 10, sendo 0 designado como "discordo totalmente" e 10 como "concordo totalmente".

Essa versão foi submetida a um pré-teste, antes da utilização efetiva, para, assim corrigir as possíveis falhas existentes, tais como: perguntas mal formuladas, ambiguidades, inconsistência de questões e se o questionário era confiável e válido. Nesse momento, foram usados dois tipos de questionários para avaliar se a forma como os cenários estavam evidenciados gerava, no respondente, o viés de confirmação.

A pesquisadora aplicou pessoalmente $\mathrm{o}$ instrumento de coleta de dados junto a 38 respondentes (10 responderam ao questionário do tipo $\mathrm{A}$ e 28 do tipo $\mathrm{B}$, todos considerados válidos), no mês de julho de 2014. Não foi observada nenhuma 
diferença entre as respostas dos 2 tipos de instrumento. Apesar da pequena amostra, o instrumento foi submetido ao teste Alfa de Cronbach, o qual indicou uma baixa confiabilidade $(0,102)$ para o grupo de variáveis do viés insensibilidade à previsibilidade e um comportamento negativo $(-0,958)$ nas variáveis que mensuravam o viés ilusão de validade.

Devido a essa sinalização, observou-se a necessidade de alteração do instrumento de coleta de dados, para, só após, ser aplicado definitivamente. Além da reformulação dos cenários com indicativos de futuros problemas, a ordem das subdivisões foi alterada, passando a primeira parte, conforme descrita anteriormente, a ser a última. Também foram corrigidas falhas na linguagem utilizada em algumas questões, por dificultarem o entendimento. $O$ tempo de aplicação foi aceitável (em média 30 minutos) e o questionário, de um modo geral, permitiu o alcance do objetivo geral da pesquisa. Através dessas constatações, foi possível promover as mudanças necessárias, reformulando, adicionando e excluindo algumas questões.

O instrumento final de coleta de dados (como pode ser visto no Apêndice A) está dividido em três parte, como pode ser visto, resumidamente, no Quadro 2. 
Quadro 2 - Síntese do Instrumento de coleta de dados

\begin{tabular}{|c|c|c|c|}
\hline Parte & Descrição & & Variáveis \\
\hline I & $\begin{array}{l}\text { Mensurar a } \\
\text { capacidade } \\
\text { cognitiva dos } \\
\text { sujeitos estudados }\end{array}$ & $\begin{array}{l}\text { - Pontuação obtida } \\
\text { no CRT }\end{array}$ & $\begin{array}{l}\text { - Um taco e uma bola juntos custam } \mathrm{R} \$ 110 . \mathrm{O} \\
\text { taco custa } \mathrm{R} \$ 100 \text { a mais que a bola. Quanto } \\
\text { custa a bola? (Resposta impulsiva: } \mathrm{R} \$ 10 ; \\
\text { resposta correta: } \mathrm{R} \$ 5 \text { ). } \\
\text { - São necessários } 5 \text { minutos de } 5 \text { máquinas } \\
\text { para fazer } 5 \text { camisas. Quanto tempo levariam } \\
100 \text { máquinas para fazer } 100 \text { camisas? } \\
\text { (Resposta impulsiva: } 100 \text { min.; resposta } \\
\text { correta: } 5 \text { min.). } \\
\text { - Em um lago, há uma vitória régia. Todos os } \\
\text { dias, ela dobra de tamanho. Se a vitória régia } \\
\text { demora } 100 \text { dias para cobrir todo o lago, } \\
\text { quanto tempo seria necessário para que } \\
\text { cobrisse metade desse lago? (Resposta } \\
\text { impulsiva: } 50 \text { dias; resposta correta: } 99 \text { dias). }\end{array}$ \\
\hline \multirow{6}{*}{ II } & \multirow{6}{*}{$\begin{array}{l}\text { Identificar a } \\
\text { influências dos } \\
\text { vieses cognitivos } \\
\text { gerados pela } \\
\text { heurística da } \\
\text { representatividade } \\
\text { na tomada decisão }\end{array}$} & $\begin{array}{l}\text { - Viés } \\
\text { Insensibilidade à } \\
\text { taxa base }\end{array}$ & - Questões 1, 4, 11, 16 e 21 \\
\hline & & $\begin{array}{l}\text { Viés } \\
\text { Insensibilidade à } \\
\text { previsibilidade }\end{array}$ & - Questões 7, 14, 17, 22 e 27 \\
\hline & & $\begin{array}{l}\text { Viés } \\
\text { Insensibilidade ao } \\
\text { tamanho da } \\
\text { amostra } \\
\end{array}$ & - Questões 3, 13, 18, 24 e 28 \\
\hline & & $\begin{array}{l}\text { - Viés llusão de } \\
\text { validade }\end{array}$ & - Questões 2, 5.1, 5.2, 6 e 8 \\
\hline & & $\begin{array}{l}\text { - Viés Chance de } \\
\text { equívocos }\end{array}$ & - Questões 9, 12, 15, 19 e 25 \\
\hline & & $\begin{array}{l}\text { - Viés Equívoco na } \\
\text { regressão }\end{array}$ & - Questões 10, 20, 23, 26 e 29 \\
\hline III & $\begin{array}{l}\text { Levantar o perfil } \\
\text { dos respondentes }\end{array}$ & \multicolumn{2}{|c|}{$\begin{array}{ll}\text { - } & \text { Gênero } \\
\text { - } & \text { Idade } \\
\text { - } & \text { Grau de instrução } \\
\text { - } & \text { Se possui outra formação superior } \\
\text { - } & \text { Experiência Profissional } \\
\text { - } & \text { Tempo de profissão } \\
& \text { Região onde reside }\end{array}$} \\
\hline
\end{tabular}

Fonte: Elaboração própria (2015)

O primeiro grupo de questões, da parte II (conforme Quadro 2), tem o objetivo de identificar o viés da insensibilidade à taxa base; para isso, foram apresentados cenários onde a taxa base é, inicialmente, fornecida e, em seguida, é realizada uma descrição irrelevante. Caso os respondentes sejam sensíveis a esse viés, julgarão, a probabilidade com base apenas na informação descritiva.

O segundo grupo busca identificar o viés da insensibilidade à previsibilidade. Caso os indivíduos sejam sensíveis a esse viés, irão fornecer maiores pontuações 
na escala fornecida, por serem insensíveis à confiabilidade das evidências apresentadas nos cenários.

O terceiro grupo de questões visa verificar o viés insensibilidade ao tamanho da amostra. Os sujeitos afetados por esse viés desconsideram o tamanho da amostra em questão e julgarão a probabilidade baseada apenas em dados irrelevantes.

O quarto grupo objetiva identificar o viés da ilusão da validade, pois as pessoas costumam fazer previsões confiáveis sobre algo ou alguém, com base em dados falíveis; e mesmo quando sabem da baixa validade desses dados, superestimam seus conhecimentos. Para o cálculo desse viés, foi solicitada ao respondente a probabilidade de acertos de itens anteriores; em seguida, foi realizada uma comparação dessa com os itens em questão. Nessa situação, caso o indivíduo marque $100 \%$ na escala e na questão anterior tenha marcado 10 , considera-se que ele superestimou seus conhecimentos, possuindo assim elevado viés da ilusão da validade.

O quinto grupo de questões, ainda da parte II, objetiva identificar se os respondentes são sensíveis ao viés chance de equívoco. Para isso, é solicitado que eles julguem qual das probabilidades fornecidas é mais possível de acontecer. Caso sejam sensíveis a esse viés, o resultado não aleatório passa a não ser representativo, concluindo-se, portanto, que sequências aleatórias são mais prováveis.

O sexto grupo tenta identificar o viés equívoco na regressão. Para tanto, são apresentados cenários em que há um retorno médio anual e, em seguida, é apresentado o retorno atual bem superior. Depois, solicita-se que os indivíduos julguem a probabilidade de o próximo retorno ser igual ou superior ao anterior. Se essa probabilidade for baixa, é devido à crença de que a performance no limite não se mantém por muito tempo, retornando ao desempenho médio.

A versão final do questionário, cujo tempo médio de resposta é de 30 minutos, totaliza 43 questões. Dessas, 3 são do CRT; 1 para avaliar a opinião dos indivíduos sobre o grau de dificuldade no teste; 30 para averiguar e mensurar a presença dos vieses estudados; 1 para captar a percepção do respondente sobre seu julgamento e tomada de decisão; 8 são de questões sociodemográficas. Para a obtenção de respostas mais reais, o anonimato dos participantes, graduandos em Ciências Contábeis e contabilistas, foi mantido. 
O instrumento de coleta de dados ficou hospedado no Google Docs, de 15 de setembro ao dia 6 de dezembro do ano de 2014. Os links de acesso eram http://goo.gl/forms/LesHL9Ekq8 e http://goo.gl/forms/EnHoaTOTas.

Após hospedagem do questionário, a pesquisadora iniciou a busca de e-mails de estudantes de graduação em Ciências Contábeis e contabilistas. Porém, houve uma resistência das IES em fornecer os contatos de alunos e ex-alunos. Assim, foi encaminhado um e-mail com o link do questionário para algumas coordenações dos cursos de Ciências Contábeis encaminharem para o seu banco de dados, através de e-mail ou plataforma institucional.

Dentre as instituições parceiras, cabe destacar: Universidade Federal do Rio Grande do Norte (UFRN), UNIFACEX, UNI-RN, Universidade Estadual do Rio Grande do Norte (UERN), Universidade Federal Rural do Semi-Árido (UFERSA), Universidade Potiguar (UNP), Universidade Federal da Paraíba (UFPB), Universidade Estadual da Paraíba (UEPB), Universidade de Brasília (UnB), Universidade Federal do Rio de Janeiro (UFRJ), Universidade Católica de Pernambuco (UNICAP), Instituto de Pesquisas e Estudos Contábeis e Tributários (IPECONT), Programa Multiinstitucional e Inter-regional de Pós Graduação em Ciências Contábeis - UnB, UFPB e UFRN, Universidade do Estado de Santa Catarina (UDESC), Universidade de São Paulo (USP), Universidade Federal de Viçosa (UFV), Universidade Federal do Rio Grande do Sul (UFRGS), Universidade Federal de Uberlândia (UFU), Universidade Paulista (UNIP), Universidade Metodista de Piracicaba (UNIMEP), Universidade de Rio Verde (UNIRV), Centro de Ensino Superior de Conselheiro Lafaiete (CES-CL), Universidade Federal de Alagoas (UFAL), Fundação Universidade Federal de Rondônia (UNIR), Unidade Integrada Vale do Taquari de Ensino Superior (UNIVATES), Conselho Regional de Contabilidade-RN. Os blogs Contabilidade Financeira, Informação Contábil, Contabilidade \& Métodos Quantitativos e Conexão Contábil da UFRN também foram divulgadores da pesquisa, além de páginas de rede social.

A pesquisadora conseguiu formar um banco de dados com contatos de profissionais contábeis, através de consultas aos sites de IES, ajuda do Sindicato dos Contabilistas do RN e e-mails de caixa postal própria. Quinzenalmente, durante o período de coleta de dados, e-mails eram enviados com o link da pesquisa, para as instituições parceiras e banco de dados. 


\subsection{POPULAÇÃO E AMOSTRA}

A população deste estudo é constituída pelos estudantes dos cursos de graduação em Ciências Contábeis das Instituições de Ensino Superior (IES) do Brasil, além de profissionais que atuam nessa área de conhecimento, convidados a participar deste estudo por e-mail, por meio do Conselho Regional de Contabilidade do Rio Grande do Norte (CRC/RN), por meio de convites colocados na plataforma da instituição e redes sociais.

Liyanarachchi e Milne (2005) afirmam que estudantes de graduação ou de pós-graduação podem ser utilizados em pesquisas acadêmicas, por serem bons substitutos de profissionais. Em sua pesquisa, eles consolidam essa opção como uma metodologia válida para ser utilizada em pesquisas empíricas.

Em algumas análises, é muito caro ou fisicamente impossível obter toda a população; nesse caso, será necessária a constituição de uma amostra. Cooper e Schindler (2003) afirmam que há várias razões para amostragem, dentre elas destaca-se: o custo mais baixo, a maior acuidade dos resultados, a coleta de dados mais rápida e a disponibilidade dos elementos da população. Sendo assim, nesta pesquisa, optar-se-á pela seleção de uma amostra, mantendo a preocupação com sua representatividade.

Sabe-se que a amostra ideal seria aquela cujas técnicas de seleção fossem probabilísticas para permitir a generalização do resultado. No entanto, como a pesquisadora não tive acesso aos bancos de dados das IES, que possuem o curso de graduação em Ciências Contábeis, e dos contabilistas, pois as instituições colaboradoras preferiram divulgar o questionário diretamente para seus alunos e egressos (para as que possuíam essa informação) e o CRC-RN também não disponibilizou os contatos dos profissionais registrados, a amostra é não probabilística intencional.

Hair et al. (2005) sugerem que a amostra seja maior, no mínimo, cinco vezes às observações, do que o número de itens avaliados; o tamanho mais aceitável teria uma proporção de dez para um. Como o questionário desta pesquisa compõem-se de 43 itens, a amostra mínima necessária seria de 215 e a ideal seria de 430.

Os questionários respondidos totalizam 1.138. Desses, 34 foram excluídos da amostra por apresentarem questões sem respostas; por não serem respondidos por contabilistas (ou ainda por identificar a falta de comprometimento por parte do 
respondente); 32 por apresentarem outliers no boxplot e 8 por estarem em duplicidade. Assim, a amostra válida deste estudo totaliza 1.064 respondentes (uma razão de aproximadamente 25 casos-por-variável), dentre estudantes de graduação em Ciências Contábeis e contabilistas, dos quais 47,3\% são do gênero feminino. Essa elevada amostra deve-se ao incentivo do sorteio de uma televisão Led Plana (Samsung), 32 Polegadas.

\subsection{HIPÓTESES DE PESQUISA}

A hipótese em uma pesquisa, de acordo com Cooper e Schindler (2003), orienta a direção do estudo, identifica os fatos relevantes e não relevantes e fornece uma estrutura para organizar os resultados.

Assim, neste estudo, são levantadas as seguintes hipóteses de pesquisa, que são uma resolução provisória do problema de pesquisa:

Hipótese 1: A incidência de vieses cognitivos gerados pela heurística da representatividade é influenciada pela capacidade cognitiva dos indivíduos pesquisados.

Estudos como Frederick (2005), Dohmen et al. (2010) e Oechssler, Roidera e Schmitz (2009), como visto no capítulo 2, identificaram que baixa capacidade cognitiva, mensurada através do CRT, influencia positivamente a incidência de vieses cognitivos na tomada de decisão. A hipótese 1 foi formulada para auxiliar na verificação da influência da alta capacidade cognitiva na incidência de vieses cognitivos gerados pela heurística da representatividade, e assim alcançar o objetivo geral.

Hipótese 2: Existe diferença estatística entre as variáveis grau de dificuldade dos respondentes nos três itens do CRT e opinião dos indivíduos sobre seu julgamento e tomada de decisão quando comparadas com a capacidade cognitiva.

Frederick (2005), em sua pesquisa, identificou que indivíduos com menores pontuações no CRT consideraram o teste mais fácil, por fornecer a primeira resposta que veio à mente, fazendo uso apenas do processamento do Tipo 1 , do que aqueles com maiores pontuações no CRT, os quais usaram processamento do Tipo 2 , processamento lento, consciente e reflexivo. 
Hipótese 3: As variáveis gênero, região e grau de instrução influenciam na incidência dos vieses cognitivos estudados.

A hipótese 3 foi formulada para identificar se existe diferença entre o impacto dos sexos feminino e masculino; da região onde reside; do grau de instrução (técnico, graduação completa e incompleta, especialização, mestrado e doutorado nos vieses cognitivos.

\subsection{TÉCNICAS DE VALIDAÇÃO DO CONSTRUCTO DOS VIESES COGNITIVOS E DE ANÁLISE DE DADOS}

Os dados coletados foram organizados em uma planilha Excel e, em seguida, convertidos em um arquivo para softwares Statistical Package for the Social Sciences (SPSS) 19, utilizando-se alguns programas para a análise. As tabelas, oriundas do SPSS, foram formatadas no Excel para uma melhor visualização.

Neste estudo, para alcançar os objetivos, construiu-se uma escala de mensuração para os vieses insensibilidade à taxa base, insensibilidade ao tamanho da amostra, chance de equívocos, equívocos na regressão, ilusão de validade e insensibilidade à previsibilidade. Para cada uma dessas dimensões, foram criados cinco cenários, ou seja, cinco variáveis, para representá-los.

Antes de submetida ao pré-teste, a validade de conteúdo do questionário foi avaliada por dois especialistas, os quais deram suas contribuições e sugestões de alterações. Segundo Hair et al. (2005), a validade de conteúdo avalia subjetivamente a correspondência entre os itens individuais e o conceito por meio de julgamentos de especialistas. Assim, por meio de sua validade, é possível averiguar que o instrumento mede com precisão o fenômeno. 
Figura 6 - Variáveis por vieses cognitivos

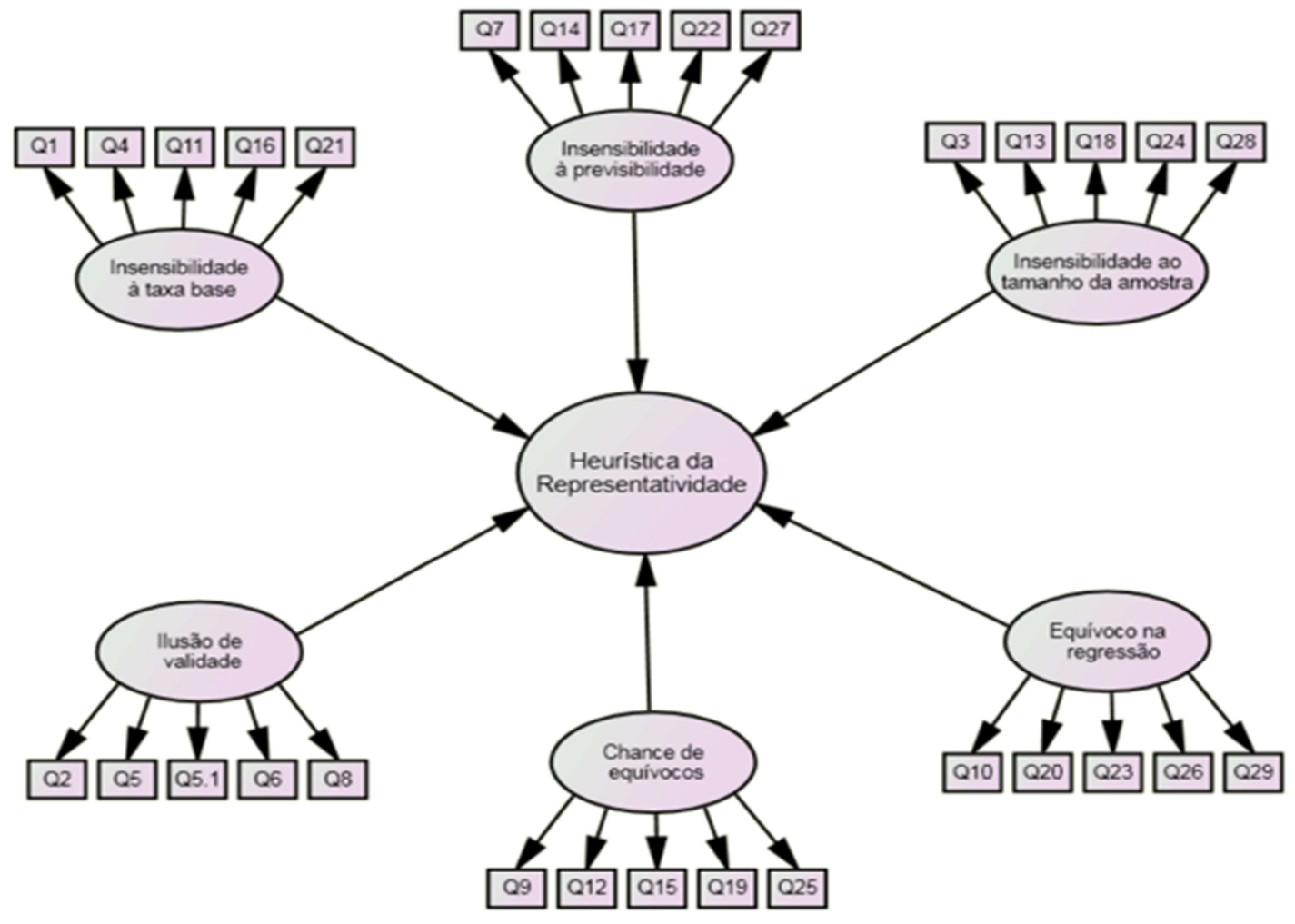

Fonte: Elaboração Própria

Após coleta de dados, de acordo com Hair et al. (2005), precisa-se averiguar a dimensionalidade e a confiabilidade. Para criação de uma escala, é essencial que os itens sejam unidimensionais, significando que eles estão fortemente associados um com o outro e representam um único conceito. A unidimensionalidade será testada através da análise fatorial. A confiabilidade é uma avaliação do grau de consistência entre múltiplas medidas de uma variável, tendo como medida, mais comumente usada, a consistência interna, cuja mensuração é feita através do Alfa de Cronbach que, segundo Hair et al. (2005), registra 0,6 como o limite inferior aceitável para as ciências sociais.

$\mathrm{Na}$ análise fatorial, são consideradas as seguintes suposições, conforme recomendação de Hair et al. (2005):

a) Teste de esfericidade de Bartlett menor que 0,001 (teste estatístico para a presença de correlações entre as variáveis, fornecendo a probabilidade estatística de que a matriz de correlação tenha correlações significantes entre, pelo menos, algumas variáveis). 
b) Medida de adequação da amostra (MSA) maior ou igual a 0,5 (outra medida que quantifica o grau de intercorrelações entre as variáveis).

c) Comunalidade maior ou igual a 0,5 (são estimativas da variância compartilhada entre as variáveis).

d) Percentual da variância explicada maior ou igual a $50 \%$ (nas ciências sociais, as informações geralmente são menos precisas).

Além dessas suposições anteriores, também foi feito o teste de Kaiser-MeyerOlkin (KMO), utilizado para avaliar a adequabilidade da amostra; valores entre 0,5 e 1,0 indicam que a análise fatorial é apropriada.

Após validação dos constructos, verificou-se a existência de diferença estatística entre classificar os vieses cognitivos pelos escores fatoriais ou pela soma das variáveis remanescentes, pelo coeficiente de Spearman, o qual mede a intensidade da relação entre variáveis ordinais, não sendo sensível a assimetrias na distribuição; e pelo coeficiente Kappa, medida de associação usada para descrever e testar o grau de concordância (confiabilidade e precisão) na classificação.

Para facilitar o entendimento dos dados coletados, utilizou-se a estatística descritiva baseada em medidas de posição, de tendência central, comparação de frequência e medidas de dispersão, por meio de tabelas.

A técnica de escalonamento multidimensional foi aplicada com o objetivo de identificar, através do mapa perceptual da Análise de Correspondência Múltipla, as relações entre o CRT e os vieses da representatividade, sinalizando variabilidade ou diferenças representativas, para assegurar conclusões tomadas como válidas. Para Hair et al. (2005), escalonamento multidimensional é um procedimento que permite a um pesquisador determinar a imagem relativa percebida de um conjunto de objetos, identificar dimensões de avaliação não reconhecidas, e avaliação comparativa de objetos.

Herdeiro (2012) corrobora a afirmação anterior e afirma que essa técnica sintetiza informações, para melhorar a capacidade de compreensão dos fenômenos, podendo ser aplicada a diversos tipos e formas de dados e temas, bastando que se deseje comparar objetos ou coisas. A maior utilidade dessa forma de avaliação é tornar claros os aspectos que não se apresentam totalmente óbvios por meio da avaliação direta de números. É uma técnica bastante simples de se usar e, em geral, não se baseia em premissas estatísticas, o que a torna de grande praticidade. 
O mapa perceptual engloba vários métodos; dentre eles, será usada a técnica de Análise de Correspondência Multípla, que é, segundo Hair et al. (2005), composicional, pois o mapa perceptual é baseado na associação entre objetos e um conjunto de características especificadas pelo pesquisador, sendo semelhante à análise fatorial, mas vai além, retratando a correspondência de categorias de variáveis.

Algumas variáveis serão cruzadas para verificar se existe associação entre elas e assim verificar a aceitação ou não das hipóteses descritas no tópico anterior. Para identificar se os resultados são significativos, será adotado o nível de significância igual a 0,05, contrabalançando as possibilidades de se cometer os erros Tipo I (rejeita-se a hipótese nula quando ela é verdadeira) e Tipo II (não se rejeita a hipótese nula sendo ela falsa). Para testá-las, foi necessário determinar a média dos vieses cognitivos estudados, separar o CRT em três grupos (os que acertarem os três itens do teste serão considerados integrantes do grupo de alta capacidade cognitiva; aqueles que obtiverem 1 ou 2 acertos serão do grupo de média capacidade cognitiva; os que errarem todos os problemas constituirão o grupo de baixa capacidade cognitiva), para, então, verificar se as médias são estatisticamente diferentes.

Para avaliar as diferenças entre médias dos grupos de variáveis de interesse, conforme hipóteses preestabelecidas, serão utilizados o Teste $t$, para situações com dois grupos e ANOVA, para três ou mais grupos. De acordo com Hair et. al (2005), a utilização de múltiplos teste $t$ para os 3 grupos de CRT aumentam a taxa de erro Tipo I geral; já o ANOVA evitou aumento do erro Tipo I por fazer múltiplas comparações de grupos de tratamento, determinando em um único teste se o conjunto inteiro de médias de amostras sugere que as amostras foram obtidas a partir da mesma população. Ainda segundo esses autores, quanto ao Teste $t$, se o valor $t$ é grande o suficiente, então se pode concluir que a diferença é verdadeira, não sendo devido à variabilidade de amostra. Para isso, basta comparar a estística $t$ com o valor crítico da estatística $\left(t_{c r i t}=0,05\right)$. Sendo ela maior, rejeita-se a hipótese nula de nenhuma diferença de médias.

Quanto ao ANOVA, Hair et. al (2005) afirmam que, nesse teste, são comparadas duas estimativas independentes da variância para a variável dependente: uma que reflete a variabilidade geral de respondentes entre grupos e outra que representa as diferenças entre grupos atribuíveis aos efeitos de 
tratamento. A hipótese nula testada é a inexistência de diferenças de grupos, através da estatística $F$. Então, se a estatística $F$ calculada não exceder a $F_{\text {crit, }}$ conclui-se que as médias dos grupos são diferentes. Mas esse teste não identifica quais médias são diferentes. Para isso, usa-se o método da diferença honestamente significante (HSD) de Tukey.

Para utilizar o teste ANOVA, foram testadas as suposições de normalidade e igualdade de matrizes de variância-covariância. Quanto à normalidade dos dados, procedeu-se à observação pelo Teorema Central do Limite, em que o vetor de médias converge para a distribuição normal multivariada em grandes amostras, como é o caso desta pesquisa. Em relação à igualdade de matrizes de variânciacovariância, a verificação foi feita via estatística de Levene. No caso da existência de heterocedasticidade, os testes de Welsh e Brown-Forsythe apresentam-se como recurso possível.

\subsection{LIMITAÇÕES DA PESQUISA}

Devido à abrangência do objetivo deste trabalho, serão necessárias algumas delimitações em que se circunscreve a abordagem temática.

a) Como é financeiramente inviável investigar todos os indivíduos economicamente ativos, que realizam julgamentos sobre a probabilidade de determinado evento na prática, este estudo tem como população alunos de graduação em Ciências Contábeis e contabilistas, sendo a amostra formada de maneira não probabilística.

b) Os resultados alcançados neste estudo dependem do comprometimento dos participantes.

c) Esta pesquisa não investigará os vieses cognitivos oriundos das heurísticas da Disponibilidade e da Ancoragem e Ajustamentos.

d) A capacidade cognitiva será mensurada pelo CRT e não serão investigadas as suas causas. 


\section{ANÁLISE DE DADOS}

Neste capítulo, são apresentados e analisados os resultados do estudo, obtidos através da aplicação do questionário. No primeiro tópico, serão evidenciados e analisados os resultados dos testes para validação das escalas dos vieses cognitivos objetos de estudo. Em seguida, realiza-se a análise descritiva dos dados sociodemográficos dos respondentes, além do CRT e dos vieses cognitivos oriundos da Heurística da Representatividade. Por último, efetua-se a análise das hipóteses de pesquisa.

\subsection{DIMENSIONALIDADE E CONFIABILIDADE DA ESCALA}

Neste item, são evidenciados e discutidos os resultados da dimensionalidade, cujos testes serão realizados através da análise fatorial, e a confiabilidade, mensurada por meio do Alfa de Cronbach para as escalas dos vieses cognitivos. Para a escala do Cognitive Reflection Test, não será realizada nenhuma análise adicional, pois essa já foi validada para o idioma português, na tese de Liberali (2012) e no artigo de Sequeira et al. (2013). Esses autores defendem que a contribuição desses estudos reside no fato de as questões do CRT poderem ser usadas em outras pesquisas de língua portuguesa, podendo ser adaptadas da forma mais conveniente à investigação. 
Tabela 4 - Medidas estatísticas para a validação da dimensionalidade e confiabilidade da escala através da análise fatorial dos vieses

\begin{tabular}{|c|c|c|c|c|}
\hline & Viés 1 & Viés 2 & Viés 3 \\
\hline \multirow[b]{2}{*}{$\begin{array}{l}\text { Teste da esfericidade } \\
\text { de Bartlett }\end{array}$} & Estatística & 1470,966 & 760,960 & 1057,990 \\
\hline & Valor-P & $<0,001$ & $<0,001$ & $<0,001$ \\
\hline \multicolumn{2}{|l|}{ Alpha de Cronbach - } & 0,762 & 0,661 & 0,807 \\
\hline \multicolumn{2}{|c|}{ IC 95\% para Alpha Cronbach } & 0,738 a 0,784 & 0,627 a 0,693 & 0,786 a 0,826 \\
\hline \multicolumn{2}{|c|}{$\begin{array}{l}\text { Alpha de Cronbach para item } \\
\text { excluído }\end{array}$} & 0,639 a 0,784 & 0,560 a 0,612 & 0,701 a 0,768 \\
\hline \multicolumn{2}{|c|}{ Kaiser-Meier-Olkin (KMO) } & 0,712 & 0,609 & 0,708 \\
\hline \multicolumn{2}{|c|}{$\begin{array}{l}\text { Medida de Adequação Amostral } \\
\text { (MSA) }\end{array}$} & 0,677 a 0,763 & 0,596 a 0,619 & 0,678 a 0,743 \\
\hline \multicolumn{2}{|c|}{ Comunalidades } & 0,586 a 0,810 & 0,742 a 0,778 & 0,690 a 0,760 \\
\hline \multirow{2}{*}{\multicolumn{2}{|c|}{ \% Variância explicada }} & $52 \%$ & $50 \%$ & $72 \%$ \\
\hline & & Viés 4 & Viés 5 & Viés 6 \\
\hline \multicolumn{2}{|c|}{ Estatística (Teste de Bartlett) } & 489,210 & 2726,999 & 426,258 \\
\hline \multicolumn{2}{|c|}{ Valor-P (Teste de Bartlett) } & $<0,001$ & $<0,001$ & $<0,001$ \\
\hline \multicolumn{2}{|c|}{ Alpha de Cronbach - } & 0,676 & 0,889 & 0,684 \\
\hline \multicolumn{2}{|c|}{ IC 95\% para Alpha Cronbach } & 0,640 a 0,708 & 0,878 a 0,899 & 0,273 a 0,332 \\
\hline \multicolumn{2}{|c|}{$\begin{array}{l}\text { Alpha de Cronbach para item } \\
\text { excluído }\end{array}$} & 0,564 a 0,603 & 0,642 a 0,691 & 0,653 a 0,713 \\
\hline \multicolumn{2}{|c|}{ Kaiser-Meier-Olkin (KMO) } & 0,664 & 0,792 & 0,645 \\
\hline \multicolumn{2}{|c|}{$\begin{array}{l}\text { Medida de Adequação Amostral } \\
\text { (MSA) }\end{array}$} & 0,653 a 0,679 & 0,732 a 0,883 & 0,618 a 0,671 \\
\hline \multicolumn{2}{|c|}{ Comunalidades } & 0,586 a 0,625 & 0,587 a 0,830 & 0,547 a 0,646 \\
\hline \multicolumn{2}{|l|}{ \% Variância explicada } & $72 \%$ & $75 \%$ & $59 \%$ \\
\hline
\end{tabular}

Fonte: Dados da pesquisa (2015)

A tabela 4 mostra os finais dos testes após a retirada de variáveis para atender as presunções necessárias.

Em relação ao viés 1, todas as variáveis observadas permaneceram para mensuração do viés Insensibilidade à taxa base, após cumprimento das exigências iniciais, em que o teste de esfericidade de Bartlett indica a presença de correlações entre as variáveis, por ser menor que 0,001 ; o KMO é de 0,712 , indicando uma boa adequabilidade da amostra; o MAS, ou seja, o grau de intercorrelações entre as variáveis, está entre 0,677 e 0,763 , quando o exigido como mínimo é 0,5 ; as comunalidades estão entre 0,586 e 0,810; o percentual da variância explicada é $52 \%$; e o Alpha de Cronbash para o grupo é de 0,762 .

Quanto ao viés insensibilidade à previsibilidade (viés 2), ao fazer uso de todas as variáveis inicialmente propostas, na primeira análise, a variável Q7 apresentou uma comunalidade de 0,334, não atingindo um dos pressupostos definidos anteriormente, sendo necessária sua retirada, para então ser realizada uma nova análise fatorial, que obedeceu todas as suposições efetuadas com as quatro variáveis observáveis remanescentes. 
$\mathrm{Na}$ primeira análise fatorial do constructo do viés da insensibilidade ao tamanho da amostra, o percentual da variância explicada foi menor que $50 \%$. Para melhorá-la, foram retiradas as variáveis Q3 e Q24, obtendo, as variáveis restantes, boas condições para mensurar o viés pretendido, como pode ser visto na tabela 4 , além de um Alpha de Cronbach de 0,807.

O viés ilusão de validade, inicialmente, possuía 5 variáveis de mensuração; porém, na análise fatorial, foi observado que, no cálculo das estimativas da variância compartilhada entre as variáveis, a Q5.1 $(0,079)$ e Q.6 $(0,321)$ apresentaram baixíssimos valores. Dessa forma, foram retiradas do constructo e, mais uma vez, foi feita a análise fatorial, que apresentou resultados satisfatórios para mensuração do viés com as variáveis Q2, Q5.2 e Q8.

A avaliação da dimensionalidade do constructo do viés chance de equívocos apresentou uma baixa comunalidade para a variável Q15 $(0,30)$, sendo ela retirada das medidas. Após exclusão da referida variável, as demais cumpriram as suposições iniciais, em que se apresentou um Alpha de Cronbash de 0,889; o teste de esfericidade de Bartlett foi significativo, indicando a presença de correlações entre as variáveis; o KMO é de 0,792, revelando que a amostra é adequada para avaliar o referido viés pelos sujeitos; o MSA está entre 0,732 e 0,883; as comunalidades estão entre 0,587 e 0,830; e o percentual da variância explicada é $75 \%$.

A análise fatorial das variáveis propostas para mensurar o viés equívoco na regressão apontou uma baixa comunalidade nas variáveis Q10 $(0,266)$ e Q29 $(0,463)$. Como é inferior a 0,5 , obedeceu a um dos pressupostos inicialmente. Após suas retiradas, foi realizada uma nova análise fatorial, a qual obedeceu todas as suposições: teste de esfericidade de Bartlett menor que 0,001; MAS > 0,5; comunalidades maiores que 0,5; percentual da variância explicada > 50\%; e KMO > 0,5; e Alpha de Cronbash > 0,6.

A qualidade de um instrumento de medida verifica-se pela sua confiabilidade e validade. Em resumo, pode-se concluir que o instrumento apresentou, em média, uma boa confiabilidade, mensurada através de Alpha de Cronbach (consistência interna), indicando que as medidas medem o fenômeno estudado. A anáilse da dimensionalidade verificou, após retiradas de algumas variáveis, que, dentro do constructo, elas estão associadas, uma com as outras, devido ao cumprimento das suposições iniciais para todos os vieses. 
Figura 7 - Desenho final da pesquisa

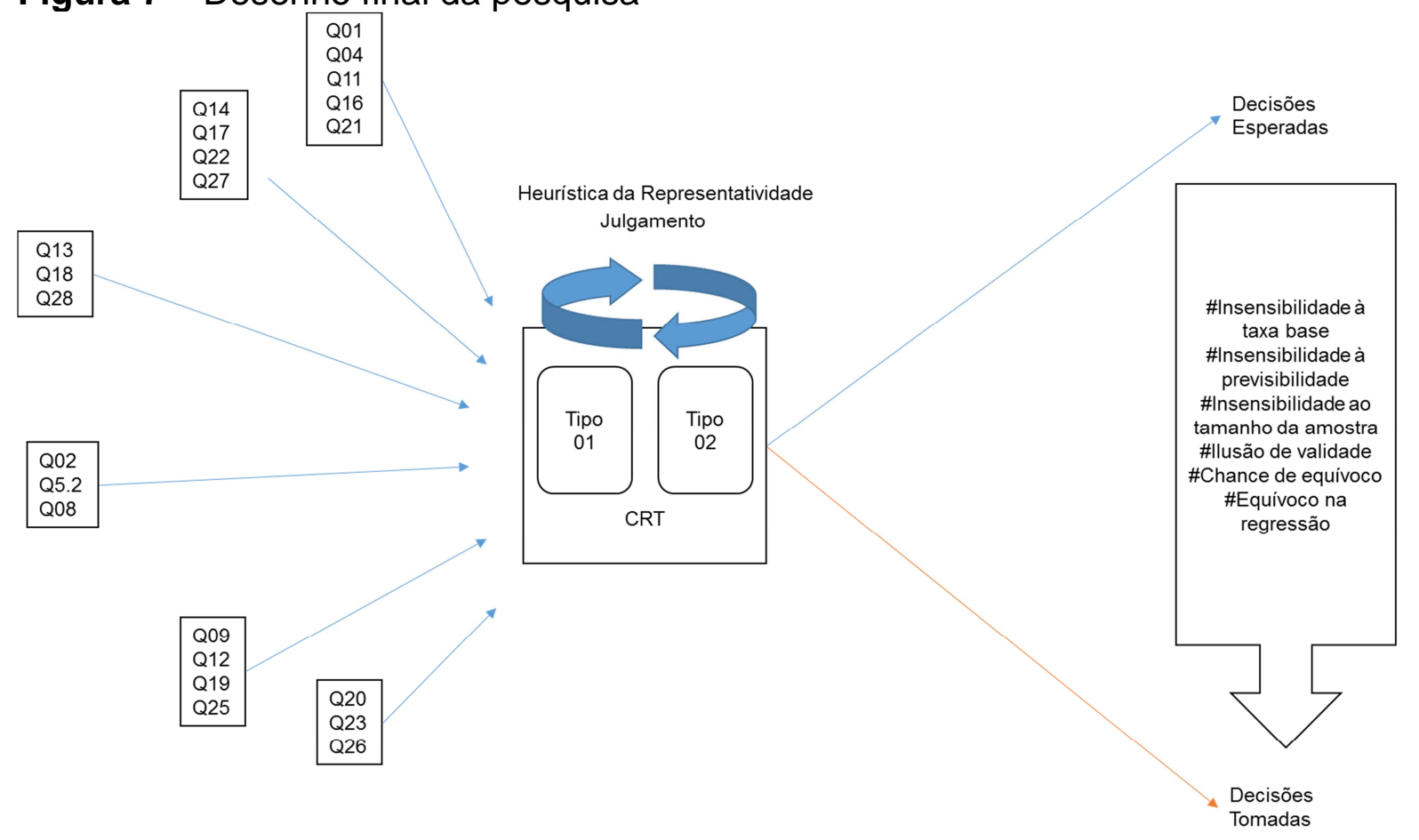

Fonte: Elaboração própria (2015)

O desenho de pesquisa final pode ser visto na figura 7 , após a retirada das variáveis Q3, Q5, Q6, Q7, Q10, Q15, Q24 e Q29. Pode-se verificar, após validação dos constructos, que as variáveis remanescentes são boas medidas para a mensuração de cada viés cognitivo estudado: insensibilidade à taxa base (Q1, Q4, Q11, Q16 e Q21); insensibilidade à previsibilidade (Q14, Q17, Q22, Q27); insensibilidade ao tamanho da amostra (Q13, Q18, Q28); ilusão de validade (Q2, Q5.2, Q8); chance de equívocos (Q9, Q12, Q19, Q25); e equívoco na regressão (Q20, Q23, Q28).

Então, para se prosseguir com a análise de dados surgiu o seguinte questionamento: qual a diferença entre classificar os vieses cognitivos pelos escores fatoriais ou pela média das variáveis remanescentes?

Tabela 5 - Escores fatoriais e Escores somas das variáveis remanescentes

\begin{tabular}{c|c|c|c|c}
\hline \multirow{2}{*}{ Viés } & \multicolumn{2}{|c|}{ Spearman } & \multicolumn{2}{c}{ Kappa } \\
\cline { 2 - 5 } & Estatística & Valor-p & Estatística & Valor-p \\
\hline 1 & 0,624 & $<0,001$ & 0,416 & $<0,001$ \\
\hline 2 & 0,602 & $<0,001$ & 0,428 & $<0,001$ \\
\hline 3 & 0,925 & $<0,001$ & 0,810 & $<0,001$ \\
\hline 4 & 0,972 & $<0,001$ & 0,953 & $<0,001$ \\
\hline 5 & 0,989 & $<0,001$ & 0,982 & $<0,001$ \\
\hline 6 & 0,973 & $<0,001$ & 0,956 & $<0,001$ \\
\hline
\end{tabular}

Fonte: Dados da pesquisa 
Para responder se existe diferença entre os escores a serem utilizados, foi calculada a correlação de Spearman, que evidencia que os dois escores estão correlacionados de forma significante, e também foi calculada a medida de concordância Kappa, a qual mostra que as duas classificações são concordantes significativamente. Como para todos os vieses, a análise fatorial não possui poder explicativo de $100 \%$ da variância total; e como a intenção não é criar um índice, optou-se pelo uso dos escores média das variáveis remanescentes.

\subsection{CARACTERIZAÇÃO DOS PARTICIPANTES}

Este tópico apresenta uma descrição dos dados obtidos através do questionário, que resultou em uma amostra válida de 1.064 respondentes.

Tabela 6 - Grau de Instrução da amostra

\begin{tabular}{l|r|r}
\hline \multicolumn{1}{c|}{ Grau de Instrução } & \multicolumn{1}{c|}{ N } & \multicolumn{1}{c}{$\%$} \\
\hline Graduação incompleta & 546 & 51,3 \\
\hline Graduação completa & 237 & 22,3 \\
\hline Especialização & 151 & 14,2 \\
\hline Mestrado & 94 & 8,8 \\
\hline Doutorado & 32 & 3,0 \\
\hline Técnico & 4 & 0,4 \\
\hline Total & 1.064 & 100,0 \\
\hline
\end{tabular}

Fonte: Dados da pesquisa (2015)

A tabela 6 evidencia que, dos 1.064 dados válidos, um pouco mais da metade correspondia às respostas de estudantes (graduação incompleta) e um pouco menos da metade representava as respostas dos sujeitos que possuíam, pelo menos, graduação quando responderam ao questionário.

Tabela 7 - Distribuição dos respondentes por Região

\begin{tabular}{l|r|r}
\multicolumn{1}{c|}{ Região } & N & \multicolumn{1}{c}{$\%$} \\
\hline Centro-Oeste & 50 & 4,7 \\
\hline Nordeste & 745 & 70,1 \\
\hline Norte & 13 & 1,2 \\
\hline Sudeste & 176 & 16,5 \\
\hline Sul & 80 & 7,5 \\
\hline Total & 1.064 & 100,0 \\
\hline
\end{tabular}

Fonte: Dados da pesquisa (2015)

$\mathrm{Na}$ tabela 7, é possível observar que houve uma predominância de participantes na região Nordeste $(70,1 \%)$. Possivelmente esse elevado percentual deva-se ao fato de ser a região onde a pesquisadora teve um maior acesso junto 
aos coordenadores do curso de graduação em Ciência Contábeis, além do estabelecimento de parceria com o Conselho Regional de Contabilidade do Rio Grande do Norte na divulgação da pesquisa. A região com o segundo maior número de respondentes foi a Sudeste, com um total de 176 sujeitos respondentes (16,5\%).

Tabela 8 - Região versus Grau de Instrução

\begin{tabular}{|c|c|c|c|c|c|c|c|c|c|}
\hline & \multicolumn{6}{|c|}{ Instrução } & \multirow[b]{2}{*}{ Total } \\
\hline & & & Técnico & $\begin{array}{c}\text { Grad. } \\
\text { Completa }\end{array}$ & $\begin{array}{c}\text { Grad. } \\
\text { Incompleta }\end{array}$ & $\begin{array}{c}\text { Esp. } \\
\text { Completa }\end{array}$ & Mestrado & Doutorado & \\
\hline \multirow{10}{*}{ 通 } & \multirow{4}{*}{$\begin{array}{l}\begin{array}{l}\text { Centro- } \\
\text { oeste }\end{array} \\
\text { Nordeste }\end{array}$} & $\mathbf{N}$ & 0 & 10 & 10 & 9 & 13 & 8 & 50 \\
\hline & & $\%$ & 0,0 & 0,9 & 0,9 & 0,8 & 1,2 & 0,8 & 4,7 \\
\hline & & $\mathbf{N}$ & 2 & 175 & 389 & 113 & 53 & 13 & 745 \\
\hline & & $\%$ & 0,2 & 16,4 & 36,6 & 10,6 & 5,0 & 1,2 & 70,1 \\
\hline & \multirow[t]{2}{*}{ Norte } & $\mathbf{N}$ & 0 & 4 & 7 & 0 & 2 & 0 & 13 \\
\hline & & $\%$ & 0,0 & 0,4 & 0,7 & 0,0 & 0,2 & 0,0 & 1,2 \\
\hline & \multirow[t]{2}{*}{ Sudeste } & $\mathbf{N}$ & 1 & 43 & 81 & 25 & 19 & 7 & 176 \\
\hline & & $\%$ & 0,1 & 4,0 & 7,6 & 2,3 & 1,8 & 0,7 & 16,5 \\
\hline & \multirow[t]{2}{*}{ Sul } & $\mathbf{N}$ & 1 & 5 & 59 & 4 & 7 & 4 & 80 \\
\hline & & $\%$ & 0,1 & 0,5 & 5,5 & 0,4 & 0,7 & 0,4 & 7,5 \\
\hline \multirow[t]{2}{*}{ Total } & & $\mathbf{N}$ & 4 & 237 & 546 & 151 & 94 & 32 & 1.064 \\
\hline & & $\%$ & 0,4 & 22,3 & 51,3 & 14,2 & 8,8 & 3,0 & 100,0 \\
\hline
\end{tabular}

Fonte: Dados da pesquisa (2015)

Por meio da tabela 8, é possível verificar o cruzamento dos dados da Região onde o participante reside versus seu Grau de Instrução. Em todos os estados, existia uma maior proporção de respondentes com graduação incompleta, com exceção da região Centro-oeste, em que, dos 50 respondentes, 13 possuem título de mestre.

Tabela 9 - Distribuição dos respondentes por faixa etária

\begin{tabular}{l|r|r}
\hline Faixa etária & \multicolumn{1}{|c|}{ N } & \multicolumn{1}{c}{$\%$} \\
\hline Até 19 & 85 & 8,0 \\
\hline 20 a 29 & 602 & 56,5 \\
\hline 30 a 39 & 254 & 23,9 \\
\hline 40 a 49 & 86 & 8,1 \\
\hline 50 a 59 & 30 & 2,8 \\
\hline 60 acima & 7 & 0,7 \\
\hline Total & 1.064 & 100,0 \\
\hline
\end{tabular}

Fonte: Dados da pesquisa (2015)

A tabela 9 apresenta a distribuição de idade dos respondentes. De um total de 602 (56,5\%) tem entre 20 a 29 anos de idade, sendo 17 anos a idade mínima, 84 a máxima e 28,56 é a idade média dos sujeitos pesquisados. 
Tabela 10 - Experiência profissional versus Gênero

\begin{tabular}{|c|c|c|c|c|c|}
\hline & \multirow{3}{*}{\multicolumn{2}{|c|}{ 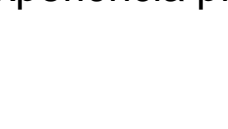 }} & \multirow{2}{*}{\multicolumn{2}{|c|}{ Gênero }} & \multirow{4}{*}{$\begin{array}{r}\text { Total } \\
661\end{array}$} \\
\hline & & & & & \\
\hline & & & Feminino & Masculino & \\
\hline \multirow{4}{*}{ 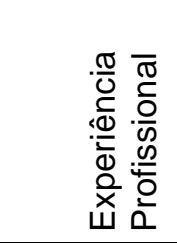 } & \multirow{2}{*}{$\frac{\varepsilon}{\omega}$} & $\mathbf{N}$ & 298 & 363 & \\
\hline & & $\%$ & 28,0 & 34,1 & 62,1 \\
\hline & \multirow{2}{*}{$\underset{2}{200}$} & $\mathbf{N}$ & 205 & 198 & 403 \\
\hline & & $\%$ & 19,3 & 18,6 & 37,9 \\
\hline \multirow{2}{*}{ Total } & & $\mathbf{N}$ & 503 & 561 & 1.064 \\
\hline & & $\%$ & 47,3 & 52,7 & 100,0 \\
\hline
\end{tabular}

Fonte: Dados da pesquisa (2015)

$\mathrm{Na}$ tabela 10 , é possível observar o cruzamento das variáveis experiência profissional e gênero. Da amostra pesquisada, 661 (62,1\%) possui experiência profissional na área contábil. Desses, 298 (28\%) é do gênero feminino e 363 (34,1\%) do masculino. Em contrapartida, $403(37,9 \%)$ não possui experiência na área pesquisada. Cabe frisar ainda que o estágio na área contábil foi considerado como experiência.

Tabela 11 - Distribuição dos respondentes por tempo de atuação profissional

\begin{tabular}{l|r|r}
\hline \multicolumn{1}{c|}{ Tempo de experiência } & $\mathbf{N}$ & \multicolumn{1}{c}{$\%$} \\
\hline Até 1 ano & 145 & 21,9 \\
\hline $1 \vdash 3$ & 146 & 22,1 \\
\hline $3 \vdash 5$ & 105 & 15,9 \\
\hline $5 \vdash 7$ & 104 & 15,7 \\
\hline$>7$ & 161 & 24,4 \\
\hline Total & 661 & 100,0 \\
\hline
\end{tabular}

Fonte: Dados da pesquisa (2015)

Quanto ao tempo de atuação profissional, conforme tabela 11, 145 (21,9\%) respondentes com experiência possuem até 1 ano; 146 (22,1\%) tem mais de um até três anos; 370 (56\%) possuem mais de três anos. Assim, é possível verificar um bom percentual de sujeitos com experiência profissional (mais de 62\%), sendo o tempo médio de profissão de aproximadamente dois anos, mínimo de menos de um e o máximo de 41 anos. 
Tabela 12 - Instituição de ensino

\begin{tabular}{l|r|r}
\hline UFRN & 268 & 44,5 \\
\hline UNIFACEX & 79 & 13,1 \\
\hline UFRGS & 47 & 7,8 \\
\hline UFV & 28 & 4,7 \\
\hline UFERSA & 24 & 4,0 \\
\hline USP & 18 & 3,0 \\
\hline UEPB & 14 & 2,3 \\
\hline UNI-RN & 13 & 2,2 \\
\hline UNIVATES & 13 & 2,2 \\
\hline UFPB & 9 & 1,5 \\
\hline FACECA & 8 & 1,3 \\
\hline UERJ & 7 & 1,2 \\
\hline UFAL & 6 & 1,0 \\
\hline UFRJ & 6 & 1,0 \\
\hline UnB & 6 & 1,0 \\
\hline UNIMEP & 6 & 1,0 \\
\hline CES-CL & 5 & 0,8 \\
\hline UFU & 5 & 0,8 \\
\hline UnB/UFPB/UFRN & 5 & 0,8 \\
\hline Outras & 35 & 5,8 \\
\hline Total & 602 & 100,0 \\
\hline Font:
\end{tabular}

Fonte: Dados da pesquisa (2015)

A tabela 12 mostra as instituições de ensino superior nas quais os participantes, ainda estudantes no período em que responderam o questionário, estão matriculados. Como era de se esperar, devido ao apoio dessas instituições a esta pesquisa, a Universidade Federal do Rio Grande do Norte apresenta uma maior quantidade de vínculos, 268 (44,5\%), seguida pela UNIFACEX, 79 (13,1\%), e Universidade Federal do Rio Grande do Sul, 47 (7,8\%).

Tabela 13 - Formação de nível superior, além de Ciências Contábeis

\begin{tabular}{l|c|c}
\hline Curso superior & $\mathbf{N}$ & $\%$ \\
\hline Administração & 39 & 26,7 \\
\hline Direito & 16 & 11,0 \\
\hline Engenharias & 16 & 11,0 \\
\hline Economia & 8 & 5,5 \\
\hline Pedagogia & 7 & 4,8 \\
\hline Matemática & 5 & 3,4 \\
\hline Ciências Econômicas & 4 & 2,7 \\
\hline Ciência da Computação & 3 & 2,1 \\
\hline Sistemas da Informação & 3 & 2,1 \\
\hline Outros & 45 & 30,7 \\
\hline
\end{tabular}

Fonte: Dados da pesquisa (2015) 
$\mathrm{Na}$ tabela 13, podem-se verificar as outras formações de nível superior dos sujeitos pesquisados, além de Ciências Contábeis. Do total de respondentes com outra formação, 39 (26,7\%) possuem graduação em Administração, 16 (11\%) em Direito, sendo esse mesmo percentual de engenharias, seguido por $8(5,5 \%)$ em Economia.

Tabela 14 - Distribuição da amostra válida por resposta aos itens do CRT

\begin{tabular}{|c|c|c|c|c|c|}
\hline \multicolumn{2}{|c|}{ Perguntas } & $\begin{array}{c}\text { Intuitiva } \\
\text { (R\$ 10) }\end{array}$ & $\begin{array}{c}\text { Reflexiva } \\
\text { (R\$ 5) }\end{array}$ & Outras & Total \\
\hline \multirow{2}{*}{ Questão 1 - CRT } & $\mathrm{N}$ & 562 & 450 & 52 & 1.064 \\
\hline & $\%$ & 52,8 & 42,3 & 4,9 & 100 \\
\hline \multicolumn{2}{|c|}{ Perguntas } & $\begin{array}{l}\text { Intuitiva } \\
\text { (100 min.) }\end{array}$ & $\begin{array}{c}\text { Reflexiva } \\
(5 \text { min.) }\end{array}$ & Outras & Total \\
\hline \multirow{2}{*}{ Questão 2 - CRT } & $\mathbf{N}$ & 485 & 376 & 203 & 1.064 \\
\hline & $\%$ & 45,6 & 35,3 & 19,1 & 100 \\
\hline \multicolumn{2}{|c|}{ Perguntas } & $\begin{array}{l}\text { Intuitiva } \\
\text { (50 dias) }\end{array}$ & $\begin{array}{l}\text { Reflexiva } \\
\text { (99 dias) }\end{array}$ & Outras & Total \\
\hline \multirow{2}{*}{ Questão 3 - CRT } & $\mathbf{N}$ & 498 & 444 & 122 & 1.064 \\
\hline & $\%$ & 46,8 & 41,7 & 11,5 & 100 \\
\hline
\end{tabular}

Fonte: Dados da pesquisa (2015)

A tabela 14 apresenta uma síntese dos resultados dos itens do CRT. Quanto ao primeiro item (taco e bola), é possível verificar que 562 (52,8\%) dos participantes responderam ao questionamento de maneira intuitiva, fazendo uso apenas do processamento do Tipo 1, e $450(42,3 \%)$ de maneira reflexiva, utilizando o processamento do Tipo 2. Em relação ao segundo item (máquinas e camisas), observa-se que houve uma redução total de respostas, tanto intuitivas (485), quanto reflexivas (376), aumentando, assim, a quantidade de outras respostas equivocadas $(19,1 \%)$. Já em relação ao terceiro item do CRT (grupo de vitória régia), os percentuais de respostas intuitivas $(46,8 \%)$, dos participantes, os quais se contentam com a primeira resposta que surge de forma espontânea em sua mente, e reflexiva $(41,7 \%)$, resistindo ao impulso inicial e refletindo de maneira mais aprofundada sobre a resposta correta, voltam a crescer. Se comparar esses resultados com os de Liberali (2012), é possível perceber que, para o primeiro item, o percentual de respostas, cujos respondentes fizeram uso do processamento do Tipo 2 é maior (30,9\%, Liberali, 2012); para o segundo item, é menor $(37,5 \%)$, porém próximo; e para o terceiro item, o percentual foi exatamente igual. 
Tabela 15 - Classificação dos respondentes quanto ao CRT

\begin{tabular}{l|r|r}
\hline \multicolumn{1}{c|}{ Classificação } & \multicolumn{1}{|c|}{ N } & \multicolumn{1}{c}{$\%$} \\
\hline $\mathrm{CRT}=0$ & 405 & 38,1 \\
\hline $\mathrm{CRT}=1$ e 2 & 452 & 42,5 \\
\hline $\mathrm{CRT}=3$ & 207 & 19,5 \\
\hline Total & 1064 & 100,0 \\
\hline
\end{tabular}

Fonte: Dados da pesquisa (2015)

A tabela 15 evidencia a classificação dos respondentes de acordo com 0 número de acerto no Cognitive Reflection Test. Do total da amostra válida (1.064), $405(38,1 \%)$ dos participantes demonstram uma baixa capacidade cognitiva, utilizando apenas processamento do Tipo 1 (intuitivo), 452 (42,5\%) uma média capacidade cognitiva e 207 (19,2\%) revela alta capacidade cognitiva, fazendo uso do processamento do Tipo 2 (reflexivo). Esses percentuais são próximos ao obtidos por Frederick (2005), em sua pesquisa, cujo percentual do CRT (alto e baixo) foi, respectivamente, $17 \%$ e $33 \%$. A média de acertos dos respondentes desta pesquisa foi de 1,81 questões; superior, portanto, à média das instituições analisadas na pesquisa de Frederick $(1,24)$.

Tabela 16 - Vieses cognitivos por classificação dos respondentes por grupo de CRT

\begin{tabular}{|c|c|c|c|c|}
\hline & CRT & $\mathbf{N}$ & Média & Desvio Padrão \\
\hline 0 & Viés 1 & 405 & 6,63 & 1,83 \\
\hline & Viés 2 & 405 & 6,80 & 1,90 \\
\hline & Viés 3 & 405 & 6,43 & 2,05 \\
\hline & Viés 4 & 405 & 3,23 & 3,33 \\
\hline & Viés 5 & 405 & 5,62 & 3,06 \\
\hline & Viés 6 & 405 & 5,43 & 1,99 \\
\hline 1 e 2 & Viés 1 & 452 & 6,25 & 2,22 \\
\hline & Viés 2 & 452 & 6.91 & 1,88 \\
\hline & Viés 3 & 452 & 6,35 & 2,40 \\
\hline & Viés 4 & 452 & 3,31 & 3,36 \\
\hline & Viés 5 & 452 & 5,49 & 3,17 \\
\hline & Viés 6 & 452 & 5,48 & 2,16 \\
\hline 3 & Viés 1 & 207 & 5,15 & 2,58 \\
\hline & Viés 2 & 207 & 7,01 & 1,78 \\
\hline & Viés 3 & 207 & 6,49 & 2,56 \\
\hline & Viés 4 & 207 & 2,46 & 3,30 \\
\hline & Viés 5 & 207 & 5,41 & 3,15 \\
\hline & Viés 6 & 207 & 5,59 & 2,30 \\
\hline
\end{tabular}

Fonte: Dados da pesquisa (2015)

Na tabela 16, é possível verificar a média e desvio padrão dos vieses cognitivos estudados (em que o viés 1 corresponde ao viés insensibilidade à taxa base; viés 2, insensibilidade à previsibilidade; viés 3, insensibilidade ao tamanho da amostra; viés 4, ilusão de validade; viés 5 , chance de equívocos e viés 6 , equívocos na regressão), separados por grupos de CRT. Como resultado interessante, tem-se 
que a média do grupo de indivíduos que não acertaram nenhuma questão do CRT é de 5,69, sendo maior que a do grupo que teve 1 ou 2 acertos $(5,63)$ e a do grupo com 3 acertos (5,35). Assim, sem a utilização de técnicas estatísticas mais avançadas, é possível confirmar a pressuposição inicial do estudo de que indivíduos com baixa capacidade cognitiva (os quais tomam decisão com base na intuição) são mais sensíveis aos vieses cognitivos do que aqueles com alta capacidade cognitiva, os quais fazem uso do processamento do Tipo 2 (mais reflexivo).

Tabela 17 - Classificação da sensibilidade dos respondentes aos vieses cognitivos

\begin{tabular}{l|r|r|r|r|r|r}
\cline { 2 - 7 } & \multicolumn{2}{c|}{ Insensível } & \multicolumn{2}{c|}{ Sensível } & \multicolumn{2}{c}{ Total } \\
\cline { 2 - 7 } & \multicolumn{1}{c|}{$\mathbf{N}$} & \multicolumn{1}{c|}{ \% } & \multicolumn{1}{c}{ N } & \multicolumn{1}{c}{$\mathbf{N}$} & $\%$ \\
\hline Insensibilidade à taxa base & 256 & 24,1 & 808 & 75,9 & 1.064 & 100 \\
\hline Insensibilidade à previsibilidade & 130 & 12,2 & 934 & 87,8 & 1.064 & 100 \\
\hline $\begin{array}{l}\text { Insensibilidade ao tamanho da } \\
\text { amostra }\end{array}$ & 217 & 20,4 & 847 & 79,6 & 1.064 & 100 \\
\hline $\begin{array}{l}\text { Ilusão de validade } \\
\text { Chance de equívocos }\end{array}$ & 156 & 14,7 & 908 & 85,3 & 1.064 & 100 \\
\hline Equívocos na regressão & 384 & 36,1 & 680 & 63,9 & 1.064 & 100 \\
\hline
\end{tabular}

Fonte: Dados da pesquisa (2015)

Para essa classificação da sensibilidade aos vieses cognitivos, foi calculada a média das variáveis de cada viés; em seguida identificada a sensibilidade do respondente. Se a média é menor que 5, o indivíduo é considerado insensível ao viés; se maior ou igual, é sensível, à exceção do viés 4, cujo ponto de ruptura foi zero, já que sua escala vai de -10 a 10. Assim, na tabela 17, é possível observar que a maioria dos sujeitos pesquisados é sensível aos seguintes vieses, por ordem crescente: insensibilidade à previsibilidade $(87,8 \%)$, ilusão de validade $(85,3 \%)$, insensibilidade ao tamanho da amostra (79,6\%), insensibilidade à taxa base (75,9\%), equívocos na regressão (66,5\%) e chance de equívocos $(63,9 \%)$.

Os contabilistas e estudantes de Ciências Contábeis, assim como qualquer outro indivíduo, podem estar sujeitos aos vieses cognitivos da heurística da representatividade. As evidências empíricas, conforme vistas no tópico 2.6 deste trabalho, mostram que os indivíduos são sensíveis aos vieses cognitivos no 
processo de julgamento e tomada de decisão. Na Contabilidade, as decisões tomadas pelos contabilistas geram informações que influenciam na tomada de decisão de diversos usuários, haja vista esse ser seu objetivo principal.

Para alcançar o respectivo objetivo, a Contabilidade vem sofrendo mudanças, em nível global, no intuito de acompanhar a expansão dos mercados e dirimir a complexidade no reconhecimento, mensuração e evidenciação dos eventos econômicos, aumentando a relevância, a fidedignidade, a confiabilidade, a comparabilidade e a transparência da informação. Nesse processo de mudança, as medidas subjetivas e o julgamento do profissional contábil são inseridos na preparação das informações para atender melhor as necessidades de seus mais variados usuários. É nesse ponto que surge a importância de se estudar os vieses cognitivos incidentes no processo de julgamento e, consequentemente, na tomada de decisão. Como resultado, pode-se ver, na tabela 18, que a maioria dos respondentes, estudantes de graduação em Ciências Contábeis e Contabilistas, são sensíveis aos vieses estudados. Esse saber é importante, porque, só assim, é possível tentar minimizar as falhas cognitivas. Sendo conhecidos os vieses, os erros gerados por eles (como a distorções na percepção, imprecisão, falta de lógica ou má interpretação no julgamento), podem, possivelmente, ser corrigidos.

\subsection{ANÁLISE DAS HIPÓTESES DE PESQUISA}

A primeira técnica utilizada para a análise dos dados foi a Análise de correspondência múltipla, a qual vai permitir evidenciar a associação entre as variáveis categóricas: a classificação do CRT (em três grupos 0, 1-2, 3) e a classificação dos vieses cognitivos (alto, médio e baixo).

Tabela 18 - Análise de Correspondência para a influência do CRT sobre os vieses

\begin{tabular}{l|r|r|r}
\hline \multicolumn{1}{c|}{ Dimensão } & Valor Singular & \multicolumn{1}{c}{ Inércia } & \% de Inércia \\
\hline 1 & 1,989 & 0,284 & 28,4 \\
\hline 2 & 1,554 & 0,222 & 22,2 \\
\hline Total & 3,543 & 0,506 & 50,6 \\
\hline
\end{tabular}

Fonte: Dados da pesquisa

$\mathrm{Na}$ tabela 18, pode-se perceber que o CRT e os Vieses (classificados em baixo, médio e alto) podem ser explicados por duas dimensões (1 e 2), com 50,6\% 
da inércia. Esse resultado depende, fundamentalmente, do grau de associação entre as categorias.

Figura 8 - Mapa perceptual da Análise de Correspondência Múltipla para o CRT e os vieses da representatividade

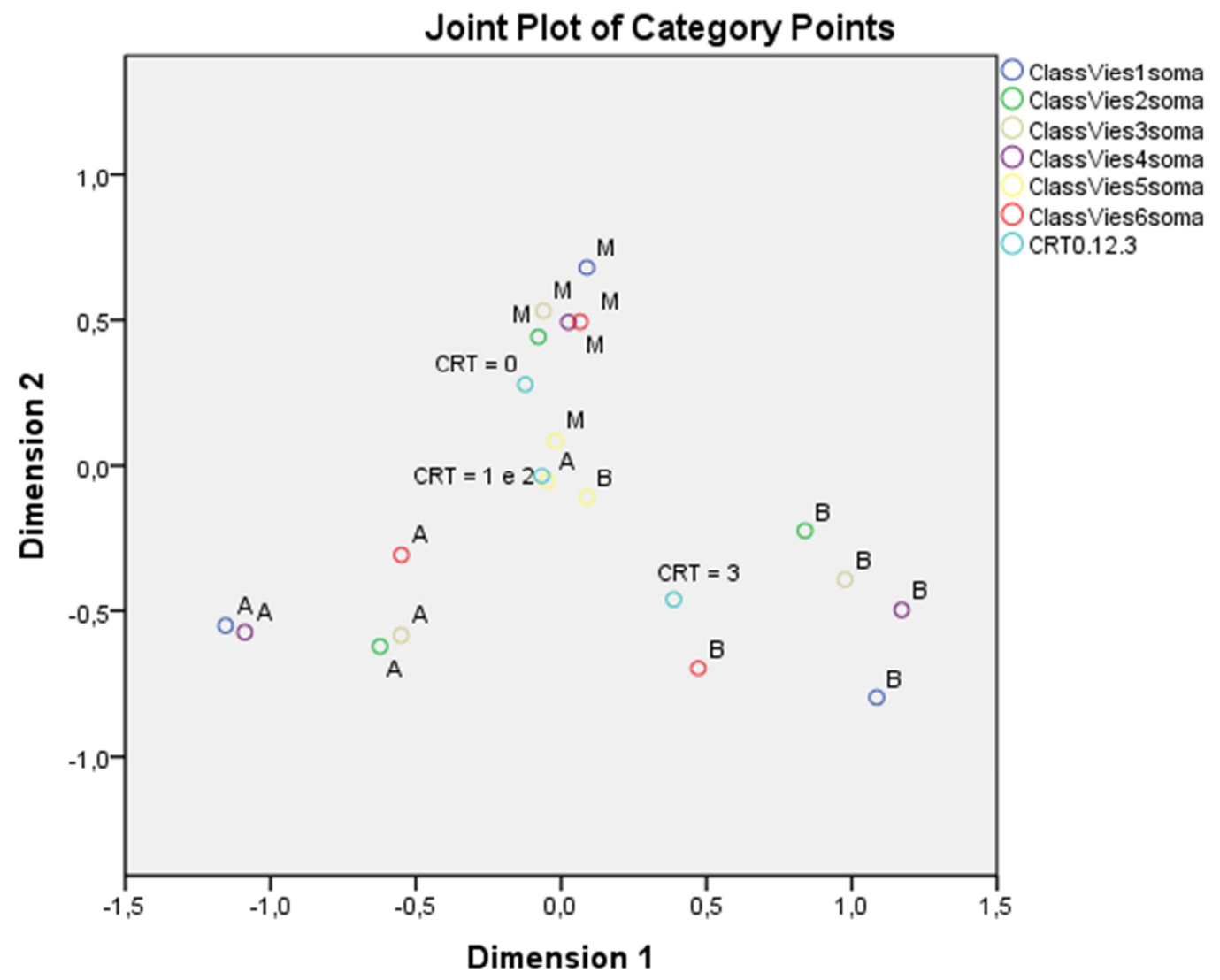

Variable Principal Normalization.

Fonte: Dados da pesquisa

A figura 8 mostra o mapa perceptual de todas as variáveis categóricas analisadas, com a representação visual de percepções que um respondente tem sobre todos os seis vieses cognitivos estudados e o CRT (separado pelas quantidades de acertos nas três questões: $C R T=0, C R T=1$ e 2, CRT=3) em duas dimensões. A legenda dos vieses refere-se à classificação, conforme tabela 17. Dessa forma, ClassVies1soma significa classificação da soma das variáveis remanescentes do viés insensibilidade à taxa base por quartis (baixo, médio e alto) e, assim, sucessivamente para os vieses insensibilidade à previsibilidade, insensibilidade ao tamanho da amostra, ilusão da validade, chance de equívocos e equívocos na regressão. Sob essa perspectiva, é possível observar, pela posição espacial, a forte relação existente entre os respondentes com alto valor no CRT e a 
baixa incidência de todos os vieses cognitivos estudados. Em contrapartida, as outras relações não estão claramente evidenciadas.

\subsubsection{Hipótese 1}

A Hipótese 1 busca verificar se a incidência de vieses cognitivos gerados pela heurística da representatividade é influenciada pela capacidade cognitiva dos indivíduos pesquisados. Para verificar a diferença entre as médias nos grupos classificados, conforme número de acertos no CRT: alta capacidade cognitiva (CRT=3 acertos), média capacidade cognitiva (CRT=1 ou 2 acertos), baixa capacidade cognitiva $(\mathrm{CRT}=0)$, será usado o ANOVA, em que a hipótese nula testada é a igualdade de médias da variável dependente ao longo do grupo. No caso de existir heterocedasticidade nas variâncias, serão usados os testes de Welsh e Brown-Forsythe, conforme tabela 19. Como se possui uma grande amostra, pode-se aceitar a normalidade das médias amostrais, pelo Teorema Central do Limite.

Tabela 19 - Comparação dos vieses cognitivos estudados, nos grupos alta, média e baixa capacidade cognitiva

\begin{tabular}{|c|c|c|c|c|c|}
\hline & & Média & $\begin{array}{l}\text { Desvio } \\
\text { Padrão }\end{array}$ & ANOVA & $\begin{array}{l}\text { Welch/ } \\
\text { Brown- } \\
\text { Forsythe }\end{array}$ \\
\hline \multirow{4}{*}{$\begin{array}{l}\text { Insensibilidade à taxa } \\
\text { base }\end{array}$} & $\mathrm{CRT}=0$ & 6,63 & 1,83 & - & \multirow{4}{*}{$\begin{array}{l}<0,001 / \\
<0,001\end{array}$} \\
\hline & $\mathrm{CRT}=1 \mathrm{e} 2$ & 6,25 & 2,22 & & \\
\hline & $\mathrm{CRT}=3$ & 5,15 & 2,58 & & \\
\hline & Total & 6,18 & 2,22 & & \\
\hline \multirow{4}{*}{$\begin{array}{l}\text { Insensibilidade à } \\
\text { previsibilidade }\end{array}$} & $\mathrm{CRT}=0$ & 6,80 & 1,90 & \multirow{4}{*}{0,390} & \multirow{8}{*}{$\begin{array}{l}0,777 \\
0,764\end{array}$} \\
\hline & $\mathrm{CRT}=1$ e 2 & 6,91 & 1,88 & & \\
\hline & $\mathrm{CRT}=3$ & 7,01 & 1,78 & & \\
\hline & Total & 6,89 & 1,87 & & \\
\hline \multirow{4}{*}{$\begin{array}{l}\text { Insensibilidade ao } \\
\text { tamanho da amostra }\end{array}$} & $\mathrm{CRT}=0$ & 6,43 & 2,05 & \multirow{4}{*}{ - } & \\
\hline & $\mathrm{CRT}=1$ e 2 & 6,35 & 2,40 & & \\
\hline & $\mathrm{CRT}=3$ & 6,49 & 2,56 & & \\
\hline & Total & 6,40 & 2,31 & & \\
\hline \multirow{4}{*}{ llusão de validade } & $\mathrm{CRT}=0$ & 3,23 & 3,33 & \multirow{4}{*}{0,006} & \\
\hline & $\mathrm{CRT}=1 \mathrm{e} 2$ & 3,31 & 3,36 & & \\
\hline & $\mathrm{CRT}=3$ & 2,46 & 3,30 & & \\
\hline & Total & 3,11 & 3,35 & & \\
\hline \multirow{4}{*}{ Chance de equívocos } & $\mathrm{CRT}=0$ & 5,62 & 3,06 & \multirow{4}{*}{0,686} & \\
\hline & $\mathrm{CRT}=1$ e 2 & 5,49 & 3,17 & & \\
\hline & $\mathrm{CRT}=3$ & 5,41 & 3,15 & & \\
\hline & Total & 5,52 & 3,12 & & \\
\hline \multirow{4}{*}{$\begin{array}{l}\text { Equívocos na } \\
\text { regressão }\end{array}$} & $\mathrm{CRT}=0$ & 5,43 & 1,99 & \multirow{4}{*}{0,704} & \\
\hline & $\mathrm{CRT}=1$ e 2 & 5,48 & 2,16 & & \\
\hline & CRT = 3 & 5,59 & 2,30 & & \\
\hline & Total & 5,48 & 2,13 & & \\
\hline
\end{tabular}

Fonte: Dados da pesquisa 
O viés insensibilidade à taxa base apresentou as médias 6,63, 6,25 e 5,15, nos grupos com CRT=0,1-2, 3, respectivamente. A constatação é a de que quanto menor a capacidade, maior a sensibilidade dos respondentes ao viés, negligenciam a taxa base e direcionam sua atenção para outras informações, corroborando o referencial teórico. Assim, quando os dados necessários para o julgamento e tomada de decisão possuir alguma descrição, os contabilistas precisam ficar mais atentos para não ignorar a taxa base. Ao realizar o teste de homogeneidade das variâncias, através da estatística de Levene, observou-se a ocorrência de heterocedasticidade ( $p$-valor $<0,0001)$. Para isso, foram usados os testes de Welsh e Brown-Forsythe, os quais revelam que existe diferença significante estatisticamente entre as médias.

Outro viés que apresentou diferença significativa estatisticamente entre as médias nos 3 grupos do CRT foi ilusão de validade, como pode ser visto na tabela 19, em que o grupo CRT = 3 tem média 2,46, CRT= 1 e 2 possui média igual 3,31 e $\mathrm{CRT}=0$, a média é 3,23. O teste prévio de homocedasticidade de Levene (p-valor = 0,279) confirmou variâncias iguais nos três grupos; então, pôde-se usar o ANOVA, que indicou diferença estatística significante entre as médias ( $p$-valor =0,006).

Esse resultado comprova que muitas pessoas disseminam informações sem verificar a sua validade. Dessa forma, ao utilizar informações para fazer julgamento e tomar decisões, é necessário verificar o rigor de seu conteúdo, mesmo que esse nos pareça verídico.

O viés chance de equívocos (assim como os vieses insensibilidade à taxa base e ilusão da validade) apresentou uma média menor nos grupos de respondentes, com 3 acertos no CRT, e maiores médias nos grupos com 1 e 2 acertos $(5,49)$ e nenhum acerto $(5,62)$. Não obstante, vale ressalvar que essa diferença não é significativa estatisticamente pelo ANOVA.

Nos demais vieses, insensibilidade à previsibilidade, insensibilidade ao tamanho da amostra e equívocos na regressão, não foi encontrada a relação inversa entre a incidência de vieses cognitivos e grupos do CRT, corroborando estudos como o de West; Meserve; Stanovich (2012), Stanavich (2009) e Barrouillet (2011), conforme visto no referencial teórico, os quais evidenciam que nem sempre a correlação negativa entre a inteligência e os vieses existe, pois indivíduos inteligentes podem agir inconscientemente, por terem falsas crenças, ausência ou contaminação de aparato mental. 
O teste de Tukey foi usado para mostrar a separação das médias obtidas nos vieses insensibilidade à taxa base e ilusão de validade por grupos de CRT. Nos demais vieses, não se registrou a separação de médias em diferentes grupos.

Tabela 20 - Teste de Tukey para os vieses insensibilidade à taxa base e ilusão de validade por CRT

\begin{tabular}{l|l|l|l}
\hline Grupos do CRT - Insensibilidade à taxa base & $\mathbf{N}$ & $\mathbf{1}$ & $\mathbf{2}$ \\
\hline CRT $=3$ & 207 & 5,15 & \\
\hline CRT $=1$ e 2 & 452 & & 6,25 \\
\hline CRT $=0$ & 405 & & 6,63 \\
\hline Grupos do CRT - Ilusão de validade & $\mathbf{N}$ & $\mathbf{1}$ & $\mathbf{2}$ \\
\hline CRT $=3$ & 207 & 2,46 & \\
\hline CRT $=0$ & 405 & & 3,23 \\
\hline CRT $=1$ e 2 & 452 & & 3,31 \\
\hline
\end{tabular}

Fonte: Dados da pesquisa

A tabela 20 confirma os resultados mostrados na tabela 19 para o viés insensibilidade à taxa base e ilusão de validade. Os respondentes com alta capacidade cognitiva apresentam menor média $(5,15)$ no viés insensibilidade à previsibilidade; assim, são classificados em um grupo separado dos participantes com média capacidade cognitiva, média $(6,25)$, e baixa capacidade cognitiva $(6,63)$. A partir disso, pode-se concluir que quanto maior o viés médio, maior a probabilidade de um indivíduo compor o grupo com um menor CRT ou vice-versa, pela diferença estatística significante entre suas médias. Para o viés ilusão de validade, os resultados são semelhantes: respondentes com CRT $=3$ registram menor média $(2,46)$, sendo agrupados, pelo teste de Tukey, em um grupo separado dos participantes com CRT $=0(3,23)$ e 1-2 $(3,31)$.

\subsubsection{Hipótese 2}

A hipótese 2 foi formulada para verificar se existe diferença estatística entre as variáveis grau de dificuldade dos respondentes nos três itens do CRT e a sua percepção quanto à forma de julgamento e tomada de decisão com a capacidade cognitiva. O teste ANOVA também foi usado para verificar a diferença entre as médias nos grupos classificados, conforme número de acertos no CRT, e o grau de dificuldade dos respondentes para os três itens do teste (Q4.1); o número de acertos no CRT e a forma como os participantes consideram seu julgamento e tomada de decisão, baseando-se na razão ou intuição (Q30). O teste de homogeneidade de 
variância de Levene confirmou variâncias iguais nos três grupos de CRT, tanto para o grau de dificuldade dos respondentes para os três itens teste do CRT (p-valor= 0,071) quanto para a forma como os participantes consideram seu julgamento e tomada de decisão ( $p$-valor=0,720).

Tabela 21 - Comparação de grau de dificuldade e de como considera seu julgamento e tomada de decisão por classificação do CRT

\begin{tabular}{c|l|c|c|c}
\hline Variável & \multicolumn{1}{c|}{ CRT } & Média & DP & ANOVA \\
\hline \multirow{2}{*}{ Q4.1 } & CRT $=3$ & 4,41 & 2,75 & \multirow{2}{*}{$<0,001$} \\
\cline { 2 - 4 } & CRT $=1$ e 2 & 5,29 & 2,61 & \\
\cline { 2 - 4 } & CRT $=0$ & 4,70 & 2,71 & \\
\hline \multirow{2}{*}{ Q30 } & CRT $=3$ & 5,24 & 2,65 & $<0,001$ \\
\cline { 2 - 4 } & CRT $=1$ e 2 & 4,52 & 2,62 & \\
\cline { 2 - 4 } & CRT $=0$ & 4,13 & 2,55 & \\
\hline
\end{tabular}

Fonte: Dados da pesquisa

Tanto o grau de dificuldade dos respondentes para os três itens do teste CRT (Q4.1) quanto a forma como esses participantes consideram seu julgamento e tomada de decisão, baseados na razão ou intuição (Q30), comparados com números de acertos no CRT, apresentaram diferenças significantes estatisticamente entre suas médias ( $p$-valor <0,0001 para ambas as relações). Conforme tabela 21 , na questão 4.1, os respondentes que não acertaram nenhum item ou acertaram 1 ou 2 itens no CRT obtiveram médias superiores (4,70 e 5,29, respectivamente) a dos que acertaram os 3 itens do CRT $(4,41)$. Porém, é possível verificar que a média dos participantes com CRT $=0(4,70)$ é bem próxima à do $\mathrm{CRT}=3(4,41)$, indicando que aqueles consideram os itens tão fáceis quanto esses (tabela 22 mostra a igualdade das médias dos dois grupos).

Esses resultados da dificuldade em relação ao número de acertos no CRT diferem um pouco dos obtidos por Frederick (2005), conforme item 2.3 do referencial teórico, em que se verificou que os indivíduos com menores pontuações no CRT consideraram o teste mais fácil, por fornecer a primeira resposta que veio à mente, fazendo uso apenas do processamento do Tipo 1, do que aquelas com maiores pontuações no CRT, os quais usaram processamento do Tipo 2 (processamento lento) consciente e reflexivo.

Quanto à percepção dos respondentes sobre a forma como julgam e tomam decisões, se baseados na intuição ou na razão, comparados à pontuação no CRT, pode-se observar que os participantes com $C R T=3$, forneceram uma maior média, ou seja, consideraram seu o julgamento e tomada de decisões mais baseados na 
razão do que os com menor pontuação $(0,1$ e 2$)$, os quais sugerem o maior uso da intuição.

Tabela 22 - Teste de Tukey para grau de dificuldade e forma de julgamento e tomada de decisão na opinião dos respondentes por CRT

\begin{tabular}{l|c|c|c}
\hline $\mathbf{Q 4}$ & $\mathbf{N}$ & $\mathbf{1}$ & $\mathbf{2}$ \\
\hline $\mathrm{CRT}=0$ & 405 & 4,41 & \\
\hline $\mathrm{CRT}=3$ & 207 & 4,70 & \\
\hline $\mathrm{CRT}=1$ e 2 & 452 & & 5,29 \\
\hline $\mathbf{Q} 30$ & $\mathbf{N}$ & $\mathbf{1}$ & $\mathbf{2}$ \\
\hline $\mathrm{CRT}=3$ & 207 & 4,13 & \\
\hline $\mathrm{CRT}=1$ e 2 & 405 & 4,52 & \\
\hline $\mathrm{CRT}=0$ & 452 & & 5,24 \\
\hline
\end{tabular}

Fonte: Dados da pesquisa

Através do teste de Tukey, é possível observar, na tabela 22, a separação das médias obtidas para o grau de dificuldade e forma de julgamento e a tomada de decisão na opinião dos respondentes, em grupos 1 e 2, corroborando os resultados da tabela 22. Em relação à opinião dos participantes da pesquisa sobre a forma como realizam seus julgamentos e tomada de decisão, baseando-se na razão ou intuição, comparados com o teste do CRT, com classificação em três grupos, verifica-se, por meio da tabela 23, que quanto maior o número de questões acertadas no CRT, menor a média, significando que julgamentos e tomada de decisão são mais baseados na razão, ou seja, no uso do processamento do tipo 2; e quanto menor a quantidade de acertos, maior a média, sendo o julgamento e tomada de decisão mais baseados na intuição. Esse resultado está em concordância com a figura 3 e quadro 1, do referencial teórico.

Para averiguar a diferença de médias entre o grau de instrução, região onde residem e os vieses cognitivos também foi utilizado o teste ANOVA, Welsh ou Brown-Forsythe. Enquanto que para verificar a diferença nos vieses pelo gênero do respondente foi utilizado o teste $t$.

\subsubsection{Hipótese 3}

A Hipótese 3 foi formulada para identificar se existe diferença entre o impacto dos sexos feminino e masculino, da região onde reside (Centro-oeste, Nordeste, Norte, Sudeste e Sul) e grau de instrução (técnico, graduação completa e incompleta, especialização, mestrado e doutorado). O teste ANOVA foi utilizado para 
verificar a diferença entre as médias nos grupos classificados por região e grau de instrução. Para avaliar as diferenças entre médias dos vieses cognitivos com o gênero dos respondentes, foi utilizado o Teste $t$.

Tabela 23 - Comparação dos vieses cognitivos estudados por grau de instrução

\begin{tabular}{|c|c|c|c|c|}
\hline & & Média & ANOVA & $\begin{array}{l}\text { Welch/ } \\
\text { Brown-Forsythe }\end{array}$ \\
\hline \multirow{6}{*}{ Insensibilidade à taxa base } & Técnico & 7,85 & & \multirow{6}{*}{$\begin{array}{l}<0,001 / \\
<0,001\end{array}$} \\
\hline & Grad. Completa & 6,40 & & \\
\hline & Grad. Incompleta & 6,38 & & \\
\hline & Esp. Completa & 5,99 & & \\
\hline & Mestrado & 5,19 & & \\
\hline & Doutorado & 4,66 & & \\
\hline \multirow{6}{*}{$\begin{array}{l}\text { Insensibilidade à } \\
\text { previsibilidade }\end{array}$} & Técnico & 7,40 & \multirow{6}{*}{0,377} & \\
\hline & Grad. Completa & 6,95 & & \\
\hline & Grad. Incompleta & 6,95 & & \\
\hline & Esp. Completa & 6,61 & & \\
\hline & \begin{tabular}{|l|} 
Mestrado \\
\end{tabular} & 6,75 & & \\
\hline & Doutorado & 7,03 & & \\
\hline \multirow{6}{*}{$\begin{array}{l}\text { Insensibilidade ao tamanho } \\
\text { da amostra }\end{array}$} & Técnico & 4,28 & \multirow{6}{*}{0,043} & \\
\hline & Grad. Completa & 6,47 & & \\
\hline & Grad. Incompleta & 6,43 & & \\
\hline & Esp. Completa & 6,19 & & \\
\hline & Mestrado & 6,20 & & \\
\hline & Doutorado & 7,38 & & \\
\hline \multirow{6}{*}{ llusão de validade } & Técnico & 5,90 & \multirow{6}{*}{0,170} & \\
\hline & Grad. Completa & 3,50 & & \\
\hline & Grad. Incompleta & 3,01 & & \\
\hline & Esp. Completa & 2,88 & & \\
\hline & Mestrado & 3,16 & & \\
\hline & \begin{tabular}{|l|} 
Doutorado \\
\end{tabular} & 2,63 & & \\
\hline \multirow{6}{*}{ Chance de equívocos } & Técnico & 3,90 & \multirow{6}{*}{0,767} & \\
\hline & Grad. Completa & 5,48 & & \\
\hline & Grad. Incompleta & 5,60 & & \\
\hline & Esp. Completa & 5,56 & & \\
\hline & Mestrado & 5,23 & & \\
\hline & Doutorado & 5,27 & & \\
\hline \multirow{6}{*}{ Equívocos na regressão } & Técnico & 6,78 & \multirow{6}{*}{0,277} & \\
\hline & Grad. Completa & 5,43 & & \\
\hline & Grad. Incompleta & 5,45 & & \\
\hline & Esp. Completa & 5,45 & & \\
\hline & Mestrado & 5,92 & & \\
\hline & Doutorado & 5,20 & & \\
\hline
\end{tabular}

Fonte: Dados da pesquisa

O viés insensibilidade à taxa base, conforme tabela 24, apresentou, para o grau de instrução técnico, graduação completa, graduação incompleta, especialização completa, mestrado e doutorado, as seguintes médias, respectivamente: $7,85,6,40,6,38,5,99,5,19$ e 4,66. Resultado que evidencia que quanto maior o nível de escolaridade, menor a incidência do viés insensibilidade à 
taxa base. Através da estatística de Levene, realizou-se o teste de homogeneidade das variâncias, em que se observou a presença de heterocedasticidade ( $p$-valor $<0,0001$ ), não sendo possível a utilização do ANOVA. Por essa razão, foram utilizados os testes de Welsh e Brown-Forsythe, os quais apresentaram a existência de diferença estatística significante entre as médias dos vieses.

Como se pode ver, na tabela 23, o viés insensibilidade ao tamanho da amostra também apresentou diferença significativa, estatisticamente, entre os diferentes graus de instrução, por meio do teste ANOVA. Porém o resultado difere do viés insensibilidade à taxa base, pois mostra que respondentes com doutorado são mais sensíveis à incidência do viés insensibilidade ao tamanho da amostra do que aqueles com outros níveis de instrução. Pelo ANOVA, os demais vieses não apresentaram diferença estática significante entre suas médias por diferentes graus de instrução.

Os resultados revelam que o aumento da instrução, não necessariamente, diminui à sensibilidade dos indivíduos aos vieses cognitivos estudados.

Para mostrar em que graus de instrução as médias dos vieses insensibilidade à taxa base e insensibilidade ao tamanho da amostra foram realmente diferentes, foi aplicado o teste de Tukey. Vale esclarecer ainda que o viés chance de equívoco também apresentou diferença em relação ao nível de escolaridade.

Tabela 24 - Teste de Tukey para os vieses insensibilidade à taxa base, insensibilidade ao tamanho da amostra e chance de equívoco por grau de instrução

\begin{tabular}{l|r|r|r}
\hline Insensibilidade à taxa base & $\mathbf{N}$ & $\mathbf{1}$ & \multicolumn{1}{|c}{$\mathbf{2}$} \\
\hline Doutorado & 32 & 4,66 & \\
\hline Mestrado & 94 & 5,19 & \\
\hline Esp. Completa & 151 & 5,99 & 5,99 \\
\hline Grad. Incompleta & 546 & 6,38 & 6,38 \\
\hline Grad. Completa & 237 & 6,40 & 6,40 \\
\hline Técnico & 4 & & 7,85 \\
\hline Insensibilidade ao tamanho da amostra & $\mathbf{N}$ & $\mathbf{1}$ & $\mathbf{2}$ \\
\hline Técnico & 4 & 4,28 & \\
\hline Esp. Completa & 151 & 6,19 & 6,19 \\
\hline Mestrado & 94 & 6,20 & 6,20 \\
\hline Grad. Incompleta & 546 & & 6,43 \\
\hline Grad. Completa & 237 & & 6,47 \\
\hline Doutorado & 32 & & 7,38 \\
\hline Chance de equívoco & $\mathbf{N}$ & $\mathbf{1}$ & $\mathbf{2}$ \\
\hline Doutorado & 32 & 2,63 & \\
\hline Esp. Completa & 151 & 2,88 & 2,88 \\
\hline Grad. Incompleta & 546 & 3,01 & 3,01 \\
\hline Mestrado & 94 & 3,16 & 3,16 \\
\hline Grad. Completa & 237 & 3,50 & 3,50 \\
\hline Técnico & 4 & & 5,90 \\
\hline Fonte: Dados psqusa
\end{tabular}

Fonte: Dados da pesquisa 
Com base na tabela 24, é possível observar que, para o viés insensibilidade à taxa base, o teste de Tukey conclui que as médias dos respondentes com mestrado e doutorado são, estatisticamente, diferentes dos que só possuem curso técnico em contabilidade. Quanto ao viés insensibilidade ao tamanho da amostra, constatou-se que existe diferença estatística entre os participantes com técnico e aqueles com graduação incompleta, completa e com doutorado. Já em relação ao viés chance de equívoco, o método da diferença honestamente significante, de Tukey, encontra diferença estatística entre indivíduos com doutorado e curso técnico. Esperava-se, nesta pesquisa, que quanto maior fosse o grau de instrução menor seria a ocorrência dos vieses cognitivos no julgamento e tomada de decisão, supondo que, quanto mais instruído, mais o indivíduo fizesse uso do processamento do tipo 2 , sendo menos sensível aos vieses cognitivos; porém, essa situação só foi encontrada nos extremos dos vieses insensibilidade à taxa base e chance de equívoco.

Tabela 25 - Comparação dos vieses cognitivos estudados por região

\begin{tabular}{|c|c|c|c|c|}
\hline & & $\mathbf{N}$ & Média & ANOVA \\
\hline \multirow{5}{*}{$\begin{array}{l}\text { Insensibilidade à taxa } \\
\text { base }\end{array}$} & Centro-oeste & 50 & 5,27 & \multirow{5}{*}{$<0,0001$} \\
\hline & Nordeste & 745 & 6,43 & \\
\hline & Norte & 13 & 6,75 & \\
\hline & Sudeste & 176 & 5,80 & \\
\hline & Sul & 80 & 5,14 & \\
\hline \multirow{5}{*}{$\begin{array}{l}\text { Insensibilidade à } \\
\text { previsibilidade }\end{array}$} & Centro-oeste & 50 & 6,55 & \multirow{5}{*}{0,218} \\
\hline & Nordeste & 745 & 6,96 & \\
\hline & Norte & 13 & 7,35 & \\
\hline & Sudeste & 176 & 6,79 & \\
\hline & Sul & 80 & 6,61 & \\
\hline \multirow{5}{*}{$\begin{array}{l}\text { Insensibilidade ao } \\
\text { tamanho da amostra }\end{array}$} & Centro-oeste & 50 & 6,24 & \multirow{5}{*}{0,472} \\
\hline & Nordeste & 745 & 6,49 & \\
\hline & Norte & 13 & 5,97 & \\
\hline & Sudeste & 176 & 6,21 & \\
\hline & Sul & 80 & 6,22 & \\
\hline \multirow{5}{*}{ llusão de validade } & Centro-oeste & 50 & 2,31 & \multirow{5}{*}{0,006} \\
\hline & Nordeste & 745 & 3,33 & \\
\hline & Norte & 13 & 3,55 & \\
\hline & Sudeste & 176 & 2,82 & \\
\hline & Sul & 80 & 2,15 & \\
\hline \multirow{5}{*}{ Chance de equívocos } & Centro-oeste & 50 & 5,24 & \multirow{5}{*}{0,349} \\
\hline & Nordeste & 745 & 5,61 & \\
\hline & Norte & 13 & 6,21 & \\
\hline & Sudeste & 176 & 5,46 & \\
\hline & Sul & 80 & 4,94 & \\
\hline \multirow{5}{*}{ Equívocos na regressão } & Centro-oeste & 50 & 5,91 & \multirow{5}{*}{0,257} \\
\hline & Nordeste & 745 & 5,42 & \\
\hline & Norte & 13 & 6,18 & \\
\hline & Sudeste & 176 & 5,45 & \\
\hline & Sul & 80 & 5,74 & \\
\hline
\end{tabular}

Fonte: Dados da pesquisa 
Pelo teste da homogeneidade das variâncias de Levene, não se rejeitou a hipótese de homocedasticidade entre as variáveis; assim, para averiguar as diferenças de médias dos vieses por região, foi usado o ANOVA, por meio do qual se encontrou diferenças estatisticamente significantes entre as regiões nos vieses insensibilidade à taxa base e ilusão de validade, com significância menor que 0,001 e igual a 0,006 para o teste $F$, respectivamente. Esse resultado revela que a localidade geográfica, muitas vezes utilizada como proxy para cultura, influência na sensibilidade dos sujeitos investigados quantos a esses vieses.

Tabela 26 - Teste de Tukey para os vieses insensibilidade à taxa base por região

\begin{tabular}{l|r|r|r|r}
\hline Insensibilidade à taxa base & N & \multicolumn{1}{|c|}{$\mathbf{1}$} & \multicolumn{1}{|c|}{$\mathbf{2}$} & \multicolumn{1}{c}{$\mathbf{3}$} \\
\hline Sul & 80 & 5,14 & & \\
\hline Centro-oeste & 50 & 5,27 & 5,27 & \\
\hline Sudeste & 176 & 5,80 & 5,80 & 5,80 \\
\hline Nordeste & 745 & & 6,43 & 6,43 \\
\hline Norte & 13 & & & 6,75 \\
\hline
\end{tabular}

Fonte: Dados da pesquisa

De acordo com a tabela 26, o teste de Tukey complementa o teste ANOVA, identificando 3 grupos para o viés insensibilidade à taxa base por região. Numa comparação do primeiro grupo com o segundo, verifica-se a diferença estatística de forma significante entre as médias da região Sul $(5,14)$ e Nordeste $(6,43)$. Também se observa diferença significativa entre a região Centro-oeste $(5,27)$ e Norte $(6,75)$, além da diferença entre a região Sul (grupo 1) e Norte (grupo 3).

Tabela 27 - Comparação dos vieses cognitivos estudados por gênero

\begin{tabular}{|c|c|c|c|c|}
\hline & & $\mathbf{N}$ & Média & Teste $t$ \\
\hline \multirow{2}{*}{ Insensibilidade à taxa base } & Feminino & 503 & 6,39 & \multirow{2}{*}{0,003} \\
\hline & Masculino & 561 & 5,99 & \\
\hline \multirow{2}{*}{ Insensibilidade à previsibilidade } & Feminino & 503 & 6,90 & \multirow{2}{*}{0,825} \\
\hline & Masculino & 561 & 6,88 & \\
\hline \multirow{2}{*}{ Insensibilidade ao tamanho da amostra } & Feminino & 503 & 6,24 & \multirow{2}{*}{0,031} \\
\hline & Masculino & 561 & 6,55 & \\
\hline \multirow{2}{*}{ llusão de validade } & Feminino & 503 & 2,88 & \multirow{2}{*}{0,028} \\
\hline & Masculino & 561 & 3,33 & \\
\hline \multirow{2}{*}{ Chance de equívocos } & Feminino & 503 & 5,72 & \multirow{2}{*}{0,049} \\
\hline & Masculino & 561 & 5,34 & \\
\hline \multirow{2}{*}{ Equívocos na regressão } & Feminino & 503 & 5,33 & \multirow{2}{*}{0,032} \\
\hline & Masculino & 561 & 5,61 & \\
\hline
\end{tabular}

Fonte: Dados da pesquisa

Em relação ao gênero, conforme tabela 27, quase todos os vieses estudados, com exceção do viés insensibilidade à previsibilidade, revelam diferença de médias. 
Porém não há um padrão justificativo para o fato de que as mulheres participantes da pesquisa são mais sensíveis aos vieses da representatividade do que os homens.

Nos vieses insensibilidade à taxa base e chance de equívocos, os respondentes do gênero feminino detêm uma maior média; já os respondentes do gênero masculino são mais sensíveis aos vieses insensibilidade ao tamanho da amostra, ilusão de validade e equívocos na regressão. Os vieses ilusão de validade e equívocos na regressão apresentaram um resultado no teste de Levene com pvalor menor que 5\%, o que indica a presença de diferença de variâncias. Assim, usou-se o teste de média com diferença de variância. Esses achados sugerem diferenças entre os gêneros no processo de julgamento e tomada decisão quando envolvem vieses da heurística da representatividade.

Tabela 28 - Resumo dos resultados das hipóteses de pesquisa

\begin{tabular}{|c|c|c|}
\hline & Resultado esperado & Resultado obtido \\
\hline Hipótese 1 & $\begin{array}{l}\text { Relação inversa entre capacidade } \\
\text { cognitiva e vieses estudados }\end{array}$ & $\begin{array}{l}\text { Só foi encontrada a relação inversa nos } \\
\text { vieses insensibilidade à taxa base e ilusão } \\
\text { de validade, indicando que, independente } \\
\text { da capacidade cognitiva, existe a } \\
\text { incidência dos vieses na tomada de } \\
\text { decisão. }\end{array}$ \\
\hline Hipótese 2 & $\begin{array}{l}\text { - Grau de dificuldade nos três } \\
\text { itens do CRT maior para os indivíduos } \\
\text { com CRT=3 } \\
\text { • Percepção do julgamento e } \\
\text { tomada de decisão estão condizentes } \\
\text { com CRT }\end{array}$ & $\begin{array}{l}\text { - Grau de dificuldade nos três itens } \\
\text { do CRT menor para os indivíduos com } \\
\text { CRT=3, mas os indivíduos com CRT=0 } \\
\text { acharam o teste fácil. } \\
\text { - Quanto maior o CRT, mais a } \\
\text { percepção do julgamento e tomada de } \\
\text { decisão se aproximam da razão. }\end{array}$ \\
\hline Hipótese 3 & $\begin{array}{l}\text { Diferença de gênero, região e grau de } \\
\text { instrução nos vieses cognitivos }\end{array}$ & $\begin{array}{l}\text { - Quanto ao gênero, só não foi } \\
\text { observada diferença no va viés } \\
\text { insensibilidade à previsibilidade. } \\
\text { - Quanto às regiões, os vieses } \\
\text { impactados por essa variável foram } \\
\text { insensibilidade à taxa base e ilusão de } \\
\text { validade. } \\
\text { - Quanto ao grau de instrução, os } \\
\text { vieses impactados por essa variável foram } \\
\text { insensibilidade à taxa base e } \\
\text { insensibilidade ao tamanho da amostra. }\end{array}$ \\
\hline
\end{tabular}

Fonte: Dados da pesquisa (2015) 


\section{CONSIDERAÇÕES FINAIS}

O conhecimento de quais vieses cognitivos incidem no julgamento e na tomada de decisão dos contabilistas e estudantes de graduação em Ciências Contábeis pode ajudar na minimização das falhas cognitivas, por ser possível compreender a influência desses no processamento das informações, melhorando, dessa forma, a capacidade decisória, posto que os erros podem ser corrigidos caso sejam conhecidos.

Para agregar valor a essa área de conhecimento, esta pesquisa tem como objetivo geral investigar se a capacidade cognitiva de estudantes do curso de graduação em Ciências Contábeis e dos profissionais contábeis influencia na ocorrência dos vieses cognitivos gerados pela heurística da representatividade. Tendo em vista esse alcance, foi realizado um estudo do tipo levantamento, através de um questionário com um total de 43 questões, dentre itens do CRT e opinião dos indivíduos sobre o grau de dificuldade no teste visando averiguar (e mensurar) a presença dos vieses insensibilidade à taxa base, insensibilidade ao tamanho da amostra, chance de equívocos, equívocos na regressão, ilusão de validade e insensibilidade à previsibilidade, percepção do respondente sobre seu julgamento e tomada de decisão, além de questões sociodemográficas.

A amostra válida deste estudo corresponde a 1.064 respondentes, dentre estudantes de graduação em Ciências Contábeis e contabilistas, dos quais 47,3\% são do gênero feminino e 52,7\% do masculino; $51,3 \%$ possuem graduação incompleta e 48,3\% possuem graduação completa, especialização, mestrado ou doutorado. Cerca de $70 \%$ desses sujeitos residem na região Nordeste do Brasil e os demais estão distribuídos nas outras regiões. Em seu conjunto, esses sujeitos têm em média 28,6 anos. Mais da metade deles já tem experiência profissional.

A partir da pesquisa survey, buscou-se alcançar o já citado objetivo geral, por meio dos objetivos específicos contemplados a seguir.

Quanto ao primeiro objetivos específico, mensurar a capacidade cognitiva de contabilistas e estudantes em Ciências Contábeis, através dos três itens do Cognitive Reflection Test (CRT) e, consequentemente, do tipo de processo cognitivo utilizado, considera-se, para este, um grau de plena satisfação, ao verificar que dos 1.064 participantes da pesquisa, 405 (38,1\%) demonstraram uma baixa capacidade cognitiva, utilizando apenas o processamento do Tipo 1, já que forneceram a 
primeira resposta que lhes veio a mente, de forma intuitiva, rápida, automática e inconsciente, não acertando nenhum dos itens no CRT. 452 (42,5\%) revelaram média capacidade cognitiva, ou seja, acertaram 1 ou 2 itens no teste, fazendo uso, em alguns momentos, do processamento do Tipo 1; em outros, do processamento do Tipo 2. O grupo de participantes considerados com alta capacidade, que acertaram todos os itens do CRT, totaliza 207 (19,2\%). Estes fizeram uso do processamento do Tipo 2, que é reflexivo, controlado e consciente, e resiste ao impulso de fornecer a primeira resposta que vem à mente. Totalizando, aproximadamente $62 \%$ dos indivíduos participantes da pesquisa possuem média ou alta capacidade cognitiva e fazem uso do processamento do Tipo 2 no momento do julgamento e tomada de decisão.

Através do segundo objetivo específico, verificar a ocorrência dos vieses cognitivos insensibilidade à taxa base, insensibilidade ao tamanho da amostra, chance de equívocos, equívocos na regressão, ilusão de validade e insensibilidade à previsibilidade, foi possível identificar que, em mais de 60\% dos sujeitos pesquisados há a incidência de todos os vieses estudados no processo de julgamento e tomada de decisão. Os vieses que apresentaram uma maior ocorrência foram insensibilidade à previsibilidade $(87,9 \%)$ e ilusão da validade $(85,3 \%)$, gerando um indicativo de que as pessoas precisam ficar atentas ao rigor de conteúdo das informações disponíveis, mesmo que esse seja consistente com suas crenças mais acessíveis e também precisam ter ciência de que as previsões não devem ser influenciadas por descrições, sejam elas positivas ou negativas, sem a breve verificação de sua confiabilidade.

Em relação ao terceiro objetivo, investigar se o nível de escolaridade, gênero a que pertencem e região onde residem influencia, diferentemente, nos vieses cognitivos, verifica-se o seu alcance quando se identifica, quanto ao nível de instrução dos respondentes, que existe diferença de médias dos vieses insensibilidade à taxa base e insensibilidade ao tamanho da amostra nos diferentes graus de instrução. Ainda assim, não se pode deixar de registrar o fato de que, para os demais vieses, não existiram essas diferenças. A variável gênero só não impactou, de maneira significativa, nas médias do viés insensibilidade à previsibilidade; em todos os demais, ser do sexo feminino ou masculino influencia na ocorrência dos vieses, mas não há um padrão justificativo para o fato de que as mulheres participantes da pesquisa são mais sensíveis aos vieses da 
representatividade do que os homens. A região do país onde residem os participantes, influenciou diferentemente os vieses insensibilidade à taxa base e ilusão de validade. Os respondentes os quais residem nas regiões Centro-oeste, Sudeste e Sul são menos sensíveis a esses vieses do que os residentes na região Nordeste e Norte, podendo esse resultado ser justificado por fatores culturais.

O quarto objetivo específico, que visa comparar e identificar se existe diferença estatística das variáveis grau de dificuldade dos respondentes nos três itens do CRT e percepção sobre seu julgamento e tomada de decisão com a capacidade cognitiva, foi alcançado quando foram identificadas diferenças significantes, estatisticamente, entre suas médias classificadas dos grupos de CRT. Os respondentes que não acertaram nenhum item ou acertaram 1 ou 2 itens no CRT obtiveram médias superiores na variável grau de dificuldade nos três itens do CRT em relação aos que acertaram os 3 itens. No entanto, observa-se que a média dos participantes com $C R T=0(4,70)$ é bem próxima ao do $C R T=3(4,41)$, indicando que aqueles consideraram os itens tão fáceis quanto esses. Em relação à opinião dos participantes da pesquisa sobre a forma como realizam seus julgamentos e tomada de decisão, baseando-se na razão ou intuição, verifica-se que quanto maior o número de questões acertadas no CRT, menor a média, significando que julgamento e tomada de decisão são mais baseados na razão, e quanto menor a quantidade de acertos maior a média, por serem estes mais baseados na intuição.

O quinto e último objetivo específico, analisar se existe diferença no nível de capacidade cognitiva entre os seis vieses cognitivos estudados, também foi alcançado. Foi encontrada diferença entre as médias do viés insensibilidade à taxa base e ilusão de validade nos grupos com baixa, média e alta capacidade cognitiva, indicando que quanto menor a capacidade cognitiva, maior a sensibilidade do respondente ao viés, corroborando o referencial teórico. Nos demais vieses não foram encontradas diferenças, indicando que mesmo os participantes que possuem alta capacidade cognitiva, de uma forma geral, também estão sujeitos a incidência dos vieses cognitivos estudados no processo decisório, ou seja, o QI não é suficiente para determinar a racionalidade, uma vez que pessoas inteligentes podem comportar-se de forma igênua.

Os resultados deste estudo indicam que contabilistas e estudantes de Ciências Contábeis, assim como qualquer outro indivíduo, estão sujeitos aos vieses cognitivos da heurística da representatividade. Assim, precisa conhecê-los, para 
tentar evitá-los, a fim de cumprir seu objetivo principal, que é o fornecimento de informações úteis para atender melhor as necessidades de seus mais variados usuários. Cabe enfatizar que os achados desta pesquisa confirmam que indivíduos com alta capacidade cognitiva podem agir inconscientemente.

Para futuras pesquisas, sugere-se aplicar o instrumento de pesquisa junto a indivíduos de diferentes cursos para verificar se os achados se repetem ou se registram diferenças devido à formação; em outro estudo, pode-se fazer uso do questionário para aplicação junto a todo e qualquer sujeito para comprovar a incidência dos vieses no processo de julgamento e tomada de decisão; utilizar experimentos para investigar se em situação que simulam a realidade e possuam variáveis de controle também há a incidência dos vieses da heurística da representatividade; elaborar e aplicar um novo instrumento que contemple os vieses cognitivos das heurísticas da disponibilidade e ancoragem e ajustamento. 


\section{REFERÊNCIAS}

BARON, J., et al. Why does the Cognitive Reflection Test (sometimes) predict utilitarian moral judgment (and other things)? Journal of Applied Research in Memory and Cognition, 2014.

BARROS, Lucas Ayres Barreira de Campos. Decisão de financiamento e de investimento das empresas sob a ótica de gestores otimistas e excessivamente confiantes. $261 \mathrm{f}$. Tese de doutorado do Programa de Pósgraduação em Administração da Universidade de São Paulo: São Paulo, 2005.

BARROUILLET, Pierre. Dual-process theories of reasoning: The test of development. Developmental Review, v. 31, p.151-179, 2011.

BASEL, Jörn; BRÜHL, Rolf. Concepts of rationality in management research from unbounded rationality to ecological rationality. ESCP Europe Working Paper, n. 57, mar. 2011.

BASILE, Thaissa Fernandes. A importância intrínseca dos finais de semana: a influência das experiências de recuperação na tomada de decisão dos trabalhadores. 2012. 63 f. Dissertação (mestrado) - Escola Brasileira de Administração Pública e de Empresas, Centro de Formação Acadêmica e Pesquisa. Orientador: Filipe João Bera de Azevedo Sobral.

BAZERMAN, M. H. Judgment in Managerial Decision Making. 3. ed. New York: Wiley, 1994.

BAZERMAN, Max H; MOORE, Dan. Processo decisório. 7. ed. Rio de Janeiro: Elsevier, 2010.

BELKAOUI, Ahmed. Behavioral management accounting. Londres: Quorum Books, 2002.

BERGMAN, Oscar; ELLINGSEN, Tore; JOHANNESSON, Magnus; SVENSSON, Cicek. Anchoring and cognitive ability. Economics Letters, n. 107, p. 66-68, 2010.

BIRNBERG, J. G. A proposed framework for behavioral accounting research. Behavioral Research In Accounting, v. 23, n. 1, p.1-43, 2011.

BIRNBERG, J. G.; GANGULY, Ananda Roop. Is neuroaccounting waiting in the wings? An essay. Accounting, Organizations and Society, v.37, p. 1-13, 2012.

BIRNBERG, J. G; LUFT, J; SHIELDS, M, D. Psychology Theory in Management Accounting Research. In: HOPWOOF, A. G.; CHAPMAN, C, S. (ORG). Management Accounting Research, Amsterdã: Elsevier, 2007.

BROWNE, Matthew; et al. Reflective minds and open hearts: Cognitive style and personality predict religiosity and spiritual thinking in a community sample. European Journal of Social Psychology, 2014. 
BUKSZAR, E. Does overconfidence lead to poor decisions? A comparison of decision making and judgment under uncertainty. Journal of Business and Management, v. 9, n. 1, p. 33-43, 2003.

CAGNIN, S. Neuropsicologia Cognitiva e Psicologia Cognitiva: o que o estudo da cognição deficitária pode nos dizer sobre o funcionamento cognitivo normal?

Psicologia em Pesquisa, v. 3, n. 1, p. 16-30, jan.jun. 2009.

CHEN, Gongmeng; KIM, Kenneth A.; NOFSINGER, John R; RUI, Oliver M. Trading Performance, Disposition Effect, Overconfidence, Representativeness Bias, and Experience of Emerging Market Investors. Journal of Behavioral Decision Making, n. 20, p. 425-451, 2007.

COOPER, Donald R.; SCHINDLER, Pamela S. Métodos de pesquisa em Administração. Tradução: Luciana de Oliveira da Rocha. 7. ed. São Paulo: Bookman, 2003.

COSTA, Sayonara S. C. da. Modelos mentais e resolução de problemas em física. 348 f. Universidade Federal do Rio Grande do Sul. Instituto de Física. Tese de doutorado. Porto Alegre, 2005.

COWAN, Nelson. The magical number 4 in short-term memory: a reconsideration of mental storage capacity. Behavioral and Brain Sciences, v. 24, p. 87-185, 2000.

DAS, T. K.; TENG, Bing-Sheng. Cognitive biases and strategic decision processes: an integrative perspective. Journal of Management Studies, v. 36, n. 6, nov.1999.

DOHMEN, Thomas; FALK, Armin; HUFFMAN, David; SUNDE, Uwe. Are Risk Aversion and Impatience Related to Cognitive Ability? American Economic Review, v. 100, n.3, p. 1238-1260, 2010.

DYCKMAN, T. R.. The ascendancy of the behavioral paradigm in accounting: The last 20 years. Behavioral Research in Accounting, 10 (Supplement), p. 1-10, 1998.

EINHORN, Hillel J.; HOGARTH, Robin M. Behavioral decision theory: processes of judgment and choice. Annual Review of Psychology, v. 32, p.53-88, 1981.

EINHORN, Hillel J.; HOGARTH, Robin M. Confidence in judgment: Persistence of the illusion of validity. Psychological Review, v. 85, n. 5, p. 395-416, 1978.

ERCEG, N.; GALIC, Z. Overconfidence bias and conjunction fallacy in predicting outcomes of football matches. Journal of Economic Psychology, 2014. Disponível em: <http://dx.doi.org/10.1016/j.joep.2013.12.003>. Acesso em: 15 out. de 2014.

EVANS, J. St. B. T. Dual process theories of reasoning: Contemporary issues and developmental applications. Developmental Review, v. 31, n. 2-3, p. 86-102, 2011.

EVANS, Jonathan ST. B. T. Dual-Processing Accounts of Reasoning, Judgment, and Social Cognition. Annual Review of Psychology, v. 59, p. 255-278, 2008. 
EVANS, Jonathan ST. B. T. The heuristic-analytic theory of reasoning: Extension and evaluation. Psychonomic Bulletin \& Review, v. 13, n.3, p. 378-395, 2006.

EVANS, Jonathan ST. B. T; STANOVICH, Keith E. Dual-Process Theories of Higher Cognition: Advancing the Debate. Perspectives on Psychological Science, v. 8, n. 3, p. 223-241, 2013.

FEITOSA, Arnaldo Barros; SILVA, Pablo Rogers; SILVA, Dany Rogers. A influência de vieses cognitivos e motivacionais na tomada de decisão gerencial: evidências empíricas em uma empresa de construção civil brasileira. Revista de Negócios, v. 19, n. 3, p. 3-22, 2014.

FREDERICK, Shane. Cognitive Reflection and Decision Making. Journal of Economic Perspectives, v. 19, n 4, p. 25-42, 2005.

GILOVICH, Thomas; GRIFFIN, Dale; KAHNEMAN, Daniel. Heuristics and biases: The psychology of intuitive judgment. New York: Cambridge University Press, 2002.

GLADWELL, Malcolm. Blink: a decisão num pisca de olhos. Trad. Nivaldo Montingelli Jr. Rio de Janeiro: Rocco, 2005.

GONDIN, João Paulo. Bope confunde furadeira com arma e mata morador de favela no Rio. Folha de São Paulo, 19 maio 2010. Disponível em:

<http://www1.folha.uol.com.br/folha/cotidiano/ult95u737524.shtml - 14h44>. Acesso em: 1 fev. 2013.

HAIR, J.F. Jr; et al. Análise multivariada de dados. Trad. Adonai Schlup Sant ana e Anselmo Chaves Neto. 5 ed. Porto Alegre: Bookman, 2005.

HERDEIRO, Roberto Francisco Casagrande. Escalonamento Multidimensional. In_: Fundação Instituto de Pesquisas Contábeis, Atuariais e Financeiras. Análise Multivariada: para os cursos de administração, cieências contábeis e economia. Luiz J. Corrar, Edilson Paulo, José Maria Dias Filho (coord.). 1.ed. São Paulo: Atlas, 2012.

HILBERT, Martin. Toward a Synthesis of Cognitive Biases: How Noisy Information Processing Can Bias Human Decision Making. Psychological Bulletin - American Psychological Association, v. 138, n. 2, p. 211-237, 2012.

HINSZ, Verlin B.; TINDALE, R. Scott; NAGAO, Dennis H.. Accentuation of information processes and biases in group judgments integrating base-rate and case-specific information. Journal of Experimental Social Psychology, v.44, p.116-126, 2008.

HOFFMAN, Robert R.; DEFFENBACHER, Kenneth A. A Brief History of Applied Cognitive Psychology. Applied cognitive psychology, v. 6, p. 1-48, 1992. 
HOGARTH, Robin M. Cognitive Processes and the Assessment of Subjective Probability Distributions. Journal of the American Statistical Association, v. 70, n. 350, p. 271-289, jun. 1975.

HOPPE, Eva I.; KUSTERER, David J. Behavioral biases and cognitive reflection. Economics Letters, 110, p. 97-100, 2011.

HSIAO, Kuo-Lun; LU, Hsi-Peng; LAN, Wan-Chin. The influence of the components of storytelling blogs on readers' travel intentions. Internet Research, v. 23, n. 2, p. 160182, 2013.

JAMES, W. The principles of psychology, New York: Dover, 1950.

JOYCE, Edward J.; BIDDLE, Gary C. Are Auditors' Judgments Sufficiently Regressive? Journal of Accounting Research, v. 19, n. 2, p. 323-349, 1981.

KAHNEMAN, D.; SLOVIC, P.; TVERSKY, A. Judgment under uncertainty: Heuristics and biases. Cambridge, England: Cambridge University Press, 1982. Disponível em: <http://books.google.com.br/books?hl=pt-

$B R \& \mid r=\& i d==0 H 8 g w j 4 a 1 M C \& O i=f n d \& p g=P R 8 \& d q=u d g m e n t+u n d e r+u n c e r t a i n t y:+H e u$ ristics+and+biases\&ots=YCcgbSX1_L\&sig=h6zIPIzQYZTW2xIteh3R5oEcCis\#v=one page\& $q=$ udgment $\% 20$ under\%20uncertainty\%3A\%20Heuristics\%20and\%20biases\& $f$ =false>. Acesso em 20 jan. 2012.

KAHNEMAN, D.; TVERSKY, A. On the Reality of Cognitive Illusions. Psychological Review, v.103, n. 3, p. 582-591, 1996.

KAHNEMAN, Daniel. A Perspective on Judgment and Choice Mapping Bounded Rationality. American Psychologist, set. 2003.

KAHNEMAN, Daniel. A Perspective on Judgment and Choice: Mapping Bounded Rationality. American Psychologist, v. 58, n. 9, p. 697-720, 2003.

KAHNEMAN, Daniel. Maps of Bounded Rationality: Psychology for Behavioral Economics. The American Economic Review, v. 93, n.5, p. 1449-1475, dez. 2003.

KAHNEMAN, Daniel; FREDERICK, Shane. A Model of Heuristic Judgment. In.: The Cambridge handbook of Thinking and Reasoning. Editado por Keith $\mathrm{J}$ Holyoak e Robert G. Morrison. New York: Cambridge University Press, 2005.

KAHNEMAN, Daniel; FREDERICK, Shane. Representativeness revisited: attribute substitution in intuitive judgment. In_ GILOVICH, Thomas; GRIFFIN, Dale;

KAHNEMAN, Daniel. Heuristics and biases: the psychology of intuitive judgment. New York: Cambridge University Press, 2002.

KAHNEMAN, Daniel; FREDERICK, Shane. Representativeness revisited: Attribute substitution in intuitive judgment. Princeton University, 2 ago. 2001.

KAHNEMAN, Daniel; TVERSKY, Amos. Prospect Theory: An Analysis of Decision under Risk. Econometrica, v. 47, n. 2, p. 263-292, mar. 1979. 
KAHNEMAN, Daniel; TVERSKY, Amos. Subjective Probability: A Judgment of Representativeness. Cognitive Psychology, v. 3, p.430-454, 1972.

KIM, Keunsoo; BYUN, Jinho. Studies on Korean Capital Markets from the Perspective of Behavioral Finance. Asian Review of Financial Research, v. 24, n. 3, ago. 2011.

KIMURA, Herbert. Aspectos comportamentais associados às reações do mercado de capitais. RAE-eletrônica, v. 2, n. 1, jan./jun. 2003. Disponível em:

$<$ http://www.rae.com.br/eletronica/index.cfm?FuseAction=Artigo\&ID=1880\&Secao=2 PWC\&Volume=2\&Numero=1\&Ano=2003>. Acesso em: 25 abr. 2011.

KORTE, Russell F. Biases in Decision Making and Implications for Human Resource Development. Advances in Developing Human Resources, v. 5, n. 4, p. 440-457, nov. 2003.

LAGROUE, Harold Joseph. The Effectiveness of Virtual Facilitation in Supporting GDSS Appropriation and Structured Group Decision Making. 2006. $242 \mathrm{f}$. Tese de Doutorado em Filosofia - Graduate Faculty of the Louisiana State University and Agricultural and Mechanical College. Interdepartmental Program in Business Administration, Louisiana, 2006.

LIBBY, Robert; BLOOMFIELD, Robert; NELSON, Mark W. Experimental research in financial accounting. Accounting, Organizations and Society, v. 27, p.775-810, 2002.

LIBBY, Robert; RENNEKAMP, Kristina. Self-Serving Attribution Bias, Overconfidence, and the Issuance of Management Forecasts. Journal of Accounting Research, v. 50, n. 1, Mar. 2012.

LIBERALI, Jordana M.; REYNA, Valerie F.; FURLAN, Sarah, STEIN, Lilian M.; PARDO, Seth T.. Individual differences in numeracy and cognitive reflection, with implications for biases and fallacies in probability judgment. Journal of Behavioral Decision Making, n.25, p.361-381, 2012.

LIBERALI, Jordana Folle de Menezes. O papel da memória no julgamento e tomada de decisão. Tese (Doutorado) - Faculdade de Psicologia, PUCRS. 186 f. Porto Alegre, 2012.

LILIENFELD, Scott O.; LYNN, Steve Jay; RUSCIO, John; BEYERSTEIN, Barry L. 50 Great myths of popular psychology: shattering widespread misconceptions about human behavior. Hong Kong: Wiley-blackwell, 2010.

LIMA FILHO, Raimundo Nonato; BRUNI, Adriano Leal. Quanto mais faço, mais erro? Uma análise sobre a presença de vieses cognitivos em julgamentos sobre orçamento. Revista Base (Administração e Contabilidade) da UNISINOS, v. 10, n. 3, p. 224-239, jul./set., 2013. Disponível em: <http://www.redalyc.org/pdf/3372/337228655004.pdf>. Acesso em: 30 jan. 2014. 
LIMA FILHO, Raimundo Nonato; BRUNI, Adriano Leal; SAMPAIO, Márcio Santos. A influência do gênero, idade e formação na presença de heurísticas em decisões de orçamento: um estudo quase experimental. Revista Universo Contábil, FURB, Blumenau, v. 8, n. 2, p. 103-117, abr./jun., 2012

LIMA FILHO, Raimundo Nonato; BRUNI, Adriano Leal; SAMPAIO, Márcio Santos; CORDEIRO FILHO, Jose Bernardo; CARVALHO JÚNIOR, César Valentim de Oliveira. Heurísticas e Práticas Orçamentárias: Um Estudo Experimental.

Sociedade, Contabilidade e Gestão, v. 5, n. 1, 2010. Disponível em: <SSRN: http://ssrn.com/abstract=2153922>. Acesso em: 30 de jan. 2014.

LIMA FILHO, Raimundo Nonato; BRUNI, Adriano Leal; SAMPAIO, Márcio Santos. A influência do gênero, idade e formação na presença de heurísticas em decisões de orçamento: um estudo quase experimental. Revista Universo Contábil, Blumenau, v. 8 , n. 2, p. 103-117, abr./jun. 2012

LIMA, Diogo Henrique Silva de. Efeito formulação e contabilidade: uma análise da influência da forma de apresentação de demonstrativos e relatórios contábeis sobre o processo decisório de usuários de informações contábeis. 143 f. Dissertação de mestrado pelo Programa Multiinstitucional e Inter-Regional de Pós-graduação em Ciências Contábeis da Universidade de Brasília, Universidade Federal da Paraíba e Universidade Federal do Rio Grande do Norte. Natal, RN, 2007.

LIMA, Diogo Henrique Silva de; RODRIGUES, Jomar Miranda; SILVA, César Augusto Tibúrcio; SILVA, José Dionísio Gomes da. Impacto do nível de evidenciação de informações contábeis sobre a precificação de ações no contexto de seleção adversa: uma pesquisa experimental. Revista Brasileira de Gestão de Negócios, São Paulo, v. 14, n.43, p. 159-175, abr./jun. 2012.

LIYANARACHCHI, G. A.; MILNE, M. J. Comparing the investment decisions of accounting practitioners and students: an empirical study on the adequacy of student surrogates, Accounting Forum, v. 29, p. 121-35, 2005.

LUCENA, Wenner Glaucio Lopes; FERNANDES, Maria Sueli Arnoud; SILVA, José Dionísio Gomes da. A contabilidade comportamental e os efeitos cognitivos no processo decisório: uma amostra com operadores da contabilidade. Revista Universo Contábil, FURB, Blumenau, v. 7, n. 3, p. 41-58, jul./set. 2011

MACEDO, Marcelo Álvaro da Silva; DANTAS, Manuela Moura; OLIVEIRA, Rafael Fernandes da Silva de. Análise do comportamento decisório de profissionais de contabilidade sob a perspectiva da racionalidade limitada: um estudo sobre os impactos da teoria dos prospectos e das heurísticas de julgamento. Revista Ambiente Contábil, v. 4, n. 1, 2012.

MACEDO, Marcelo Álvaro da Silva; FONTES, Patrícia Vivas da Silva. Análise do comportamento decisório de analistas contábil-financeiros: um estudo com base na teoria da racionalidade limitada. Revista contemporânea de Contabilidade, Florianópolis, ano 06, v.1, n.11, p. 159-186, jan./jun. 2009. 
MATIAS-PEREIRA, José. Manual de metodologia da pesquisa científica. 2. ed. São Paulo: Atlas, 2010.

MCDOWELL, Michelle E.; OCCHIPINTI, Stefano; CHAMBERS, Suzanne K. The Influence of Family History on Cognitive Heuristics, Risk Perceptions, and Prostate Cancer Screening Behavior. Health Psychology, v. 32, n. 11, p. 1158-1169, 2013.

MELO, Clayton Levy Lima de; SILVA, César Augusto Tibúrcio. Finanças comportamentais: um estudo da influência da faixa etária, gênero e ocupação na aversão à perda. Revista de Contabilidade e Organizações (RCO), v. 4, n. 8, p. 323, jan.-abr. 2010.

MORITZ, Brent; SIEMSEN, Enno; KREMER, Mirko. Judgmental Forecasting: Cognitive Reflection and Decision Speed. Production and Operations Management Society, v. 23, n. 7, p. 1146-1160. jul. 2014.

MORSANYI, Kinga, Simon J. Handley and Sylvie Serpell. Making heads or tails of probability: An experiment with random generators. British Journal of Educational Psychology, n. 83, p.379-395, 2013.

MUSSWEILER, Thomas. \& ENGLICH, Birte. Subliminal anchoring: judgmental consequences and underlying mechanism. Organizational Behavior and Human Decision Processes, v. 98, n. 2, p. 133-143, 2005.

NARDY, André; FAMÁ, Rubens. As Finanças Comportamentais no Brasil Através de um Estudo de Publicações e Congressos nos anos 2001-2012. Revista de Administração da Fatea, v. 7, n. 7, p. 6-22, ago./dez., 2013.

OECHSSLERA, Jörg; ROIDERA, Andreas; SCHMITZB, Patrick W. Cognitive abilities and behavioral biases. Journal of Economic Behavior \& Organization, v.72, n.1, p. 147-152, 2009.

PEREIRA, Antonio Gualberto; BRUNI, Adriano Leal. Habilidades cognitivas, comprometimento com a profissão e decisões sobre alocação de recursos. Enfoque: Reflexão Contábil UEM, v. 32, n. 2, p. 1-19, maio/ago. 2013.

PEREIRA, Antonio Gualberto; BRUNI, Adriano Leal. Intuição, preferências intertemporais e orçamento. BASE - Revista de Administração e Contabilidade da Unisinos, v.11, n. 3, p. 231-245, jul./set. 2014.

QUINTANILHA, Thiago Meirelles; MACEDO, Marcelo Álvaro da Silva. Análise do comportamento decisório sob a perspectiva das heurísticas de julgamento e da teoria dos prospectos: um estudo com discentes de graduação em ciências contábeis. RIC - Revista de Informação Contábil - ISSN 1982-3967 - v. 7, n. 3, p. 1-24, jul./set. 2013.

RAUPP, Maury; BEUREN, Ilse Maria. Metodologia da pesquisa aplicável às ciências sociais. In_BEUREN, Ilse Maria (Org). Como elaborar trabalhos monográficos em Contabilidade: Teoria e Prática. 2. ed. São Paulo: Atlas, 2004. 
RICCO, Robert B.; OVERTON, Willis F. Dual systems Competence - Procedural processing: A relational developmental systems approach to reasoning.

Developmental Review, v. 31, p. 119-150, 2011.

RITTER, Jay R. Behavioral Finance. Pacific-Basin Finance Journal, v. 11, n. 4, p. 429-437, set. 2003.

RODRIGUES, Lílian Cavalheiro; ABREU-RODRIGUES, Josele. Falácia da Conjunção: Definição e Variáveis de Controle. Psicologia: Teoria e Pesquisa, v. 23, n. 4, p. 433-442, out./dez. 2007.

SAMUELSON, William; ZECKHAUSER, Richard. Status Quo Bias in Decision Making. Journal of Risk and Uncertainty, 1, p.7-59, 1988.

SCHOEKE, A.; et al. Cognitive psychology and cognitive neuroscience. Books4x Company, 2004. Disponível em:

http://upload.wikimedia.org/wikipedia/commons/d/d8/Cognitive_Psychology_and_Co gnitive_Neuroscience.pdf. Acesso em: 20 fev. 2012.

SEQUEIRA, Mariana; FERREIRA, Mário B.; ALMEIDA Tiago. Construção de uma Bateria de Problemas de Julgamento e Decisão em Língua Portuguesa. Laboratório de Psicologia, v.11, n. 2, p. 121-142, 2013.

SHANTEAU, James. Cognitive heuristics and biases in behavioral auditing: review, comments and observations. Accounting, Organizations and Society, 14, p. 165$177,1989$.

SIEGEL, Gary; RAMANAUSKAS-MARCONI, Helene. Behavioral Accounting. Ohio: South-Western Publisinhg Co.,1989.

SILVA, César Augusto Tibúrcio; GONÇALVES, Anna Gabriela Dicesar Martins de Araujo. $O$ efeito da demonstração pro forma sobre a decisão dos usuários. Anais... Congresso USP de Iniciação Científica em Contabilidade, 8. São Paulo, jul. 2011.

SIMON, Herbert A. Comportamento Administrativo: Estudo dos Processos Decisórios nas Organizações Administrativas. Rio de Janeiro: Centro de Publicações Técnicas da Aliança para o Progresso, 1965.

SIMON; Herbert A. A Behavioral Model of Rational Choice. The Quarterly Journal of Economics, v. 69, n. 1, p. 99-118, fev. 1955.

SLOVIC, P.; FISCHHOFF, B; LICHTENSTEIN, S. Behavioral decision theory. Annual Review of Psychology, 28, p. 1-39, 1977.

SOUZA, Alexandre Lyra Couto de. Influência dos sentimentos na resolução de problemas complexos e intuitivos: Implicações para a tomada de decisão.

Dissertação de Mestrado. 86 f. Fundação Getúlio Vargas. EBAPE - Escola Brasileira de Administração Pública e de Empresas. Mestrado Executivo em Gestão Empresarial. Rio de Janeiro, 1 jun. 2010. 
SPIEGEL, Thaís; CAULLIRAUX, Heitor Mansur. A tomada de decisão diante da racionalidade limitada: revisão da literatura. Ciências \& Cognição, v. 18, n.2, p. 186-207, 2013.

STANOVICH, K.; WEST, R. F.; TOPLAK, M. E. The complexity of developmental predictions from dual process models. Developmental Review, v. 31, n. 2-3, p. 103118, 2011.

STANOVICH, Keith E.; WEST, Richard F. Individual differences in reasoning: Implications for the rationality debate? Behavioral and brain sciences, 23, p. 645726, 2000.

TAYLOR, R. Concepts, theory and techniques, psychological determinants of bounded rationality: implications for decision-making strategies. Decision Science, 6, p. 409-429, 1975.

TENTORI, Katya; CRUPI, Vincenzo; RUSSO, Selena. On the Determinants of the Conjunction Fallacy: Probability Versus Inductive Confirmation. Journal of Experimental Psychology: General (American Psychological Association), v. 142, n. 1, p. 235-255, 2013.

TONETTO, Leandro Miletto; RENCK, Priscila Brust; STEIN, Lílian Milnitsky. Cognição, Design e Consumo: A Racionalidade Limitada na Tomada de Decisão. Estudos em Design, Rio de Janeiro, v. 20, n. 2, 2012.

TVERSKY, A., KAHNEMAN, D. Extensional versus intuitive reasoning: The conjunction fallacy in probability judgment. Psychological Review, v. 90, p. 293315, 1983.

TVERSKY, A., KAHNEMAN, D. Judgment under uncertainty: heuristics and biases. Science, v. 185, n. 4.157, p. 1.124-1.131, 1974.

TVERSKY, A.; KAHNEMAN, D. Availability: a heuristic for judging frequency and probability. Cognitive Psychology, v. 4, p. 207-232, 1973.

TVERSKY, A.; KAHNEMAN, D. Belief in the law of small numbers. Psychological Bulletin, v. 76, n. 2, p. 105-110, 1971.

TVERSKY, Amos; KAHNEMAN, Daniel. The framing of decisions and the psychology of choice. Science, n. 211, v. 4481, p. 453-458, 1981.

URIBE, Rodrigo; MANZUR, Enrique; HIDALGO, Pedro. Exemplars' impacts in marketing communication campaigns. Journal of Business Research, v.66, p.1787-1790, 2013.

VASCONCELLOS, Sílvio José Lemos; VASCONCELLOS, Cristiane Teresinha de Deus Virgili. Uma análise das duas revoluções cognitivas. Psicologia em estudo, v.12, n.2, p. 385-391, 2007. 
VEERARAGHAVAN, K. Role of behavioural finance: a study. International Journal of Enterprise and Innovation Management Studies, v. 1, n. 3, 2010.

VERIM, Burcu. The impact of modality and feedback on reasoning about base rate neglect problems in behavioral and eye tracking studies: A cognitive science perspective. A thesis submitted to the graduate school of informatics of the Middle East Technical University in partial fulfillment of the requirement for the degree of Master of Science in Cognitive Science. set. 2014, p. 73.

WALSH, J. P. Managerial and organizational cognition: notes from a trip down memory lane. Organization Science, v. 6, p. 280-321, 1995.

WELSH, Matthew B.; NAVARRO, Daniel J. Seeing is believing: Priors, trust, and base rate neglect. Organizational Behavior and Human Decision Processes, v. 119, p. 1-14, 2012.

WEST, Richard F.; MESERVE, Russell J.; STANOVICH, Keith E. Cognitive sophistication does not attenuate the bias blind spot. Journal of Personality and Social Psychology, Jun. 2012.

WILLIAMS, P. F.; JENKINS, G.; INGRAHAM, L. The Winnowing away of Behavioral Accounting Research in the US: the process for anointing academic elites.

Accounting, Organizations and Society. v. 31, p. 783-818, 2006.

YU, Erica C.; SPRENGER, Amber M.; THOMAS, Rick P.; DOUGHERTY, Michael R.. When decision heuristics and science collide. Psychonomic Society, v. 21, p. 268282, 2014. 


\section{APÊNDICE - Instrumento de Pesquisa}

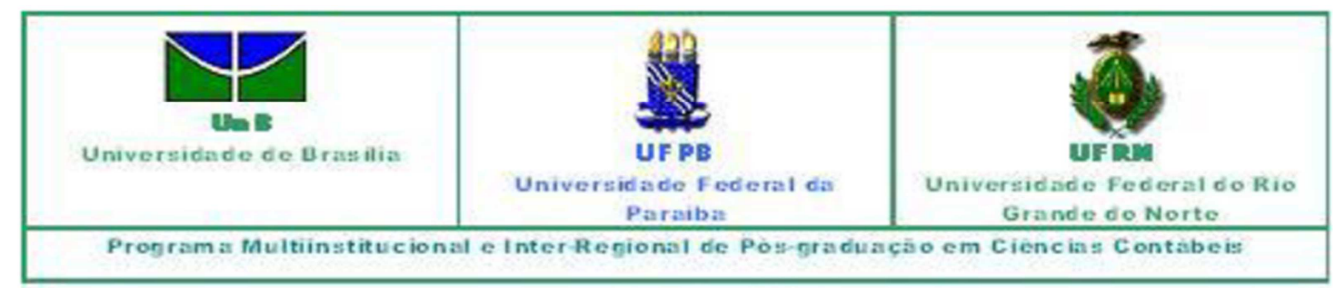

Prezado (a) respondente,

Este é o instrumento utilizado para coleta de dados da tese de doutorado de Edzana Roberta Ferreira da Cunha Vieira Lucena, aluna do Programa Multi-Institucional e Inter-regional de Pós Graduação em Ciências Contábeis - UnB, UFPB e UFRN, orientada pelo Professor Dr. César Augusto Tibúrcio Silva. Para alcançar os objetivos da tese, vimos solicitar a colaboração do (a) senhor (a), estudante de Ciências Contábeis ou profissional Contábil, para responder o questionário.

Os dados fornecidos serão utilizados para fins estritamente científicos, em nenhum momento serão divulgados os nomes dos respondentes. O êxito da pesquisa depende da integridade das respostas do (a) senhor (a), assim é necessária total atenção na leitura.

Desde já, agradecemos a participação!

Atenciosamente,

César Augusto Tibúrcio Silva

Professor do Programa Multi-Institucional e Inter-regional de Pós-Graduação em Ciências Contábeis - UnB, UFPB e UFRN

Edzana Roberta Ferreira da Cunha Vieira Lucena

Doutoranda do Programa Multi-Institucional e Inter-regional de Pós-Graduação em Ciências Contábeis - UnB, UFPB e UFRN 
Parte I

1. Um taco e uma bola juntos custam $R \$ 110,00$. O taco custa $R \$ 100,00$ a mais que a bola. Quanto custa a bola?

2. São necessários 5 minutos de 5 máquinas para fazer 5 camisas. Quanto tempo levariam 100 máquinas para fazer 100 camisas?

3. Em um lago, há grupo de vitórias-régias. Todos os dias, o grupo dobra de tamanho. Se leva 100 dias para o grupo cobrir todo o lago, quanto dias seria necessário para o grupo cobrir metade do lago?

4. Assinale na escala abaixo o grau de dificuldade dos três itens anteriores:

\begin{tabular}{l}
\begin{tabular}{|l|l|l|l|l|l|l|l|l|l|l|}
\hline 0 & 1 & 2 & 3 & 4 & 5 & 6 & 7 & 8 & 9 & 10 \\
\hline Muito \\
fácil
\end{tabular} \\
\hline
\end{tabular}

5. Qual você julga ser a sua probabilidade aproximada de acertos para as 3 primeiras questões dessa página?

\begin{tabular}{|l|l|l|l|}
\hline 0 & $33,33 \%$ & $66,67 \%$ & $100 \%$ \\
\hline
\end{tabular}

Parte II

1. Em uma região, $1 \%$ das empresas elabora e faz uso do plano de negócio. $A$ Companhia Beta está localizada nessa região. A empresa está no mercado há aproximadamente 10 anos, possui uma boa carteira de clientes e seu produto principal é bem aceito na localidade. Você acredita que a probabilidade de a Companhia Beta utilizar o plano de negócio é alta.

\begin{tabular}{|l|l|l|l|l|l|l|l|l|l|l|}
\hline 0 & 1 & 2 & 3 & 4 & 5 & 6 & 7 & 8 & 9 & 10 \\
\hline
\end{tabular}
Muito
fácil

2. Qual probabilidade de você acertar a questão anterior?

\begin{tabular}{|l|l|l|l|l|l|l|l|l|l|l|}
\hline 0 & $10 \%$ & $20 \%$ & $30 \%$ & $40 \%$ & $50 \%$ & $60 \%$ & $70 \%$ & $80 \%$ & $90 \%$ & $100 \%$ \\
\hline
\end{tabular}


3. Uma pesquisa realizada junto a 100 analistas financeiros indicou que um determinado empreendimento imobiliário é considerado muito bom. Você possui recurso suficiente para investir nesse empreendimento. Dois familiares seus conheceram o empreendimento e lhe disseram para não comprar por ser muito ruim. Você confia em seus familiares. Então a probabilidade de você adquirir o empreendimento é baixa.

\begin{tabular}{|l|l|l|l|l|l|l|l|l|l|c|}
\hline 0 & 1 & 2 & 3 & 4 & 5 & 6 & 7 & 8 & 9 & 10 \\
\hline
\end{tabular}
Discordo
totalmente
Concordo
totalmente

4. Em um curso de instituição pública de ensino superior, $85 \%$ de seus alunos fizeram o ensino médio em escola pública. Natália, aluna desse curso, possui carro do ano e sempre acompanha todas as tendências de moda. Você acredita que a probabilidade de Natália ter cursado o ensino médio em escola particular é alta.

\begin{tabular}{|l|l|l|l|l|l|l|l|l|l|c|}
\hline 0 & 1 & 2 & 3 & 4 & 5 & 6 & 7 & 8 & 9 & 10 \\
\hline
\end{tabular}
Discordo
totalmente

5. Qual probabilidade de você acertar a questão anterior?

\begin{tabular}{|l|l|l|l|l|l|l|l|l|l|l|}
\hline 0 & $10 \%$ & $20 \%$ & $30 \%$ & $40 \%$ & $50 \%$ & $60 \%$ & $70 \%$ & $80 \%$ & $90 \%$ & $100 \%$ \\
\hline
\end{tabular}

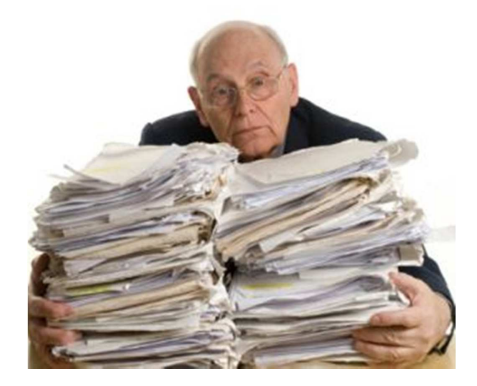

6. O senhor acima é João, ele tem 50 anos e possui formação superior. Em sua vida pessoal é conservador, muito tímido e não tem vida social ativa. Profissionalmente, dedica quase todas as horas do dia ao seu escritório. Você acredita que a probabilidade de João ser um contador é alta.

\begin{tabular}{|l|l|l|l|l|l|l|l|l|l|c|}
\hline 0 & 1 & 2 & 3 & 4 & 5 & 6 & 7 & 8 & 9 & 10 \\
\hline
\end{tabular}
Discordo
totalmente

7. Você leu em um site na internet: "Os últimos 5 anos foram marcados principalmente pela expansão internacional da Companhia Z. Foram 
investidos, em um ano, cerca de $R \$ 1$ bilhão em sua atividade principal. Durante esse ano, a referida empresa adotou uma política de preços competitiva." Assim, você acredita que a probabilidade de o lucro da companhia aumentar nos próximos anos é alta.

\begin{tabular}{|l|l|l|l|l|l|l|l|l|l|c|}
\hline 0 & 1 & 2 & 3 & 4 & 5 & 6 & 7 & 8 & 9 & 10 \\
\hline
\end{tabular}
Discordo
totalmente

8. Qual probabilidade de você acertar a questão anterior?

\begin{tabular}{|l|l|l|l|l|l|l|l|l|l|l|}
\hline 0 & $10 \%$ & $20 \%$ & $30 \%$ & $40 \%$ & $50 \%$ & $60 \%$ & $70 \%$ & $80 \%$ & $90 \%$ & $100 \%$ \\
\hline
\end{tabular}

9. Verificando um investimento com rendimento variável e alto risco, você observou que normalmente há uma probabilidade de $50 \%$ para o desempenho ser bom/ positivo $(P)$ e de $50 \%$ para ser ruim/ negativo $(N)$. Durante o período de 6 meses, a probabilidade de desempenho P, N, P, P, N, $\mathrm{N}$ é mais provável de acontecer que $\mathrm{N}, \mathrm{N}, \mathrm{N}, \mathrm{N}, \mathrm{N}, \mathrm{N}$ ou $\mathrm{P}, \mathrm{P}, \mathrm{P}, \mathrm{P}, \mathrm{P}, \mathrm{P}$.

\begin{tabular}{|l|l|l|l|l|l|l|l|l|l|c|}
\hline 0 & 1 & 2 & 3 & 4 & 5 & 6 & 7 & 8 & 9 & 10 \\
\hline
\end{tabular}
Discordo
totalmente

10. Um investimento gerou, por 4 anos, uma taxa de retorno médio negativa de $5 \%$ a.a. No ano passado, a taxa chegou a $-10 \%$. Em sua opinião, a probabilidade de essa última taxa se repetir é baixa, pois você acredita que o retorno tenderá ao desempenho médio.

\begin{tabular}{|l|l|l|l|l|l|l|l|l|l|c|}
\hline 0 & 1 & 2 & 3 & 4 & 5 & 6 & 7 & 8 & 9 & 10 \\
\hline
\end{tabular}
Discordo
totalmente

11. Em determinada região, $2 \%$ das empresas elaboram e fazem uso do planejamento estratégico. Nessa região está localizada a empresa Plus, a qual está no mercado há aproximadamente 3 anos, possui uma boa carteira de clientes e seu produto principal é bem aceito na localidade. Você acredita que a probabilidade de a empresa Plus elaborar o planejamento estratégico é alta.

\begin{tabular}{|c|c|c|c|c|c|c|c|c|c|c|}
\hline 0 & 1 & 2 & 3 & 4 & 5 & 6 & 7 & 8 & 9 & 10 \\
\hline
\end{tabular}
Discordo
totalmente


12. Ao lançar uma moeda para cima 8 vezes, o resultado CKCKCCKK é mais provável de acontecer que KKKKKKKK (onde $\mathrm{K}=\mathrm{Cara}$ e $\mathrm{C}=\mathrm{Coroa}$ ).

\begin{tabular}{|l|c|c|c|c|c|c|c|c|c|c|}
\hline 0 & 1 & 2 & 3 & 4 & 5 & 6 & 7 & 8 & 9 & 10 \\
\hline
\end{tabular}
Discordo
totalmente

13. Em determinada instituição de ensino superior, a média dos alunos na disciplina Contabilidade Básica é 8,5. Ao selecionar uma amostra de 20 alunos, você acredita que a probabilidade de a média ser 8,5 é alta.

\begin{tabular}{|c|c|c|c|c|c|c|c|c|c|c|}
\hline 0 & 1 & 2 & 3 & 4 & 5 & 6 & 7 & 8 & 9 & 10 \\
\hline
\end{tabular}
Discordo
totalmente

14. Uma informação encontrada no Google revela que a Cia Cruz tornou-se menos transparente e confiável. Agora no segundo semestre, essa empresa irá ofertar a emissão de ações. Você possui recurso para tal aquisição, mas a probabilidade de comprar essas ações é baixa.

\begin{tabular}{|c|c|c|c|c|c|c|c|c|c|c|}
\hline 0 & 1 & 2 & 3 & 4 & 5 & 6 & 7 & 8 & 9 & 10 \\
\hline
\end{tabular}
Discordo
totalmente

15. Você começou a comprar ações pela internet, iniciou adquirindo de cinco empresas distintas. Todas elas tiveram uma queda no preço logo após sua compra. Enquanto se prepara para fazer uma sexta compra, você raciocina: essa terá um melhor desempenho do que as outras da carteira.

\begin{tabular}{|l|l|l|l|l|l|l|l|l|l|c|}
\hline 0 & 1 & 2 & 3 & 4 & 5 & 6 & 7 & 8 & 9 & 10 \\
\hline
\end{tabular}
Discordo
totalmente

16. Em determinada instituição privada de ensino superior, $10 \%$ de seus alunos possuem bolsa integral do ProUni (baixa renda). Maria é estudante dessa instituição, nasceu no interior, é muito esforçada e comprometida com o que faz. Você acredita que a probabilidade de Maria ser uma dentre os estudantes contemplados com a bolsa integral do ProUni é alta.

\begin{tabular}{|c|c|c|c|c|c|c|c|c|c|c|}
\hline 0 & 1 & 2 & 3 & 4 & 5 & 6 & 7 & 8 & 9 & 10 \\
\hline
\end{tabular}
Discordo
totalmente


17. Em um site, você leu a seguinte informação: "Os últimos 5 anos foram marcados principalmente pela recessão econômica da Empresa W, o que ocasionou uma queda no nível de produção". Assim, você acredita que a probabilidade de o prejuízo da companhia aumentar nos próximos anos é alta.

\begin{tabular}{|l|l|l|l|l|l|l|l|l|l|c|}
\hline 0 & 1 & 2 & 3 & 4 & 5 & 6 & 7 & 8 & 9 & 10 \\
\hline
\end{tabular}
Discordo
totalmente

18. O QI médio da população de alunos da oitava série em uma cidade é 100. Você selecionou uma amostra aleatória de 50 adolescentes para um estudo. Você acredita que a probabilidade de o QI médio dessa amostra ser igual a 100 é muito alta.

\begin{tabular}{|l|c|c|c|c|c|c|c|c|c|c|}
\hline 0 & 1 & 2 & 3 & 4 & 5 & 6 & 7 & 8 & 9 & 10 \\
\hline
\end{tabular}
Discordo
totalmente
Concordo
totalmente

19. Ao lançar uma moeda para cima 6 vezes, o resultado CKCCKK é mais provável de acontecer que CCCCCC (onde $\mathrm{K}=$ Cara e $\mathrm{C}=$ Coroa).

\begin{tabular}{|c|c|c|c|c|c|c|c|c|c|c|}
\hline 0 & 1 & 2 & 3 & 4 & 5 & 6 & 7 & 8 & 9 & 10 \\
\hline
\end{tabular}
Discordo
totalmente

20. Uma empresa teve um crescimento médio de suas receitas de $3 \%$ ao ano durante um período de 20 anos. No primeiro semestre de 2014, suas receitas aumentaram $15 \%$ comparadas as do ano anterior. Você acredita que é baixa a probabilidade de o aumento das receitas ser igual ou superior ao primeiro semestre de 2014.

\begin{tabular}{|c|c|c|c|c|c|c|c|c|c|c|}
\hline 0 & 1 & 2 & 3 & 4 & 5 & 6 & 7 & 8 & 9 & 10 \\
\hline
\end{tabular}
Discordo
totalmente

21. Em uma instituição privada de ensino superior, $15 \%$ de seus alunos fizeram o ensino médio em escola privada. Luiza, aluna dessa instituição, possui carro e sempre anda bem vestida. Você acredita que a probabilidade de Luiza ter cursado o ensino médio em escola particular é alta. 


\begin{tabular}{|c|c|c|c|c|c|c|c|c|c|c|}
\hline 0 & 1 & 2 & 3 & 4 & 5 & 6 & 7 & 8 & 9 & 10 \\
\hline
\end{tabular}
Discordo
totalmente

22. Uma informação encontrada em um site de busca revela que a Cia. XC tornou-se menos transparente e confiável. Você possui recurso destinado para aquisição de ações. Porém, a probabilidade de você comprar ações dessa empresa é baixa.

\begin{tabular}{|c|c|c|c|c|c|c|c|c|c|c|}
\hline 0 & 1 & 2 & 3 & 4 & 5 & 6 & 7 & 8 & 9 & 10 \\
\hline
\end{tabular}
Discordo
totalmente

23. Um investimento gerou uma taxa média de retorno positiva de $8 \%$ a.a., durante 10 anos. No ano de 2013, o retorno desse investimento atingiu $15 \%$ a.a. Em sua opinião, a probabilidade de o retorno anual desse investimento para o ano de 2014 ser igual ou superior a do ano passado é baixa.

\begin{tabular}{|l|c|c|c|c|c|c|c|c|c|c|}
\hline 0 & 1 & 2 & 3 & 4 & 5 & 6 & 7 & 8 & 9 & 10 \\
\hline
\end{tabular}
Discordo
totalmente
Concordo
totalmente

24. Uma cidade possui dois hospitais. No maior, nascem cerca de 45 bebês por dia e, no menor, nascem aproximadamente 15 por dia. Como você sabe, cerca de $50 \%$ de todos os bebês são meninos. Mas esse percentual varia diariamente, para mais ou para menos. Por um período de um ano, os dois hospitais registraram os dias em que mais de $60 \%$ dos recém-nascidos eram meninos. Você acredita que o hospital maior registrou um maior número de dias.

\begin{tabular}{|c|c|c|c|c|c|c|c|c|c|c|}
\hline 0 & 1 & 2 & 3 & 4 & 5 & 6 & 7 & 8 & 9 & 10 \\
\hline
\end{tabular}
Discordo
totalmente

25. Determinado investimento possui, normalmente, uma probabilidade de $50 \%$ para o desempenho ser bom/ positivo $(\mathrm{P})$ e de $50 \%$ para ser ruim/ negativo (N). Durante o período de 5 meses, a probabilidade de desempenho N, P, N, $\mathrm{P}, \mathrm{P}$ é mais provável de acontecer que $\mathrm{N}, \mathrm{N}, \mathrm{N}, \mathrm{N}, \mathrm{N}$ ou $\mathrm{P}, \mathrm{P}, \mathrm{P}, \mathrm{P}, \mathrm{P}$.

\begin{tabular}{|c|c|c|c|c|c|c|c|c|c|c|}
\hline 0 & 1 & 2 & 3 & 4 & 5 & 6 & 7 & 8 & 9 & 10 \\
\hline
\end{tabular}
Discordo
totalmente


26. Determinado investimento gerou, por 10 anos, uma taxa média de retorno positiva de $10 \%$ a.a. No ano passado, o retorno desse investimento atingiu $20 \%$ a.a. Em sua opinião, a probabilidade de essa última taxa se repetir ou ser maior é baixa, pois você acredita que o retorno tenderá ao desempenho médio.

\begin{tabular}{|l|l|l|l|l|l|l|l|l|l|c|}
\hline 0 & 1 & 2 & 3 & 4 & 5 & 6 & 7 & 8 & 9 & 10 \\
\hline
\end{tabular}
Discordo
totalmente

27. Você leu a seguinte notícia na internet: "Os últimos 2 anos foram marcados pela recessão econômica da Cia TR, o que ocasionou uma queda no nível de produção". Assim, você acredita que a probabilidade de o prejuízo da companhia aumentar nos próximos anos é alta.

\begin{tabular}{|c|c|c|c|c|c|c|c|c|c|c|}
\hline 0 & 1 & 2 & 3 & 4 & 5 & 6 & 7 & 8 & 9 & 10 \\
\hline
\end{tabular}
Discordo
totalmente

28. Em determinada instituição de ensino superior, a média dos alunos na disciplina Teoria da Contabilidade é 8,0. Ao selecionar uma amostra de 10 alunos, você acredita que a probabilidade de a média ser 8,0 é alta.

\begin{tabular}{|c|c|c|c|c|c|c|c|c|c|c|}
\hline 0 & 1 & 2 & 3 & 4 & 5 & 6 & 7 & 8 & 9 & 10 \\
\hline
\end{tabular}
Discordo
totalmente

29. As receitas de venda de uma empresa caíram, em média, $2 \%$ a cada ano, nos últimos 5 anos. No primeiro semestre deste ano, a queda foi de $10 \%$, comparada ao ano anterior. Você acredita que é baixa a probabilidade de a redução das receitas de vendas ser igual ou superior a do primeiro semestre deste ano.

\begin{tabular}{|c|c|c|c|c|c|c|c|c|c|c|}
\hline 0 & 1 & 2 & 3 & 4 & 5 & 6 & 7 & 8 & 9 & 10 \\
\hline
\end{tabular}
Discordo
totalmente

30. Como você considera seu julgamento e tomada de decisão?

\begin{tabular}{|l|c|c|c|c|c|c|c|c|c|c|}
\hline 0 & 1 & 2 & 3 & 4 & 5 & 6 & 7 & 8 & 9 & 10 \\
\hline
\end{tabular}
Baseado na
razaso nado na
intuição


Parte III

1. Gênero:

( ) Feminino

( ) Masculino

2. Idade: anos

3. Grau de instrução:

( ) Técnico

( ) Graduação completa

( ) Graduação incompleta

( ) Especialização completa

( ) Mestrado completo

( ) Doutorado completo

4. Caso possua outra formação de nível superior, além de Ciências Contábeis, por favor, informe qual:

5. Possui experiência profissional na área contábil?

( ) Sim

( ) Não

6. Caso atue profissionalmente na área contábil, indique o tempo (em anos completos).

7. Caso ainda seja estudante, em qual instituição de ensino você está matriculado?

8. Em qual região do Brasil você reside?

( ) Centro-oeste

( ) Nordeste

( ) Norte

( ) Sudeste

( ) Sul

9. Caso deseje, pode utilizar o espaço abaixo para fazer algum comentário. 